\title{
INTEGRAL LENGTH SCALES AND TIME SCALES OF TURBULENCE IN AN OPTICAL SPARK-IGNITION ENGINE
}

\section{P.G. Aleiferis*}

Department of Mechanical Engineering, Imperial College London, UK

\author{
M.K. Behringer ${ }^{1}$ and J.S. Malcolm ${ }^{2}$ \\ Department of Mechanical Engineering, University College London, UK
}

*Author for Correspondence:

Prof. Pavlos Aleiferis

Imperial College London

Department of Mechanical Engineering

Exhibition Road, London SW7 2AZ, UK

Tel: +44-(0)20-75947032

E-mail: p.aleiferis@imperial.ac.uk

${ }^{1}$ Currently at Micro-Epsilon, Ortenburg, Germany.

${ }^{2}$ Currently at Ford Motor Company, Dunton, UK.

Full length article accepted for publication by Flow, Turbulence and Combustion. 


\begin{abstract}
In-cylinder air flow structures are known to play a major role in mixture preparation and flame development in spark-ignition engines. In this paper both LDV and PIV measurements were undertaken in an optical spark-ignition at 1500 RPM, 0.5 bar inlet plenum pressure. One of the primary PIV planes was vertical, cutting through the centrally located spark plug (tumble plane) inside the pentroof at ignition timing. The other plane was horizontal inside the pentroof $1 \mathrm{~mm}$ below the spark plug. LDV was conducted $1 \mathrm{~mm}$ below the spark plug on a line from inlet to exhaust but also on a lower line $14 \mathrm{~mm}$ below the spark plug. In-cylinder PIV data at specific crank angles in the intake and compression strokes were also analysed on the central tumble plane and on a horizontal plane 14 $\mathrm{mm}$ below the spark plug. The combination of both techniques allowed high spatial and temporal resolution as the two data sets complemented each other to provide details of mean flow and turbulence characteristics on different levels, aiming ultimately for quantification of integral time scales and length scales. LDV cycle-resolved analysis distinguished between the classic approach of using the time integral of the autocorrelation function to obtain the integral time scale and a high-frequency cut-off analysis to obtain high- and low-frequency fluctuations about an in-cycle mean.
\end{abstract}




\section{INTRODUCTION}

\section{BACKGROUND}

Direct Injection Spark Ignition (DISI) engine technology has become commonplace within the automotive industry as a replacement for port fuel injection engines. This is due to benefits associated with improved efficiency from charge cooling effects and increased flexibility in mixture formation by a variety of injection strategies. Therefore, understanding in-cylinder air flow characteristics in DISI engines is of great importance because air flow is inherently coupled to mixture formation via spray-flow interactions. A variety of velocimetry techniques can be used to characterise in-cylinder flows. Laser Doppler Velocimetry (LDV) provides highly time-resolved data of the flow field at fixed points in space, whilst Particle Image Velocimetry (PIV) returns 2D maps of the flow field. Although early PIV studies of engine flows had highlighted the issue of bias in the statistical analysis of small batches of engine cycles [1, 2], data storage issues and processing time have forced most researchers to use no more than 50-200 cycles for their analysis [3-6]. More recently kHz range high-speed PIV has been utilised for typical 2D flow mapping but also with volume-based characterisation that can be used for validation of Large Eddy Simulation (LES) of engine flows [7-9]. High-speed PIV allows crank-angle resolved measurements to be undertaken and has been shown to give insights into the field of cycle-to-cycle flow variability, including sprayflow and flame-flow interactions [10-16], nevertheless at the expense of data storage requirements, especially if large numbers of cycles are sought after for statistical analysis. Moreover, for turbulent time scale analysis at engine speeds of $1500 \mathrm{RPM}$ or higher, imaging frequencies in the tens of $\mathrm{kHz}$ are necessary to achieve sub-crankangle resolution. This poses further camera and storage challenges when one needs to maintain whole-field spatial image resolution and over a series of many hundreds of cycles. Therefore, 'low-speed' high spatial resolution cycle-resolved PIV still has its own merits as an experimental tool for in-cylinder flows because it can provide with relative ease the number of samples needed for faithful statistical analysis of the flow at predefined crank angles of interest, especially if information on turbulent kinetic energy (TKE) and integral length scales is also aimed for. An integral length scale represents an average of all turbulent scales in the flow, but with the larger energy containing eddies governing mainly its magnitude. Data on in-cylinder integral length scales carry great significance in understanding fundamental phenomena like airflow effects on initial flame kernel wrinkling and the turbulent flame speeds of various fuels $[17,18]$, as well as fuel atomisation during high-pressure in-cylinder injection processes [19], especially under low-load engine operation.

\section{PRESENT CONTRIBUTION}

There are very few studies in the literature that have conducted direct comparisons between PIV and LDV data for an engine at identical operating conditions. More to the point, most of these studies discussed effects on enginehead test benches at steady-state flow conditions, e.g. see [20-23], and not inside the pentroof and cylinder of a running optical engine with DISI configuration. Within the objectives of the current paper, cycle-resolved PIV experiments were undertaken in a pentroof geometry DISI optical engine running at 1500 RPM, low-load conditions of 0.5 bar inlet plenum pressure. Two planes were primarily considered inside the pentroof: one vertical 'tumble' plane passing through the centre of the combustion chamber and one horizontal 'swirl' plane $1 \mathrm{~mm}$ below the spark plug's ground electrodes close to compression Top Dead Centre (TDC), both imaged at ignition timing. The main aim was to quantify, apart from 'mean' velocity and turbulence intensity, maps of integral length scales of the flow at ignition timing that do not really exist in the literature at such engine operating conditions; most 
earlier studies on integral length scales in 4-valve engines focused on 600-1200 RPM wide-open-throttle, without direct pentroof access, e.g. [3, 4]. LDV measurements were also conducted at $1 \mathrm{~mm}$ below the spark plug electrode along a horizontal axis from inlet to exhaust in order to provide time history data of the flow inside the pentroof and quantify integral time scales. Filtering was also applied to LDV data in an attempt to distinguish between ensemble-averaging effects and cycle-resolved low- and high-frequency components. Some additional LDV and PIV measurements were analysed inside the cylinder $14 \mathrm{~mm}$ below the spark plug to study the time history and flow effects on a plane associated typically with spray/flow interactions for injection strategies in the early intake stroke.

\section{EXPERIMENTAL ARRANGEMENT \\ OPTICAL ENGINE AND OPERATING PARAMETERS}

The optical engine on which the present work was performed was a single-cylinder research engine designed and built by MAHLE Powertrain Ltd., specifically for optical studies of air flows, fuel sprays and combustion. The engine head was based on a serial production 4-cylinder 2-litre 16-valve DISI engine. The Bowditch style piston allowed for a $45^{\circ}$ mirror to be positioned inside the extended hollow piston core and give optical access to the combustion chamber through a titanium piston crown equipped with a sapphire circular window. The cylinder liner was fully optical and contoured at the top to fit the pent-roof gable ends; it was clamped in place by four hydraulic rams. Sealing was achieved by the installation of a silicon gasket in a spark-eroded groove on the underside of the engine head. The piston rings were made of high-temperature-grade Torlon material in order to provide good sealing and wear resistance in a non-lubricated environment. Figure 1 shows an image of the engine with the fully optical liner in place (viewed from the timing belt side of the engine) and an image of the combustion chamber as seen view through the optical piston crown (timing belt side of the engine on the left of this picture, flywheel side on the right). The intake manifold design consisted of an intake runner of similar diameter and length to that of the commercial engine. A large volume intake plenum chamber was connected upstream the intake runner to allow damping of the manifold impulse pressure fluctuations. The cam profiles and valve timings were of 'standard' type with maximum valve overlap of $11{ }^{\circ} \mathrm{CA}$ (measured to $0.02 \mathrm{~mm}$ lift). The valve timings along with other basic specifications of the engine are presented in Table 1. All timings given in ${ }^{\circ} \mathrm{CA}$ refer to 'crank angle time equivalent' at $1500 \mathrm{RPM}$, with one $1^{\circ} \mathrm{CA}$ corresponding to $0.111 \mathrm{~ms}$. The load was controlled by throttling to 0.5 bar ( \pm 0.01 bar) absolute pressure in the intake plenum. The spark plug was of triple ground electrode type with asymmetric orientation inside the combustion chamber. Under gasoline operation at 1500 RPM, 0.5 bar load, the Minimum spark advance for Best Torque (MBT) was $26{ }^{\circ} \mathrm{CA}$, hence this timing was selected for the PIV measurements that were conducted inside the pentroof. More details about the engine and its ancillary systems can be found in previous publications [24-25].

Due to the need for prolonged engine running, all PIV and LDV measurements were undertaken at motoring conditions. However, these were set to match nominally as nearly as possible those of previous work published on this engine by the current authors on direct-injection spray formation and combustion with various fuels [24, 25]. The crank and cam shafts were equipped with shaft encoders resolving 1800 increments per revolution. An AVL427 engine timing unit was employed for provision of synchronised triggering to Lasers and cameras. Acquisition of pressure and temperature data was realised by a 12-bit National Instruments (NI) PCI-6023E DAQ card capable of a sampling rate of $200 \mathrm{kS} / \mathrm{s}$ for 16 channels. Pressure sensors with respective amplifiers for in- 
cylinder pressure, intake plenum pressure, intake runner and exhaust pressure were used, logged and referenced as needed (Kistler 6041A, 4075A10V39, Kistler 4045A2V39, Kistler 7531, respectively). Their digitisation rate corresponded to $0.2{ }^{\circ} \mathrm{CA}$ at $1500 \mathrm{RPM}$. Temperatures were recorded on a separate low-speed data acquisition system which formed part of the dynamometer control system, as were all other engine running parameters.

\section{PARTICLE IMAGE VELOCIMETRY}

\section{Test Procedure PIV}

Oil droplets with a density of $920 \mathrm{~kg} / \mathrm{m}^{3}$ were created by an atomisation seeder and introduced into the engine's intake flow on four evenly distributed ports around the intake runner approximately $150 \mathrm{~mm}$ upstream the intake valves. The size of the seeding particles was measured in free flow at atmospheric conditions and these were found to be about 1-2 $\mu \mathrm{m}$ in diameter. Studying particle-size histograms and considering size changes with increasing temperatures, calculated particle response times showed that the seeding would respond well to flow frequencies of the order $0.1-0.2^{\circ} \mathrm{CA}$. The Laser/camera arrangement was based on a Quantel Big Sky ULTRA CFR 120 Nd:YAG Laser (120 mJ per pulse) and a TSI Powerview Plus 4 MP camera $(2048 \times 2048$ pixels). A Nikon $60 \mathrm{~mm}$ f/2.8 lens was used. Two planes were primarily studied inside the pentroof, a horizontal plane (also called 'swirl' plane hereafter) located $1 \mathrm{~mm}$ below the spark plug's ground electrode, or $3 \mathrm{~mm}$ above the engine's fire-face (i.e. $3 \mathrm{~mm}$ above the TDC location of the piston crown's top land) and another one, vertical centrally located, cutting through the spark-plug from inlet to exhaust side (also called 'tumble' plane hereafter). Following extensive analysis on the minimum number of cycles required for representative mean and turbulent fluctuations data from PIV data [26, 27], 540 individual cycles were averaged for each experimental test point in batches of 60 cycles per run. It is recognised though that this was still at the limit and, ideally, more than 1000 cycles should have been acquired. The practice of batching was based on memory storage capabilities and image quality deterioration by fouling of the optical access with increased duration of test runs. Due to the maximum imaging speed of the PIV-system, the data acquisition was at $6.25 \mathrm{~Hz}$, so that every second cycle was recorded at 1500 RPM engine speed.

For the swirl view measurements, the Laser beam was converted to a sheet of about $0.5-1 \mathrm{~mm}$ thickness by a combination of spherical and cylindrical lenses, fired horizontally through the pent-roof of the engine in full optical setup (quartz liner and sapphire piston window); the camera was positioned in front of the $45^{\circ}$ mirror that was situated within the Bowditch piston arrangement. The arrangement was reversed for the tumble plane measurements with the Laser firing at the $45^{\circ}$ mirror and the camera aligned normal to the optical liner for pentroof view access. The lens aperture was set to $\mathrm{f} / 11$. The image resolution was $18.4 \mu \mathrm{m}$ per pixel on the tumble plane and $34.6 \mu \mathrm{m}$ per pixel on the swirl plane view. PIV images $10 \mathrm{~mm}$ below the fire-face $(14 \mathrm{~mm}$ below the spark plug) were also analysed during both intake and compression strokes for comparison with LDV at the same location. These data were obtained with the same settings to those of the PIV data inside the pentroof but the lens aperture was set to $\mathrm{f} / 8$ and the resolution was higher on the horizontal plane (swirl), namely $23.8 \mu \mathrm{m}$, due to focus closer to the central area of the optical piston bore, and lower on the vertical plane (tumble), namely $38.3 \mu \mathrm{m}$, due to visualising a large portion of the piston's stroke. Figure 2 shows the location of the two horizontal planes.

Several aspects of the PIV technique, including practical application, precision and uncertainties were optimised according to [28] and in consultation with seminal publications on the specifics of PIV [29-36] and previously published PIV studies focused on internal combustion engine measurements [6-9, 37-39]. In this context, Table 2 summarises the system's main settings and several other details of the PIV measurements presented in this paper, 
e.g. Laser pulse time separation, interrogation area, density per interrogation window, etc. It is also noted that the FFT processing algorithms of the PIV system have been tested in-house using the standard images created by Okamoto et al. [36]. Issues of 'peak locking' were eliminated in the current set of measurements by ensuring settings that led to seeding particles being displayed typically over 2.5-3 pixels. The velocity bias error was calculated to be $0.06 \mathrm{~m} / \mathrm{s}$. Issues related to imaging through curved surfaces were eliminated by keeping the field of view smaller than about $30 \mathrm{~mm}$ in radius around the centre of the bore/pentroof, e.g. see [4, 37]. The average accumulated uncertainty of the PIV measurements performed was of the order 5-10\%.

\section{Data Processing PIV}

Spurious velocity vectors were typically less than $1 \%$, and few cycles with more spurious vectors, usually due to increased window fowling with ongoing measurement duration, had to be exempted from analysis. The ensembleaverage images for the PIV results presented later have been superimposed over a background image for positional clarity, showing the spark plug protruding into the combustion chamber in the centre of the tumble plane images and the outlining of the valve edges clearly visible in the swirl plane images. The ensemble-averaged velocity fields $U_{E A}$ were obtained over $N$ number of cycles as follows:

$$
U_{E A}(\theta, x, y)=\frac{1}{N} \sum_{i=1}^{N} U(\theta, x, y, i)
$$

where $U$ the instantaneous velocity, $i$ the running cycle number and $x, y$ the spatial co-ordinates, and $\theta$ the measurement crank angle (fixed at $26{ }^{\circ} \mathrm{CA}$ BTDC). The required velocity fluctuation for each cycle and spatial position $u(\theta, x, y, i)$ was calculated as the difference between the instantaneous velocity $U(\theta, x, y, i)$ and the ensembleaveraged mean velocity $U_{E A}(\theta, x, y)$ over all cycles. The fluctuation intensity $u^{\prime}(\theta, x, y)$ was obtained as the standard deviation at each spatial co-ordinate over the number of cycles $N$ :

$$
\begin{aligned}
& u(\theta, x, y, i)=U(\theta, x, y, i)-U_{E A}(\theta, x, y) \\
& u^{\prime}(\theta, x, y)=\sqrt{\frac{1}{N-1} \sum_{i=1}^{N}[u(\theta, x, y, i)]^{2}}
\end{aligned}
$$

LDV measurements along central symmetry lines from the intake to the exhaust side indicated that the flow during late compression was close to isotropy (i.e. approximately $u^{\prime}=v^{\prime}=w^{\prime}$ ), therefore, it was decided that the Turbulent Kinetic Energy (TKE), $k=0.5\left(u^{\prime 2}+v^{\prime 2}+w^{\prime 2}\right)$, would be established using the measured RMS of each velocity component at each point on that plane and estimating the $3^{\text {rd }}$ velocity component as the arithmetic average of the other two. This was done because characterisation of $k$ values by 3 velocity components was deemed necessary for future comparison with 3D engine simulations that are typically based on solving various forms of transport equations for $k$. Effects of this approximation are discussed further in the results section.

Cross-correlation coefficients were calculated at each point on the PIV flow fields and integral length scale maps were produced for all velocity components, $L_{u}, L_{v}, L_{w}$. In general, the integral length scale $L_{u}$ is defined as the integral of the spatial correlation coefficient $R_{x}$ of the fluctuation velocity $u$ (instantaneous minus mean) at two adjacent points in space, one at $x_{0}$ and another one at a distance $\chi$ from $x_{0}$ as follows (similarly for $L_{v}$ and $L_{w}$ ):

$$
L_{x}=\int_{0}^{\infty} R_{x} d x, R_{x}=\frac{\overline{u\left(x_{0}, t\right) \cdot u\left(x_{0}+\chi_{x} t\right)}}{u^{\prime}\left(x_{0}, t\right) \cdot u^{\prime}\left(x_{0}+\chi, t\right)}
$$

The numerical implementation was conducted as follows: The correlation coefficients $R_{\text {colvel }}(\theta, \Delta$ col, row $)$ for the horizontal velocity component (vel1) along the image columns of the $2 \mathrm{D}$ velocity maps were calculated at each location, e.g. the correlation coefficient in direction $x$ for velocity $u$ as follows: 


$$
\begin{aligned}
& R_{x u}(\theta, \Delta x, y)=\frac{\frac{1}{N-1} \sum_{i=1}^{N} u(\theta, x, y, i) \cdot u(\theta, x+\Delta x, y, i)}{u^{\prime}(\theta, x, y) \cdot u^{\prime}(\theta, x+\Delta x, y)} \\
& L_{x u}(\theta, x, y)=\int_{0}^{\infty} R_{x u}(\theta, \Delta x, y) d x
\end{aligned}
$$

At each cycle $i$ the calculation was done for each image row and a 2D correlation map was obtained and converted into the respective length scale map $L_{c o l, v e l 1}(\theta, c o l, r o w)$; similarly for the horizontal velocity along rows, i.e. $R_{\text {row,vel } 1}(\theta, \mathrm{col}, \Delta$ row $)$. Accordingly, the correlation coefficients for the vertical velocity (vel2) along image columns and rows, i.e. $R_{\text {col,vel2 } 2}(\theta, \Delta \mathrm{col}$, row $)$ and $R_{\text {row,vel } 2}(\theta, \operatorname{col}, \Delta$ row $)$, could be obtained. However, only the correlation of the velocity in its natural direction was considered, i.e. $R_{x u}(\theta, \Delta x, y), R_{y v}(\theta, x, \Delta y)$ and $R_{z w}(\theta, y, \Delta z)$, i.e. the longitudinal integral length scales were derived for each velocity component. For homogeneous isotropic turbulence the transversal integral length scales for any velocity component should be half the longitudinal ones.

\section{LASER DOPPLER VELOCIMETRY}

\section{Test Procedure LDV}

The LDV measurements on air-flow were conducted using a TSI system, based on a $5 \mathrm{~W}$ Coherent Innova 70C-5 Series $\mathrm{Ar}^{+}$Laser. A TSI Fiberlight Multicolor Beam Separator split the single multi-mode Laser beam into three components with wavelengths of $514.5 \mathrm{~nm}, 488 \mathrm{~nm}$ and $476.5 \mathrm{~nm}$, each of which was divided into two coherent beam pairs with identical polarity. A Bragg cell shifted one beam of each pair by $40 \mathrm{MHz}$ to enable the measurement of flow reversals. The beams were coupled into a fibre-optic cable that connected the beam separator and the transmitter probe (TM250-TLN05-250). Only the $514.5 \mathrm{~nm}$ and 488 beams were used though, the former for the vertical velocity component and the latter for the horizontal velocity components, as will be explained in more detail in the next section. The frequency shifting of the Bragg cell caused the fringes to move to create a frequency signal at the receiver, even when seed particles were motionless. Flow in positive and negative direction could be measured as long as the fringes moved faster than the seeding particles. The receiving probe (RV70) collected the scattered light and fed it into the Photo Detecting Module (PDM 1000-2C). A Multi-bit Digital Burst Correlator (FSA 4000-2P), which was synchronised and reset with engine TDC, was used to derive the signal frequency. The velocity of a seeding particle crossing the measurement volume could thus be obtained by multiplying the frequency signal of the scattered light with the related fringe spacing. Table 3 summarises the main parameters of the system.

Several aspects of the technique, including practical application, precision and uncertainties were optimised according to $[40,41]$ and in consultation with seminal studies on the specifics of LDV [42-45] and its application on internal combustion engines [46-55]. The main sources of uncertainty in LDV measurements are velocity bias, velocity broadening, and statistical uncertainty. Velocity bias can occur in heavily seeded flows due to the positive correlation between particle arrival rate and convection velocity in the fluid where a larger number of high velocity particles are recorded with respect to slower ones over the measured time. Several correction methods have been proposed, e.g. [42, 43] and it has been concluded that $2 \%$ and 5\% uncertainties arise in mean and RMS velocities for turbulence levels similar to the present experiments [46]. Gate time weighting was used to account for velocity bias in the current set of data. This was not found to have any significant effect over a range of crank angles. Velocity broadening effects occur when the dimensions of the optical control volume are comparable to flow scales over which changes in mean velocity arise [45]. The error is present even in stationary laminar flows and this uncertainty increases where regions of high velocity gradients are present. Typical way to overcome this error 
source is to reduce the effective length of the control volume by using a spatial filter slit in front of the photomultipliers. A $150 \mu \mathrm{m}$ slit was used for the current set of experiments. In the case of unsteady flows and ensemble averaged results, velocity broadening also occurs in the time domain and depends on the averaging time window. For the case of engine flows the maximum uncertainty in velocity broadening can be about 3\% and $10 \%$ in mean and RMS velocities, respectively [47]. Regarding statistical analysis, following the work of [44] and assuming a Gaussian velocity distribution, uncertainty errors based on the sample size for the LDV measurements (typically in excess of 5000 samples per crank angle per measurement position) were less than $2 \%$ in the mean and $5 \%$ in the RMS velocities. Other factors can also influence the uncertainty of LDV measurements but are typically negligible. These include the accuracy of the frequency counter, stability of the frequency shift and the position of the measurement volume, with the sum of those being less than $1 \%$.

\section{Measurement Setup LDV}

Defining the axes system inside the engine, the $x$-axis was selected to be the vertical axis with the origin at the engine's fire-face and positive in downwards direction from the fire-face towards the engine's bottom end. The origin of the horizontal $y$ and $z$ axis was located at the centre of the bore. The $y$-axis was defined positive in the direction from exhaust to intake side, while the $z$-axis from the engine's 'control' side (timing belt side) to the flywheel side. The definition of all in-cylinder coordinates/axes is shown in Figure 2. The velocities in $x, y$ and $z$ direction ( $u, v$ and $w$ velocities, respectively) were measured at two vertical positions $10 \mathrm{~mm}$ below and $3 \mathrm{~mm}$ above the fire-face, i.e. at $x=10 \mathrm{~mm}$ and $x=-3 \mathrm{~mm}$. The $x=-3 \mathrm{~mm}$ location corresponded to $1 \mathrm{~mm}$ below the spark plug and the $x=10 \mathrm{~mm}$ location to $14 \mathrm{~mm}$ below the spark plug where PIV measurements were also obtained. Measurement locations on the $x=10 \mathrm{~mm}$ plane along the $y$ - and $z$-direction were at $0 \mathrm{~mm}, \pm 2 \mathrm{~mm}$ from the centre and further in steps of $4 \mathrm{~mm}$ with respect to the previous position until reaching the liner walls. Similar spacing was selected for the measurements on the $x=-3 \mathrm{~mm}$ plane, but measurements were only taken until $\pm 20 \mathrm{~mm}$ from the centre of the cylinder due to the confined pentroof space.

The transmitter and receiver probes were mounted on two translation stages that allowed movement perpendicular to the engine liner axis, focusing the Laser beams through the liner walls. Careful positioning calculations were required to account for refraction effects of the Laser beams on the quartz liner walls. The difference in curvature that the horizontal beams experience due to their distance to each other when reaching the liner wall caused different measurement positions between horizontal and vertical beams. This meant that the positioning of the transmitter would have to be different for horizontal and vertical velocity measurements as the respective beam crossing points were not identical. While it would have been possible to overcome this by beam steering using alignment prisms inside the transmitter or other methods using external optics, this would have to be done at each measurement location that proved impractical. It was therefore chosen to measure horizontal and vertical velocities individually at the cost of information that could be obtained from their simultaneous measurement, such as calculation of Reynolds stresses. Effects of ray refraction on cylindrical surfaces were calculated using geometrical optics based on Snell's law [56-58]. The angular error of the horizontal measurements, which indicates the deviation of the fringes to the measurement direction, was calculated to be approximately $2^{\circ}$ for positions from the centre between $-24 \mathrm{~mm}$ and $+24 \mathrm{~mm}$. The calculated positioning results were verified and adjusted at various incylinder positions using positioning markers. The relative positioning accuracy between neighbouring locations was estimated to be better than $\pm 0.1 \mathrm{~mm}$. 
For $u$ and $v$ components ( $x$ - and $y$-directions, respectively), the transmitter fired the Laser beams through the liner on the side of the pentroof window. Once the correct transmitter beam crossing position was established, the receiver position had to be adjusted. The LDV receiver was positioned for forward scattering mode on the exhaust side of the engine in the flywheel side quadrant. Whenever possible, the transmitter-receiver angle was $30^{\circ}$ off-axis but geometrical constraints such as the hydraulic pillars of the liner clamping mechanism did not always allow for this setup to be fixed so that the angle was varied between $20^{\circ}-70^{\circ}$. The angular position was however not as critical for LDV as it would have been for phase Doppler droplet sizing and it was therefore selected for best optical access according to in-cylinder location of the probe volume. The measurement of $w$ ( $z$-direction velocity component) on the layer $1 \mathrm{~mm}$ below the spark plug ground electrode required up to $\sim 5^{\circ}$ vertical tilting of the receiver and transmitter (placed on the intake and exhaust side, respectively) to fire the Laser beams at a slight upwards angle into the pent-roof past the edge of the engine head (the tilt was then accounted for in the calculation of $w$ ).

The Laser power was set to $1.5 \mathrm{~W}$, resulting in individual beam power of $\sim 150 \mathrm{~mW}(514.5 \mathrm{~nm})$ for $u$ and $\sim 110 \mathrm{~mW}$ $(488 \mathrm{~nm})$ for $v$ and $w$ measurements. As the velocities during intake stroke were much higher than those in the compression stroke, a wide band-pass filter range of 2-20 MHz was used to cover the engine cycle. The down-mix frequency was set between $30-36 \mathrm{MHz}$ to ensure all velocities were within the measurement range after compensation for the brag cell's frequency shift. Photomultiplier tube (PMT) voltages (typically 400-500 V), burst thresholds (typically 50-120 V) and the signal-to-noise ratio of the burst detection were adjusted depending on the measurement location for best data rate.

Approximately $60 \mathrm{~s}$ of motoring were allowed for flow stabilisation prior to acquisition of measurements. Velocities of at least 1200 cycles were obtained for each measurement location and direction. The time stamps of the LDV signal bursts were obtained relative to a TDC marker created by the AVL427 engine timing unit. LDV showed high sensitivity with respect to the positioning accuracy of the transmitter and receiver. Maximum LDV sampling frequencies for ideal system setup of the Laser and data acquisition system were beyond $40 \mathrm{kHz}$ (equivalent to $0.22 \mathrm{CA}$ at $1500 \mathrm{RPM}$ ) and were considered sufficient in comparison to particle response time for the ensemble-average analysis and also for investigations regarding turbulent time scales. Typical data rates were between $20-40 \mathrm{kHz}$ but cycles were accepted during post processing, if the average data rate was above $9 \mathrm{kHz}$, i.e. one measurement per crank angle.

\section{Data Processing LDV - Ensemble Averaged Analysis}

The quasi continuous velocity signal of 1200 cycles including the respective time stamp was exported and split into individual cycles. The cyclic velocity data was then sorted into bins of $0.5{ }^{\circ} \mathrm{CA}$ and the binned data were further processed to create ensemble-averaged velocity traces over all cycles. The averaging analysis of quasi-periodic flows splits the value of the instantaneous velocity $U$ at crank angle $\theta$ of cycle $i, U(\theta, i)$, into an ensemble averaged mean value $U_{E A}(\theta)$ and a fluctuating component $u^{\prime}(\theta)$. For conventional ensemble averaging, the mean velocity at $\theta$ was derived by averaging the instantaneous velocities of all cycles $(N)$ at that required $\theta$ (i.e. phase averaging):

$$
\begin{gathered}
U_{E A}(\theta)=\frac{1}{N} \sum_{i=1}^{N} U(\theta, i) \\
u^{\prime}(\theta)=\sqrt{\frac{1}{N-1} \sum_{i=1}^{N}\left[U(\theta, i)-U_{E A}(\theta)\right]^{2}}
\end{gathered}
$$

More elaborate cycle-resolved processing procedures will be introduced in the relevant LDV results section. 


\section{RESULTS AND DISCUSSION}

\section{Instantaneous Flow Field at Ignition Timing}

The images in Figure 3 show raw flow field images of a single cycle at $26{ }^{\circ} \mathrm{CA}$ BTDC on the swirl and tumble planes. The reader may refer to Figure 2 for axes definition. No distinct general flow directionality could be seen on the swirl plane except along the main tumble plane $y$-axis from intake to exhaust. Vortex structures with diameters 5-10 $\mathrm{mm}$ were typically present all over the swirl plane, distributed evenly throughout. The tumble plane view however reveals a strong flow directionality from intake (left) to exhaust (right), showing velocities typically of the order of 5-8 m/s, higher on the left of the spark plug (black shadow area in the centre). Between spark plug ground electrode and piston top, medium scale vortex structures were visible in many images, typically of the order 3-5 mm in diameter but occasionally up to $8 \mathrm{~mm}$. Some spurious velocity vectors could be seen close to the spark plug electrode (and retained in this figure), stemming from reflections of the Laser sheet hitting metal surfaces. To the right of the spark plug, the flow velocity was reduced and several small vortices and eddies were visible, before the velocities increase and directionality strengthens again towards the right extremity of the image on the exhaust side. All images showed very similar structures with natural variations in the size and position of vortices for different cycles.

\section{PIV Flow Field and TKE at Ignition Timing}

The ensemble averaged flow and TKE fields at $26^{\circ} \mathrm{CA}$ BTDC are shown in Figure 4 for the tumble and in Figure 5 for the swirl view (both based on 540 cycles). With respect to axes definition in Figure 2, the zero value on the $x$ axis of the tumble view indicates the location of the engine's fire-face with the piston top land being at approximately $x=6 \mathrm{~mm}$ at the time of measurement. Maximum velocity values of up to $5 \mathrm{~m} / \mathrm{s}$ were present towards the intake side (top left corner of the images in Figure 4), where the bulk tumble flow came into the image area from the engine squish area and intake pentroof while the large-scale flow 'propagated' towards the exhaust side. Successively, the flow was forced against and around the spark plug. In the wake of the spark plug the velocities were strongly reduced to levels of 1-1.5 m/s, still predominantly in the direction of the exhaust port, with a recirculation zone towards the top right edge of the spark plug. None of the vortex structures that could be seen in the instantaneous images were present in the ensemble averaged field, being evidence of their 'randomness' and turbulent nature of the flow. The flow field just above the piston top showed upwards directed velocities, most probably driven directly by the motion of the piston.

The swirl view velocities are consistent with the general velocity structure on the tumble plane: high velocities on the intake side and low velocities past the spark plug. The mean flow showed two counter rotating vortices with their centres below the intake valves. The mean velocities along the $y$-axis in the centre of the bore (i.e. the axis through which the tumble plane was measured) was the nominal engine geometrical symmetry line between the two large scale-vortices. The $w$-velocity component ( $z$-direction) was very small (close to zero) in comparison to the dominant flow direction from intake to exhaust, i.e. in agreement with the expected behavior across a symmetry plane.

The TKE on the tumble plane was typically between $10-16 \mathrm{~m}^{2} / \mathrm{s}^{2}$. Increased levels of TKE featured in the area below the spark plug electrode and towards the exhaust side of the combustion chamber. Similar levels of TKE were obtained on the swirl plane, with largest values in the negative $z$-direction. When looking along the $y$-axis where the tumble view was obtained, TKE values between $8-13 \mathrm{~m}^{2} / \mathrm{s}^{2}$ were obtained. The lower values compared 
to the tumble view are believed to be a result of the estimation of the $3^{\text {rd }}$ velocity fluctuation component which was taken as the average between the two other velocity fluctuation. LDV showed that $w^{\prime}$ was of the same order but generally slightly lower than the average between $u^{\prime}$ and $v^{\prime}$, what effectively corresponded to an overestimation of the TKE by about $20 \%$ on the tumble plane, which also highlights the degree of isotropy. The TKE derived from the ensemble averaged LDV measurements showed similar values of $9-16 \mathrm{~m}^{2} / \mathrm{s}^{2}$, with highest TKE in the negative $y$ and $z$ direction. This comparison will be discussed further later.

\section{Ensemble Averaged LDV Flow Field at $x=-3 \mathrm{~mm}$}

To provide a time frame to the in-cylinder flow, Figure 6 shows the ensemble average velocity components in the vertical ( $x$ ) and horizontal (y) directions, $u$ and $v$, respectively, and their RMS fluctuations $u^{\prime}$ and $v^{\prime}$ from intake TDC to compression TDC. These were measured at the centre of the bore $3 \mathrm{~mm}$ above the fire-face $(1 \mathrm{~mm}$ below spark plug), i.e. at position $x=-3 \mathrm{~mm}, y=0 \mathrm{~mm}, z=0 \mathrm{~mm}$. The $w$-velocity component is not shown at this stage because measurements on the symmetry line of the engine resulted in mean $w$ velocities close to zero. The RMS velocity fluctuation has also been included as error bars (in red) on the mean velocity traces of $u$ and $v$ for even better clarity. Despite mean $w$ being close to zero, $w^{\prime}$ was generally of the same order to $u^{\prime}$ and $v^{\prime}$ as will be discussed in more detail later. Compression TDC and the timing of IVC has both been indicated in Figure 6. It is noted here that the crank angles in this figure and subsequent graphs are all shown with respect to TDC compression and labelled as negative ${ }^{\circ} \mathrm{CA}$ After TDC (ATDC) compression, being equivalent to positive ${ }^{\circ} \mathrm{CA}$ Before TDC (BTDC) compression.

During the intake stroke from $360{ }^{\circ} \mathrm{CA}$ BTDC to $180{ }^{\circ} \mathrm{CA}$ BTDC (i.e. $-360{ }^{\circ} \mathrm{CA}$ ATDC to $-180{ }^{\circ} \mathrm{CA}$ ATDC), the vertical velocity $(u)$ was positive and the incoming flow followed the direction of the piston's motion. The measured intake peak velocity was $53 \mathrm{~m} / \mathrm{s}$ at $320^{\circ} \mathrm{CA}$ BTDC and was followed by a plateau at $\sim 27 \mathrm{~m} / \mathrm{s}$ around the nominal start of injection at $300{ }^{\circ} \mathrm{CA}$ BTDC. Successively, low-frequency velocity fluctuations were seen on the mean velocity trace that followed a shape similar to the pressure oscillations measured in the intake runner, until the flow approached zero around intake BDC. Dynamic charging effects may therefore be considered small, as expected at such low engine speed. After BDC, the flow direction at this central location just below the spark plug remained mainly positive (i.e. downwards) until TDC compression ( $\left.0{ }^{\circ} \mathrm{CA} \mathrm{BTDC}\right)$, with low magnitudes up to 3 $\mathrm{m} / \mathrm{s}$, despite the upwards moving piston. This indicated the persistence of a clockwise tumble motion with reference to the engine schematic with the $x-y$ axes definition in Figure 2. By the late stage of compression in the region of typical ignition timings ( $40{ }^{\circ} \mathrm{CA}$ to $20^{\circ} \mathrm{CA} \mathrm{BTDC}$ ), the vertical velocity component was near zero, as can be seen more clearly in the PIV flow field of Figure 4.

The horizontal velocity component $(v)$ on the tumble plane featured a flow pattern predominantly directed towards the exhaust valves during intake. This was driven by the incoming air flowing over the top of the intake valves and will be seen more clearly in the PIV images during intake presented in the next section vertically and on the $x=10$ $\mathrm{mm}$ plane. The direction was clearly reverse only during the very early intake stroke just after valve overlap, when the in-cylinder pressure gradually equalised between the exhaust and intake runner, causing outward flow from exhaust to intake. Slightly positive values were also found around BDC. The RMS velocity values $u^{\prime}$ and $v^{\prime}$ were $7-10 \mathrm{~m} / \mathrm{s}$ at the timing of injection $\left(300^{\circ} \mathrm{CA} \mathrm{BTDC}\right)$ and $2-3 \mathrm{~m} / \mathrm{s}$ at ignition timing $\left(26^{\circ} \mathrm{CA}\right.$ BTDC). Approaching 
TDC compression, the predominant flow direction was from the intake side towards the exhaust with magnitudes of up to $5-7 \mathrm{~m} / \mathrm{s}$, as also characterized by PIV.

Velocity maps including all measurement locations on the $x=-3 \mathrm{~mm}$ layer are presented in Figures 7-8. Specifically, the graphs show the ensemble averaged velocities $u, v$ and $w$ as well as their fluctuation components $u^{\prime}, v^{\prime}$ and $w^{\prime}$, at positions between -16 to $+16 \mathrm{~mm}$ from the centre of the cylinder versus ${ }^{\circ} \mathrm{CA}$ ATDC compression along the $y$ and $z$ axes. Intake and compression TDC, BDC and IVC, as well as the intake and exhaust side, have all been indicated on the first graph of the figure matrix for clarity. A signal interruption is visible between 320 to 200 ${ }^{\circ} \mathrm{CA}$ BTDC (-320 to $-200{ }^{\circ} \mathrm{CA}$ ATDC on the graph axis), caused by the opening intake valves travelling through the Laser beams at positive $y$ directions when the transmitter was firing through the pentroof window. The signal drop out due to inlet valve clipping affected the $w$ component as the transmitter location for $w$ measurements was on the exhaust side of the engine and the receiver on the intake side. The protruding valves covered the visual access of the measurement location from 320 to $160{ }^{\circ} \mathrm{CA}$ BTDC, with the exception of the valve gap. Another dropout occurred for the $w$ measurements along the $y$-axis towards maximum $y$ positions at late crank angles 5 to 0 ${ }^{\circ} \mathrm{CA}$ BTDC (top right greyed corner in the charts), caused by the measurement arrangement as the transmitter was firing through the narrow gap between the piston at TDC and the engine head. The $u$ and $v$ components were not affected as the transmitter and receiver were located on the timing belt side and exhaust/flywheel quadrant of the engine bore, respectively. The relevant affected sections in the graphs have been greyed out. The greyed out regions for $u$ and $v$ differ due to the different path of the Laser beams.

The maximum measured velocities were present during the early and middle part of the intake stroke and of the order of $\sim 50 \mathrm{~m} / \mathrm{s}$ in the vertical direction $(x)$, while the horizontal components were $\leq 20 \mathrm{~m} / \mathrm{s}$ in $y$ and $\pm 10 \mathrm{~m} / \mathrm{s}$ in $z$ direction. The low-frequency fluctuations seen during the intake stroke at the single measurement position of Figure 6 were present for all measurements along the $y$-axis. These were also present on the $x=10 \mathrm{~mm}$ layer and can be seen more clearly in the line graphs of the next section. The high velocities reduced significantly to values of $\pm 5 \mathrm{~m} / \mathrm{s}$ when the piston approached intake BDC. The velocities close to TDC compression were low throughout, even close to zero for $u$ and $w$, while a $v$-velocity of -2 to $-8 \mathrm{~m} / \mathrm{s}$ was seen directed towards the exhaust valves. The strongest fluctuations also occurred during the early intake stroke, showing maximum magnitudes of $\sim 20 \mathrm{~m} / \mathrm{s}$ for $u^{\prime}, v^{\prime}$ and $w^{\prime}$. The $w^{\prime}$ fluctuations along the $y$ axis were high and of the same order to $u^{\prime}$ and $v^{\prime}$ despite the mean $w$ velocities being generally very low across this axis of nominal symmetry dissecting each valve pair. The PIV data on the same measurement plane also highlighted this. The fluctuations remained very consistent throughout the compression stroke, being typically $3-5 \mathrm{~m} / \mathrm{s}$ around the MBT ignition timing of $26{ }^{\circ} \mathrm{CA}$ BTDC. At TDC, the fluctuations had dropped to values between $2-3 \mathrm{~m} / \mathrm{s}$.

Figure 8 shows that velocity magnitudes on the $z$-axis were similar to those along the $y$-axis. High vertical and horizontal velocity components $u$ and $v$ were quantified in the gap between the two inlet valves. Measurement positions further away from the centre lay in the valves' shadows, resulting in low velocities. Here, re-circulations were visible with directions opposite to the main intake air stream which was generally downwards and towards the cylinder's exhaust side (this can be identified more clearly in the PIV images on the $x=10 \mathrm{~mm}$ plane shown later). The velocity fluctuations on the $z$-axis were again similar to those found along the $y$-axis, and settled at values between $3-5 \mathrm{~m} / \mathrm{s}$ during compression, whilst intake stroke fluctuations were as high as $20 \mathrm{~m} / \mathrm{s}$. 
Focusing solely on the flow field in late compression in Figures 9-10, the predominant flow along the $y$-axis was horizontal from intake to exhaust (strong negative $v$-velocity component). At $26^{\circ} \mathrm{CA}$ BTDC, $v$-velocities were -6 to $-8 \mathrm{~m} / \mathrm{s}$ with lowest values towards the exhaust side. Fluctuations $v^{\prime}$ were in the region of $3 \mathrm{~m} / \mathrm{s}$, larger on the exhaust side. The $w$-component along the symmetry axis showed fluctuations up to $3 \mathrm{~m} / \mathrm{s}$. Vertical velocities $u$ were very low, between $\pm 1.5 \mathrm{~m} / \mathrm{s}$, with fluctuations $u^{\prime}$ lower than $3 \mathrm{~m} / \mathrm{s}$. TKE levels, using all $u^{\prime}, v^{\prime}, w^{\prime}$ components in $k=0.5\left(u^{\prime 2}+v^{\prime 2}+w^{\prime 2}\right)$, were about $15 \mathrm{~m}^{2} / \mathrm{s}^{2}$, hence an equivalent mean turbulence intensity defined as $[(2 / 3) k]^{1 / 2}$ was about $3.2 \mathrm{~m} / \mathrm{s}$. Maps of TKE and turbulence intensity along the $y$-axis are shown in the left graphs of Figure 11 for the compression stroke. The intake stroke is not shown, but largest TKE values of up to $350 \mathrm{~m}^{2} / \mathrm{s}^{2}$ were found around $280{ }^{\circ} \mathrm{CA} \mathrm{BTDC}$, reducing successively to levels of $100-150 \mathrm{~m}^{2} / \mathrm{s}^{2}$ just before BDC. Lowest TKE values were typically in the range $8-12 \mathrm{~m}^{2} / \mathrm{s}^{2}$ and found around the time of IVC. In general, the turbulence intensity did not agree with the usual estimation of turbulence intensity being close to half the mean piston speed [59], the latter being $4.25 \mathrm{~m} / \mathrm{s}$, but it was of similar magnitude. This 'overestimation' of turbulence intensity may be related to the fact that most earlier measurements in the literature were done at higher engine load conditions than 0.5 bar (typically wide-open-throttle, 1 bar), or it may also be associated with the inclusion of low-frequency cyclic variability within the conventional ensemble averaging framework of analysis. As will be shown later, by using the high-frequency fluctuations only, the turbulence intensity was below half the mean piston speed even at the lowload conditions of the present study.

When moving along the $z$-axis at $26{ }^{\circ} \mathrm{CA}$ BTDC in Figure 10, it is observed that the values shown are similar to those along the $y$-axis. The $v$-velocities were between $0-5 \mathrm{~m} / \mathrm{s}$ towards the exhaust, with largest values in the region of the cylinder's centre and reducing further away along the $z$-axis. The $w$-component had values of $\pm 3 \mathrm{~m} / \mathrm{s}$, linearly increasing from the negative to the positive $z$ direction (timing belt to flywheel side of the engine), so that both horizontal components were evidence of the two counter rotating swirling vortices with their centre below the intake valves (shown more distinctly earlier by PIV). Horizontal fluctuations were around $3.2 \mathrm{~m} / \mathrm{s}$ for $v^{\prime}$ and $3 \mathrm{~m} / \mathrm{s}$ for $w^{\prime}$. The vertical velocities $u$ were between $0-2 \mathrm{~m} / \mathrm{s}$ with fluctuations $u^{\prime}$ of $2.5 \mathrm{~m} / \mathrm{s}$, so that an average TKE of $\sim 13 \mathrm{~m}^{2} / \mathrm{s}^{2}$ and turbulence intensity of $\sim 3 \mathrm{~m} / \mathrm{s}$ can be seen in the right graphs of Figure 11. The $z$-axis graphs show highest TKE towards the extremities of the measurement region (at $\pm 12-16 \mathrm{~mm}$ ), slightly higher in the negative $z$ axis side of the engine. The velocity fluctuations were of the same order of magnitude for all components along both axes, suggesting that the highly anisotropic flow during the intake stroke had developed to conditions not too far from isotropy along the studied in-cylinder axes during compression.

\section{Ensemble Averaged PIV and LDV Flow Field at $x=10 \mathrm{~mm}$}

The measurement layer at $x=10 \mathrm{~mm}$ ( $14 \mathrm{~mm}$ below the spark plug) provides further insight into the in-cylinder flow development during the intake stroke and early compression. It is also of direct significance to the origin of the mixture formation process because the fuel spray as a whole crosses this horizontal plane for injection strategies in the intake stroke, i.e. typical of 'homogeneous' engine operation. Therefore, the incoming air-flow characteristics in this region can be coupled directly with the spray droplet behaviour during injection on a cycle-by-cycle basis via two-way interactions and momentum exchange. Figure 12 shows PIV data on this plane at various crank angles during intake and compression. To assist the reader, Figure 12 also shows the central vertical plane flow behaviour at the same crank angles. Then Figures 13-14 show maps of $u, v$ and $w$ (left) and their RMS fluctuations (right) 
versus ${ }^{\circ} \mathrm{CA}$ at $x=10 \mathrm{~mm}$ along the $y$ - and $z$-axis from -36 to $+36 \mathrm{~mm}$, as obtained by LDV. Unlike on the vertical layer at $x=-3 \mathrm{~mm}$, the intake valves did not interfere with the LDV measurement paths and no signal drop out was seen at $x=10 \mathrm{~mm}$. However, no measurements were possible between $\pm 30{ }^{\circ} \mathrm{CA}$ ATDC, as the piston was covering the measurement plane.

The measurements of $u$ along the $y$-axis (Figure 13, top left graph) show a localised upwards motion for early crank angles around $300{ }^{\circ} \mathrm{CA}$ BTDC close to the liner wall on the inlet side beyond $y=32 \mathrm{~mm}$. The upwards motion was located at the back edge of the intake valves and the vortex structure was supported by the $v$-velocity, which fed into it from below the valves between $y$-positions of 24-36 mm. This flow feature is not typically accessible by PIV techniques due to optical geometry limitations, and it was not observable in the data of Figure $\mathbf{1 2}$ here either. The $v$-velocity (Figure 13, $2^{\text {nd }}$ row left graph) was again mainly directed towards the exhaust valves. Lowfrequency velocity oscillations similar to those on the $-3 \mathrm{~mm}$ plane and related to the intake runner pressure were again present (these may be seen more clearly in the line graphs of the next section). It is interesting to note that the upwards behaviour of the flow close to the walls behind the inlet valves has also been recorded recently by magnetic resonance velocimetry in engines [60,61]. Mean velocities in the $z$-direction (Figure 13, $3^{\text {rd }}$ row left graph) were again typically near zero. The behaviour of the vertical velocity component $u$ demonstrated the existence of tumble motion during the compression stroke past $100{ }^{\circ} \mathrm{CA}$ BTDC (-100 ${ }^{\circ} \mathrm{CA}$ ATDC). Here, the flow was directed upwards between $y=20 \mathrm{~mm}$ to $y=36 \mathrm{~mm}$ (on the intake side) with magnitudes mainly between $0-5$ $\mathrm{m} / \mathrm{s}$, while the negative $y$-locations (closer to the exhaust side) showed downwards flow with velocities of up to 8 $\mathrm{m} / \mathrm{s}$. The formation of this bulk flow structure can be seen more clearly in the vertical maps of Figure 12. The RMS velocity fluctuations during compression were around 3-5 m/s in all directions (Figure 13, graphs on the right).

The measurements along the $z$-axis show the vertical velocities in the valves' shadows that resulted in upwards flow into the low-pressure region just below the valves (Figure 14, top left graph). This was strongest during early intake where the highest intake velocities were seen (typically between 320 to $280{ }^{\circ} \mathrm{CA}$ BTDC), but still weakly present until TDC. Between the two valves and to their side, the incoming flow was directed downwards. The flow field was again symmetrical for positive and negative $z$ directions (to the right and left of the $y$-axis). The $v$-velocity (Figure 14, $2^{\text {nd }}$ row left graph) was in agreement with the measurements along the $y$-axis and showed a flow towards the exhaust side, but the direction reversed when leaving the centre, where flow was pulled into the valve's shadow regions. Largest $v$-velocities up to $25 \mathrm{~m} / \mathrm{s}$ were found next to the inner valve edges. This flow feature can be seen more clearly in the $310{ }^{\circ} \mathrm{CA}$ BTDC vector plot of the horizontal plane in Figure 12. These two counter rotating vortices persist till later, albeit with reduced velocities on their periphery, as seen in the $270{ }^{\circ} \mathrm{CA} B \mathrm{BDC}$ vector plot on the horizontal plane of Figure 12 as well as in the $v$ velocity values along $z$ in Figure 14. Highest $w$ velocities (Figure 14, $3^{\text {rd }}$ row left graph) were found early in the intake stroke towards the outer valve edges with magnitudes up to $25 \mathrm{~m} / \mathrm{s}$, while the $w$-velocities were generally quite low between $-10 \mathrm{~m} / \mathrm{s}$ to $8 \mathrm{~m} / \mathrm{s}$ throughout the cycle. The fluctuations in Figure 13 (right graphs) showed highest values along the central locations during air intake and were similar in amplitude to those found along the $y$-axis

Comparison between LDV and PIV Data

Figure 15 shows a comparison between the $u$ and $v$ components obtained by PIV and LDV on the $x=10 \mathrm{~mm}$ line at the $y=4 \mathrm{~mm}$ position $(z=0 \mathrm{~mm})$. The same figure also displays at the same location the TKE obtained by all three 
RMS components of the LDV data and the TKE derived by the three RMS velocity components of PIV at the intersection of the vertical central plane and the horizontal $x=10 \mathrm{~mm}$ plane using $u$ and $v$ from the vertical and $w$ from the horizontal plane. Furthermore, this figure includes TKE data at the same position obtained by PIV when using the RMS of $u$ and $v$ components and as estimation of the $3^{\text {rd }}$ velocity component fluctuation the arithmetic average $w^{\prime}=\left(u^{\prime}+v^{\prime}\right) / 2$. It can be seen that the 3-component PIV TKE is generally about $10-20 \%$ lower than that obtained by the 2-component estimation of the third component. The LDV 3-component TKE is typically closer to the 3-component PIV TKE than the 2-component TKE estimation past the late stages of the intake stroke and into compression, whilst in the early and mid-intake stroke the 3-component TKE measured by PIV appears slightly further away from the LDV TKE data - differences though are within uncertainty. TKE comparisons in the 'zoomed' graph over the compression stroke in Figure 15 shows that the LDV trace is much smoother and passes through the more irregular TKE traces made by PIV flow images $10{ }^{\circ} \mathrm{CA}$ apart. The agreement is generally similar though between PIV and LDV data throughout intake and compression along this line irrespective of measurement or estimation of the RMS of the third component of velocity. The result does not necessarily mean that the same agreement would be provided by estimating the third component anywhere in the 3D domain of the cylinder, but it certainly highlights that there is a degree of reasonable isotropy.

Comparing the time history of mean velocities on $x=10 \mathrm{~mm}$ layer over various $y$ positions across the cylinder from intake to exhaust side throughout the intake and compression strokes in Figure 15, it is clear that LDV typically characterized slightly larger velocities in absolute magnitude than those obtained by PIV. The same type of agreement was also observed when velocity profiles where compared within the pentroof on the $x=-3 \mathrm{~mm}$ layer. This can be related to several issues that may require dedicated in-depth cross-analysis of the two measurement techniques when applied in-cylinder. PIV was based on 540 cycles but LDV data were phase-averaged over more than 5000 samples at each crank angle. Issues of into-plane motion of particles during PIV image capture may also require closer analysis to quantify their exact contribution effects since the dynamic resolution of the system is fixed over a single plane and over different crank angles. This may mask features in the characterisation of flow fields with such steep gradients of directed flows on and into planes and has attracted attention in a recent publication where the in-cylinder flow was studied by PIV image frame time separations that were dynamically varied as a function of crank angle [62]. In the current study, the absolute values of $v$-velocity obtained by LDV were typically 10-20\% higher than those of PIV in the intake stroke, with even greater differences observed during compression at velocity levels of $1-2 \mathrm{~m} / \mathrm{s}$ or lower. Reasons for the differences are difficult to pinpoint with certainty but can be related to the fact that the seeder's settings were adjusted for best data rate and this was typically higher for LDV. The few comparative LDV/PIV measurements in the internal combustion engine literature also show higher values for LDV data [20-23]. It is also noted here that although velocity broadening and velocity bias (related to more fast particles being statistically captured over typical phase-averaging processes) in heavily unsteady in-cylinder flows with high degree of turbulence and large cyclic variability were studied at the time of development of LDV systems in the engine combustion chambers of the time [46, 48], these may require renewed further study to pinpoint specific effects quantitatively in engines of the modern era with their more complex three-dimensional flow fields. For example, it would be interesting to perform a direct comparison exercise between high-speed PIV and LDV data over more than 1000 cycles, preferably obtained simultaneously with methodical gating of the two measurement systems. 


\section{Cycle-by-Cycle Flow Analysis}

So far, only the flow field in terms of binned ensemble average velocity and RMS fluctuation components has been established. To obtain further information about the in-cylinder turbulence, this section establishes cycle-by-cycle turbulence characteristics such as high- and low-frequency fluctuations, as well as the integral time scale of turbulence close to spark timing from the LDV measurements at the $x=-3 \mathrm{~mm}$ position. The obtained integral time scale could then be used along with the average in-cylinder velocity to obtain an estimation of the integral length scale of turbulence. Integral length scales during intake are expected to scale with the intake valve lift ( 11 mm for the engine under study here). Close to TDC compression, integral scales are expected of the order 15-20\% of the clearance height [63-65] which was, depending on the location inside the pentroof of the current engine, about 8$15 \mathrm{~mm}$.

The time scale of turbulence in engines is generally estimated as the time integral of the autocorrelation function (autocorrelation function) of the measured velocity signal for each crank angle $\theta$ and measurement location. The calculation assumes an autocorrelation function $R$ that is steadily reducing from a value of unity at zero time lag $\tau$ and gradually approaching a value of zero at higher $\tau$ lags. However, the autocorrelation function can feature significant drops below zero or oscillations around zero (with attenuating amplitudes), or the gradient can be small and not reaching zero within the analysed time lag, etc. The former behaviour originates from low-frequency fluctuations and the work of $[66,67]$ suggested three ways to treat the integral for $R$. The first approach was to set the upper integral limit equal to the time when $R$ reached 1/e. This returned the smallest values for the time scale. About 2-3 times larger values where obtained if the integral limit was set to the initial dip point of the function below zero, while 9-10 times larger values where derived by the third approach which used the time until $R$ 's whole envelope reached 1/e. Despite the time that has passed since the introduction of such techniques, the literature still lacks consensus which approach should be adopted. Even higher uncertainty can be introduced by the treatment of the sub-zero part of the autocorrelation function which by itself reduces or increases the time scale depending on where the lower limit of the decay of $R$ is considered (signed or absolute value, e.g. see [68]). The traditional approach was introduced by $[48,69]$ and this was adopted for the present work to obtain the time scale from conventional ensemble-averaging as follows:

$$
\begin{gathered}
R(\theta, \tau)=\frac{\frac{1}{N-1} \sum_{i=1}^{N} u(\theta, i) \cdot u(\theta+\tau, i)}{u^{\prime}(\theta) \cdot u^{\prime}(\theta+\tau)} \\
L_{t}(\theta)=\int_{0}^{\infty} R(\theta, t) d t
\end{gathered}
$$

with $u(\theta, i)$ representing the velocity difference between instantaneous value and mean at crank angle $\theta$, i.e. $u(\theta, i)=U(\theta, i)-U_{E A}(\theta)$, and $u^{\prime}(\theta)$ being the standard deviation of the velocity over all cycles (=RMS fluctuation intensity). Variations of the classical ensemble-averaging method and alternative methods based on window averaging or frequency analysis are summarised in [59], including a suggestion of averaging over a reference range. In any case, it should be noted that filtering techniques alone cannot ascertain the extent to which the velocity fluctuations are random or deterministic in nature as frequencies of cycle-by-cycle variations may overlap with the frequencies of the turbulence [70].

\section{Filtering Approach}

Newer attempts to generate more accurate time scales by calculating $R$ on a 'more cyclic' basis did not use the fluctuation about the ensemble-average mean but around an 'in-cycle' mean velocity. Thereof arose the issue of 
how to distinguish between the mean and fluctuating part inside individual cycles. Possible ways to achieve this can be found in [71] who discussed using a moving average of the in-cycle velocity with a window-size selected between a turbulent microscale and the characteristic period of the piston motion, e.g. $10{ }^{\circ} \mathrm{CA}$ by [72] via polynomial curve fitting, or frequency domain filtering by [73] who used Fourier transformation of in-cycle measured velocities and its inverse after setting all Fourier coefficients above a chosen threshold to zero. The selection of such a threshold is the defining component in the latter scenario and different methods such as the inverse of the stroke duration or the maximum frequency present in the ensemble-averaged mean velocity have been suggested.

The work of $[66,67]$ calculated the Power Spectrum Density (PSD) of the ensemble-averaged velocity and that of individual cycles. The frequency where both PSDs started to deviate from each other was chosen as cut-off frequency. They found a cut off frequency of $300-400 \mathrm{~Hz}$ for $1000 \mathrm{RPM}$ and 150-200 Hz for $500 \mathrm{RPM}$ engine speed. The resulting low-pass filtered cycle velocity represents an in-cycle mean velocity $\bar{U}(\theta, i)$ which can be subtracted from the measured cycle velocity (instantaneous) to derive a high-frequency fluctuation $u_{h f}(\theta, i)$. This high-frequency fluctuation can then be used to get $u_{h f}^{\prime}(\theta)$ by:

$$
\begin{aligned}
& u_{h f}(\theta, i)=U(\theta, i)-\bar{U}(\theta, i) \\
& u_{h f}^{\prime}(\theta)=\sqrt{\frac{1}{N-1} \sum_{i=1}^{N} u_{h f}(\theta, i)^{2}}
\end{aligned}
$$

This cycle-based high-frequency velocity and its cyclic average can now be used to calculate a high-frequency turbulence time scale from the cyclic analysis using a new autocorrelation function:

$$
R(\theta, \tau)=\frac{\frac{1}{N-1} \sum_{i=1}^{N} u_{h f}(\theta, i) \cdot u_{h f}(\theta+\tau, i)}{u_{h f}^{\prime}(\theta) \cdot u_{h f}^{\prime}(\theta+\tau)}
$$

Additionally, a low-frequency fluctuation $u_{l f}(\theta, i)$ and an equivalent $u_{l f}^{\prime}(\theta)$ can be introduced, representing the fluctuation, or cyclic variability, of the in-cycle mean velocity $\bar{U}(\theta, i)$ about the ensemble-average velocity $U_{E A}(\theta)$ :

$$
\begin{aligned}
& u_{l f}(\theta, i)=\bar{U}(\theta, i)-U_{E A}(\theta) \\
& u_{l f}^{\prime}(\theta)=\sqrt{\frac{1}{N-1} \sum_{i=1}^{N} u_{l f}(\theta, i)^{2}}
\end{aligned}
$$

The high-frequency, low-frequency and instantaneous velocity can be used to recreate the ensemble-average velocity $U_{E A}(\theta)$, overall fluctuation $u(\theta, i)$ and its fluctuation intensity $u^{\prime}(\theta)$ according to:

$$
\begin{aligned}
& U_{E A}(\theta)=U(\theta, i)-u(\theta, i) \\
& u(\theta, i)=u_{l f}(\theta, i)+u_{h f}(\theta, i) \\
& u^{\prime}(\theta)=\sqrt{\overline{u(\theta, l)^{2}}}
\end{aligned}
$$

The values $u(\theta, i)$ and $u^{\prime}(\theta)$ can be used in equation (9) to calculate the autocorrelation function for the combined high and low-frequency fluctuations, as opposed to equation (13), which only focuses on the high-frequency part. The approach returns results similar to the classic ensemble averaged approach (where the RMS fluctuations inside a data bin also contain the high- and low-frequency components) and the cut-off frequency plays only a minor role as it only shifts the components between the high- and low-frequency parts.

The current analysis adopted an approach which calculated an in-cycle average velocity using a smoothing window for an initial cut-off frequency selection, followed by the low-pass filtering of the velocity signal (using the selected 
cut-off and other fixed cut-offs) to obtain an in-cycle mean velocity $\bar{U}(\theta, i)$ and a general in-cycle fluctuation component $u_{h f}(\theta, i)$ as by equation (19), which combines equations (14), (16) and (17):

$$
U(\theta, i)=\bar{U}(\theta, i)+u_{h f}(\theta, i)
$$

The turbulence fluctuation intensity $u_{h f}^{\prime}(\theta)$ can then be calculated using equation (12). $\bar{U}(\theta, i)$ can be averaged over all cycles to obtain a mean velocity which is equal to the standard ensemble-averaged velocity $U_{E A}(\theta)$. The autocorrelation coefficient and its integral can subsequently be calculated according to equations (13) and (10) in order to obtain the integral time scale of turbulence. This approach avoids the low-frequency fluctuation component for the autocorrelation, a term which is not without controversy (it is generally agreed to be a good descriptor for cyclic variability, but if it represents any 'real flow' contributing actively to turbulence or if it overlaps with the frequencies of turbulence is still a point in discussion). As mentioned earlier, the conventional ensemble averaging technique to obtain $u_{E A}^{\prime}(\theta)$ as RMS of the binned velocity over all cycles includes both the low-frequency (representing cycle-by-cycle fluctuation) as well as the high-frequency fluctuation without differentiation, resulting in values up to double $u_{h f}^{\prime}(\theta)$. The work of [74] gave an overview over typical signal reconstruction techniques, including re-sampling to obtain equidistant time spacing, and showed ways to obtain the autocorrelation function and PSD from LDV data. In preparation for the used autocorrelation method, the raw measured velocity was normally re-sampled at $18 \mathrm{kHz}$ or $36 \mathrm{kHz}$ using nearest neighbour point signal interpolation (sample and hold techniques were also tried and delivered similar results) to create an equidistant time spacing necessary for FFT, resulting in a resolution of 0.5 or $0.25{ }^{\circ} \mathrm{CA}$. The re-sampling frequency was chosen depending on the raw signal frequency. Before applying interpolation, cycles containing less than 1440 or 2880 samples for each $720{ }^{\circ} \mathrm{CA}$ cycle were excluded from the analysis for the 18 and $36 \mathrm{kHz}$ analysis, respectively. Typically, more than 800 of the 1200 measured cycles remained valid for the FFT analysis.

All measurements were analysed with respect to the turbulence time scale around ignition timing $\left(26{ }^{\circ} \mathrm{CA}\right.$ BTDC). The following section presents the results for the independently measured velocities in $x, y$ and $z$ direction for all measurement locations. The results of the cycle-to-cycle investigations will be compared at selected points for various cut-off frequencies as well as to the conventional ensemble-average analysis to highlight the differences and ambiguities. The processing procedure was based on the following steps:

- Calculation of ensemble average velocities from all valid cycles by averaging the window-smoothed individual cycle velocities $\left(2-20^{\circ} \mathrm{CA}\right.$ window width for the floating average).

- PSD calculation by multiplying the signal's FFT with its complex conjugate for the individual cycles, $\operatorname{PSD}(U(\theta$, $i)$, and the ensemble-averaged window-smoothed cycle $\operatorname{PSD}\left(U_{E A}\right)$, followed by the selection of a cut-off point at the start of divergence between both signals as suggested by [75].

- In-cycle bulk velocity $\bar{U}(\theta, i)$ calculation by low-pass filtering the individual cycles with the cut-off frequency obtained by the previous PSD analysis for fixed cut-offs of 100, 200400 and $600 \mathrm{~Hz}$. Averaging the individual low-pass filtered cycles $\bar{U}(\theta, i)$ returned the new ensemble-average for the cycle-cycle analysis $\bar{U}(\theta)$.

- Calculation of the in-cycle high-frequency turbulence fluctuation $u_{h f}(\theta, i)$ by subtracting the in-cycle mean velocity $\bar{U}(\theta, i)$ from the instantaneous velocity $U(\theta, i)$ and calculation of $u_{l f}(\theta, i)$ according to equation (17).

- Calculation of the fluctuation intensities $u_{h f}^{\prime}(\theta)$ and $u_{l f}^{\prime}(\theta)$ according to equations (12) and (15). 
- Calculation of the cyclic autocorrelation function using equations (9) and (13) with a time step size $\tau$ of 0.25 or $0.5^{\circ} \mathrm{CA}$ for 200 steps.

- Calculation of the integral time scale of turbulence using equation (10) by evaluating the integral up to $50{ }^{\circ} \mathrm{CA}$ until the autocorrelation function fell below zero or until a first local minimum (dip point) was reached.

Frequency Analysis

The details of the time scale analysis are explained on a single measurement location in the cylinder centre $1 \mathrm{~mm}$ below the spark plug ( $x=-3 \mathrm{~mm}, y=0 \mathrm{~mm}, z=0 \mathrm{~mm}$ ) for the vertical velocity component $u$. All other locations and velocities were evaluated similarly. The frequency analysis to obtain the in-cycle cut-off frequency is shown in Figure 16. The left graph shows the power spectrum of the first cycle (red dotted), the average of the FFT for all cycles (black solid) and the theoretical $-5 / 3$ turbulence cascade (black dashed). The maximum resolvable frequency was half the frequency of the re-sampled data of $36 \mathrm{kHz}$, i.e. $18 \mathrm{kHz}$.

A moving average filter was applied to the individual cycles with a window width of 4, 8, 12, 16 and $20{ }^{\circ} \mathrm{CA}$. The individual window-averaged cycles were then ensemble-averaged over all cycles to obtain the window-averaged ensemble mean velocity. The PSDs of the various window-averaged mean velocities are shown in the graph (various solid red). Also included in the graph is the PSD of the traditionally ensemble-averaged velocity (blue). The location of first distinct deviation of the averaged PSD plots from the individual cycle's PSD should be used to select the frequency cut-off. As the individual cycle's PSD was very noisy, it was found less ambiguous to use the averaged PSD over all cycles (black).

Looking at the graph, the dependence of the cut-off frequency on the window width becomes obvious, as the found point of deviation moves towards higher frequencies for smaller window sizes. The reason for this lies in the nature of the windowing, which is in itself a filter that is mathematically described by a Dirichlet function. When applying the formula to the current data set with a sample frequency of $36 \mathrm{kHz}$ and a time interval according to the required window sizes, the resulting $-3 \mathrm{~dB}$ limit frequencies are given in Table 4 , so that the graphically obtained limits are a way to get the limit frequency without calculation.

An ambiguity in the selected threshold for the in-cycle mean velocity therefore still persists. However, there was a subjective point of first strong deviation found for the 8-16 ${ }^{\circ} \mathrm{CA}$ windows between $300-400 \mathrm{~Hz}$ (greyed area in Figure 16) and around $400 \mathrm{~Hz}$ for the $4{ }^{\circ} \mathrm{CA}$ window as well as the traditional ensemble average. Suggestions based on physical relations such as the inverse of the stroke duration would return very low cut-off thresholds of 50 $\mathrm{Hz}$ and were discarded based on not resolving any of the fast incoming peak flow around $310{ }^{\circ} \mathrm{CA}$ BTDC. Using the highest frequency present in the ensemble-averaged data as cut-off, as suggested by [48], was found more useful for the current data. Two distinct peaks could be seen in the power spectrum for all ensemble-averaged functions between 100 to $1000 \mathrm{~Hz}$. The first peak started around $350 \mathrm{~Hz}$ while the second was at just above 600 Hz. In the right graph of Figure 16, the in-cycle mean velocity for a single cycle is shown for cut-off frequencies of 100, 200, 400 and $600 \mathrm{~Hz}$, as well as for traditional ensemble averaged velocity trace. Analysis of graphs over a range of cut-off frequencies from $600 \mathrm{~Hz}$ down to $100 \mathrm{~Hz}$ showed a distinct low-frequency fluctuation during the intake stroke between $330{ }^{\circ} \mathrm{CA}$ and $210{ }^{\circ} \mathrm{CA}$ BTDC of about $350-450 \mathrm{~Hz}$, believed to correspond to the first peak found in the power spectrum and also to the pressure fluctuation frequency in the intake runner, so that $400 \mathrm{~Hz}$ was selected as the preferred cut-off frequency for in-cycle analysis. Results for lower frequency cut-offs were also calculated for time scale analysis. 
Figure 17 concludes the frequency analysis for a single sample location of measurement. The zoom into the compression stroke for the individual cycle's velocity and the in-cycle mean velocity for various thresholds (top left) shows how the cut-off frequencies between $200-600 \mathrm{~Hz}$ were within the measurement envelope, while the 100 $\mathrm{Hz}$ filtering did not quite fit by subjective judgement. The calculated turbulence intensity $u_{h f}^{\prime}$ over all cycles (top right) shows that the main effect of the cut-off frequency of the filtering was during the early intake stroke in the area of largest velocities, while the differences during the compression stroke were small throughout. Around ignition timing $\left(26^{\circ} \mathrm{CA} \mathrm{BTDC}\right.$ ), all high-frequency turbulence intensities were found to be between $1.8-2.5 \mathrm{~m} / \mathrm{s}$, lowest for the highest cut-off frequency. Ensemble averages of the in-cycle mean velocities for the various cut-off frequencies (bottom left) and the low-frequency fluctuation intensities of the in-cycle mean around the ensembleaverage are also shown (bottom right). The latter, in opposition to the high-frequency showed higher values for higher cut-off frequencies, yet during the compression stroke the values were quite close between $1-2 \mathrm{~m} / \mathrm{s}$.

When using the $400 \mathrm{~Hz}$ cut-off frequency on all measurement locations at the $x=-3 \mathrm{~mm}$ location along the $y$ - and $z$ axis, mean and fluctuation velocity maps for the compression stroke similar to those of the ensemble averaging analysis were obtained for cyclic analysis. The graphs in Figures 18-19 show the ensemble-averaged individual cycle low-pass mean velocities along the $y$-and $z$-axis; the left columns show the $u, v$ and $w$ velocity components in the first, second and third row, respectively. The high- and low-frequency fluctuations, i.e. $u_{h f}^{\prime}(\theta)$ and $u_{l f}^{\prime}(\theta)$, respectively, are given in the middle and right columns accordingly. At ignition timing, the mean $u$ and $w$ velocities were close to $\pm 1 \mathrm{~m} / \mathrm{s}$, while the $v$ component showed values between 0 to $-8 \mathrm{~m} / \mathrm{s}$, agreeing closely with the values and structures obtained by the traditional ensemble-averaging method.

The high-frequency fluctuations around ignition timing were in the region of $1-2 \mathrm{~m} / \mathrm{s}$ for all components, with $v^{\prime}{ }_{h f}$ and $w^{\prime}{ }_{h f}$ having slightly higher values than $u_{h f}^{\prime}$. These values were therefore about half the fluctuation obtained by the traditional approach, due to the exclusion of the low-frequency velocity fluctuations that can be considered to represent cycle-to-cycle variations. Values of $1.5-3 \mathrm{~m} / \mathrm{s}$ were found for the low-frequency fluctuations at ignition timing, slightly highest for the $v$-component. This measure of cyclic variability was therefore of the same order of magnitude to the mean velocities and typically higher than the high-frequency fluctuations.

When calculating TKE on the basis of the high-frequency fluctuations according to $k_{h f}=0.5\left(u^{\prime 2}{ }_{h f}+v^{\prime 2}{ }_{h f}+w^{\prime 2}{ }_{h f}\right)$ and quantifying an equivalent average turbulence intensity as $\left[(2 / 3) k_{h f}\right]^{1 / 2}$, the graphs of Figure 20 were obtained for the $y$-axis (left) and $z$-axis (right). The TKE values found around ignition timing were within $3-4 \mathrm{~m}^{2} / \mathrm{s}^{2}$, i.e. distinctly lower (75\%) than when the low-frequency fluctuations had been included earlier in Figure 11. The TKE during induction (especially for the highest intake charge velocities around 300-280 ${ }^{\circ} \mathrm{CA}$ BTDC) was not as much affected, showing that the cyclic variability was not as dominant over the high-frequency fluctuations during the air intake as later during the compression stroke.

Turbulence intensity close to compression TDC was now between $1.4-1.6 \mathrm{~m} / \mathrm{s}$, below the estimate of half the mean piston speed of $4.25 \mathrm{~m} / \mathrm{s}$. The trends of TKE being slightly higher towards the negative $y$-axis (exhaust side) and towards the negative $z$-axis as shown earlier from the typical RMS analysis are still valid, but less distinct. The turbulence intensity and TKE during compression after IVC have their maximum values just before TDC when the present tumble bulk motion is considered to break down into smaller scale turbulence. This flow behaviour was also found by [76] who used cycle-resolved analysis with a $12{ }^{\circ} \mathrm{CA}$ window averaging to obtain in-cycle mean flow 
and turbulence in a 4-valve pentroof engine of under square geometry with similar bore and compression ratio to that of the current study, imposing various levels of swirl by valve deactivation when the engine was operated at 1500 RPM with wide-open-throttle. Furthermore, the velocities and turbulence intensities of [76] were similar to those of the current investigation, unlike those of $[66,67]$ where intensities close to TDC were only of the order of $0.2-0.5 \mathrm{~m} / \mathrm{s}$ for a conventional and tumble port at $500 \mathrm{RPM}$ and $1000 \mathrm{RPM}$. However, the low mean piston speed of only $1.6 \mathrm{~m} / \mathrm{s}$ at $1000 \mathrm{RPM}$ due to the short stroke of the over-square engine of $[66,67]$ could largely account for the differences found.

\section{Autocorrelation Function at Injection and Ignition Timings}

The calculated autocorrelation functions given in Figure 21 show the results for $u, v$ and $w$ at the centre of the cylinder at a vertical location of $x=-3 \mathrm{~mm}$ at $300{ }^{\circ} \mathrm{CA}$ BTDC (left column) and at $26^{\circ} \mathrm{CA}$ BTDC (right column), representing the start of injection and ignition timing, respectively. All graphs show the results for the various cutoff frequencies of the high-frequency cyclic analysis (coloured lines, no marker), as well as the value from the traditional ensemble-averaging of the binned velocities of all cycles (black lines, no marker). For the latter, the fluctuation was calculated using the RMS of the individual bins with the cyclic fluctuation component included according to equation (13). For the data point shown, the bin size was chosen to be $0.26{ }^{\circ} \mathrm{CA}$, to match the cyclic data which could be re-sampled with $36 \mathrm{kHz}$ due to the high raw signal frequency at the centre of the cylinder. The combined low- and high-frequency components according to equations (17) and (18) from the frequency analysis along with equation (13) are also included in the figure (coloured lines, circular marker). All three spatial velocity components are shown (top row: $u$, middle row: $v$, bottom row: $w$ ). The time scales given in the graph's legends were calculated using the time integral of the graphs from $R=1$ ( $t=0 \mathrm{~ms})$ until the time of first falling below $R=0$ or reaching the minimum value within $5 \mathrm{~ms}$.

Two main observations are instantly possible. Firstly, the turbulence during the high-velocity intake stroke was unsurprisingly much higher and returned very low integral time scales of turbulence in comparison to the flow around spark timing as shown in the figure's annotation. Secondly, the autocorrelation functions drop much faster for higher cut-off frequencies as larger or longer lasting flow structures are excluded. With few exceptions, the traditional approach using the bin averaging method returned much larger time scales. This may be due to all lowfrequency fluctuations being included in this analysis as opposed to the high-frequency only cyclic analysis. Recombining the low- and high-frequency components obtained from the frequency analysis returned autocorrelation function results very similar to that of traditional ensemble averaging.

At ignition timing, the traditional ensemble averaged integral time scales were $1.08 \mathrm{~ms}$ for $u, 1.87 \mathrm{~ms}$ for $v$ and $0.89 \mathrm{~ms}$ for the $w$ velocity component (i.e. $8-16{ }^{\circ} \mathrm{CA}$ ). The strong $v$ component is believed to be a direct result of the directionality of the tumble motion breaking up into smaller scale vortices. A characteristic of the autocorrelations at ignition timing was that they did not converge to zero within the expected time lag. Only at exhaust valve opening, $16 \mathrm{~ms}$ after ignition timing, an abrupt step change to zero was found. It could be that the downwards motion of the piston and volume expansion delay turbulence dissipation, resulting in long correlations.

\section{Autocorrelation Maps during Intake and Compression}

The development of the autocorrelation for the measurement location $x=-3, y=0, z=0 \mathrm{~mm}$ throughout the cycle can be seen in Figure 22. Each row in the left column of graphs shows the $u, v$ and $w$ component, respectively, for the traditional ensemble-averaging approach, while the right column contains the $200 \mathrm{~Hz}$ cut-off frequency results. 
Increasing the cut-off frequency excluded larger scale turbulent structures, keeping only smaller eddies travelling quicker through the measurement volume, such that the correlations for 300-400 Hz were typically shorter. Therefore, it was decided to show the $200 \mathrm{~Hz}$ data here in an attempt to ensure clearer representation of the colour maps for each velocity component when using the same scale between ensemble-averaged and filtered conditions. According to the traditional ensemble-averaging graphs, the time scales were very low throughout the induction stroke $(<0.5 \mathrm{~ms})$, but the situation changed abruptly after the piston reached BDC. From here on, no incoming flow past the valves would have any significant fed momentum into the cylinder and high velocities were absent. The large-scale tumble motion could now freely progress without major disturbance by external forces and vortex structures now started to naturally dissipate due to stresses and friction. Once the piston started moving towards TDC during compression, higher pressures and temperatures followed after IVC and the space available for the motion of vortices reduced. It can be seen that the horizontal components returned larger values during late compression for $v$, with longest correlations for $w$ around $120^{\circ} \mathrm{CA} \mathrm{BTDC} \mathrm{(i.e.} \mathrm{just} \mathrm{after} \mathrm{the} \mathrm{IVC} \mathrm{timing} \mathrm{of} 124{ }^{\circ} \mathrm{CA}$ BTDC). The shortest values for $v$ and $u$ were returned in the region of typical advanced ignition timings (30-50 ${ }^{\circ} \mathrm{CA}$ BTDC), whilst $w$ showed values reducing further towards TDC. The increasing time lag for $u$ and $v$ in the area of retarded ignition timings (30-0 ${ }^{\circ} \mathrm{CA}$ BTDC) could be due to time lags surpassing TDC and the downwards motion of the piston along with pressure relaxation could have an effect as mentioned earlier. However, very little vertical movement is produced per crank angle around TDC (and BDC) and other effects such as heat transfer to the outside and pressure loss due to leakage could also play a part. The high-frequency cut-off calculations at 200 $\mathrm{Hz}$ generally showed little difference in the autocorrelation lengths between intake and compression stroke. The $200 \mathrm{~Hz}$ cut-off should still include structures up to $5 \mathrm{~ms}$ equating to a piston movement interval of $45{ }^{\circ} \mathrm{CA}$ but only time scales of up to $0.1-0.2 \mathrm{~ms}$ could be found. Similar autocorrelation maps for the higher cut-off frequencies returned even shorter correlations as already indicated in Figure $\mathbf{2 1}$ for a single crank angle. The typical effect of such short autocorrelations would be the estimation of smaller integral length scales than with the ensemble approach, something that has also been seen by direct measurement of integral length scales by two-point LDV using filtered and unfiltered velocity data in a disk-shaped combustion chamber geometry [64].

\section{Integral Time Scales of Turbulence}

Due to the ambiguity in the high-frequency approach, the large difference to the classic autocorrelation technique and the wide spread use of the latter, the time scale analysis in the following discussion will be based on the traditional approach only. This should maintain good comparability for other researchers. Autocorrelation functions were calculated from $300{ }^{\circ} \mathrm{CA}$ BTDC to TDC in steps of $10{ }^{\circ} \mathrm{CA}$ for each measurement location and velocity component. The resulting integral time scale is presented in form of surface plots for the time scale development along the $y$-axis (exhaust to intake) or the $z$-axis (control to flywheel side) during intake and compression.

Figure 23 shows the results for the $y$-axis in the left column and the $z$-axis on the right for the $x=-3 \mathrm{~mm}$ plane. Velocity components $u, v$ and $w$ are shown in the $1^{\text {st }}, 2^{\text {nd }}$ and $3^{\text {rd }}$ row, respectively. As already shown for the sample autocorrelation graphs at the centre of the cylinder, all time scales during intake were very low with values typically below $0.5 \mathrm{~ms}$ along the $y$-axis and below $1 \mathrm{~ms}$ along the $z$-axis ( 4.5 and $9{ }^{\circ} \mathrm{CA}$, respectively) where the largest values were found for regions in the inlet valve shadow. During compression, integral time scales up to 2.5 ms could be found for many measurement locations and crank angles (about $22{ }^{\circ} \mathrm{CA}$ ). The time scales at the MBT ignition timing of $26^{\circ} \mathrm{CA}$ BTDC close to the spark showed values of $1.5-1.8 \mathrm{~ms}$ for $u$ (about $13-16{ }^{\circ} \mathrm{CA}$ ) and $1.3-$ 
$2.3 \mathrm{~ms}$ for $v$ along the $y$ and $z$ axes (about $12-20^{\circ} \mathrm{CA}$ ). The $w$ component was showing longer correlations along the $z$-axis with time scales of $1.2-2.2 \mathrm{~ms}$ compared to $0.8-1.3 \mathrm{~ms}$ along the $y$-axis $\left(11-20{ }^{\circ} \mathrm{CA}\right.$ and $7-12{ }^{\circ} \mathrm{CA}$, respectively). Therefore, a developing flame kernel would experience nominally airflow timescales of the order 15 ${ }^{\circ} \mathrm{CA}$ and if one considers that TDC is typically associated with the timing of 5-10\%, the flame would experience about 2 integral time scales during the critical stage of early kernel development. The time scales were typically largest between $160{ }^{\circ} \mathrm{CA}$ BTDC and $60^{\circ} \mathrm{CA}$ BTDC and were increasing again close to TDC. The time scales on the $x=10 \mathrm{~mm}$ plane shown in Figure 24 also demonstrated very low time scales during intake with values below $0.5 \mathrm{~ms}$ along the $y$-axis for all directions, but slightly larger scales along the $z$-axis in the valve's wake, with up to $1.2 \mathrm{~ms}$ for $u$ and $w$. Largest time scales were again found between BDC and $60{ }^{\circ} \mathrm{CA}$ BTDC. It is interesting to note here that duration of the injection in the intake stroke of this engine for stoichiometric operation at 1500 RPM with 0.5 bar inlet pressure, was about $1.3 \mathrm{~ms}$ and $1.8 \mathrm{~ms}$ for gasoline and ethanol fuelling, respectively, i.e. the spray would experience nominally about 1-3 integral time scales of the in-coming airflow during injection..

\section{Integral Length Scales of Turbulence}

The integral length scales could not be directly obtained using the present LDV system, as a two probe setup would be required to calculate the spatial correlation in the velocity field. Empirical equations are however often used to estimate the length scales based on the measured time scale and velocities. As the turbulence intensity during the compression stroke was of the same order of magnitude or even higher than the mean velocity, Taylor's hypothesis which uses the product of ensemble-averaged mean velocity and integral time scale $L_{x}(\theta)=\bar{U}(\theta) L_{t}(\theta)$ for length scale approximation, is considered inappropriate. This is typical for engine flows close to TDC, where alternative relations are to be used. The work of [77] suggested the use of the RMS velocities instead according to:

$$
L_{x}(\theta)=C u^{\prime}(\theta) L_{t}(\theta)
$$

with $C$ being a constant of the order unity.

In this context, the length scales on the $x=-3 \mathrm{~mm}$ layer in Figure 25 were calculated by using the fluctuation velocities $u^{\prime}, v^{\prime}$ and $w^{\prime}$ of the traditional ensemble-averaging analysis, with $C=1$. The resulting graphs return very small length scales during the intake stroke despite high velocity fluctuations, dominated by the very short integral time scales. The length scales $L_{u}$ and $L_{w}$ between ignition timing and TDC were between 3-6 mm and slightly larger for the $v$ component with values up to $10 \mathrm{~mm}$ for $L_{v}$. Length scale maps calculated by using mean velocities could be more suitable during the open-valve fast intake air flow motion. These showed slightly larger length scales during the intake stroke with up to $5 \mathrm{~mm}$ for $L_{v}$ on the $x=-3 \mathrm{~mm}$ plane (with $L_{u}$ and $L_{w}$ smaller than $1 \mathrm{~mm}$ ). However, further down inside the cylinder at $x=10 \mathrm{~mm}$ (Figure 26-27), $L_{u}$ was largest with values up to $8 \mathrm{~mm}$, while $L_{v}$ remained below $4 \mathrm{~mm}$ and $L_{w}$ below $1 \mathrm{~mm}$.

The longitudinal integral length scales obtained on the tumble and swirl plane by PIV inside the pentroof $26^{\circ} \mathrm{CA}$ BTDC are shown in Figure 28. These give clearer information than the length scales calculated by the LDVderived time scales and velocity fluctuations. The length scale $L_{u}$ in $x$-direction, obtained from the tumble view on the sides of the spark plug had values between about 3-5 mm, with largest scales towards the intake side. Smallest $L_{u}$ scales were seen below the spark plug, 1-2 mm in size, in the region where the spark plug ground electrode was protruding into the combustion chamber and narrowing the region above the piston's top land ( $y$ from 0 to $-5 \mathrm{~mm}$ ). Considering an equivalent clearance height of about $15 \mathrm{~mm}$ (calculated by dividing the clearance volume by the engine bore), $L_{u}$ scaled to about $7-30 \%$. $L_{v}$ values along the $y$-axis for the swirl and tumble view measurements 
matched reasonably well, both showing an increased length scale at $y$ positions $0-5 \mathrm{~mm}$. $L_{v}$ was between $4-8 \mathrm{~mm}$ along the $y$-axis and up to $10 \mathrm{~mm}$ towards the negative $z$-axis, i.e. about $5-12 \%$ of the bore. $L_{w}$ was obtained from the swirl view and was generally lower than $L_{v}$. Largest values for $L_{w}$ can be seen towards the intake side of the engine (7-8 $\mathrm{mm}$ in size), in the area of the largest $w$-velocities of the two counter-rotating swirl structures below the intake valves.

Despite limitations related to equation (20), the integral length scales obtained by LDV on the basis of RMS velocities showed generally similar range of magnitudes in all directions. Looking at each one of the scales, it is interesting to note the following: $L_{u}$ values at ignition timing (top right graph of Figure 25) show slightly larger values in the positive $y$ direction than those derived by PIV (intake side of engine). In further agreement, the values at the spark plug location near (i.e. around $y=0 \mathrm{~mm}$ ) were the smallest. Even quantitatively, despite the coarse resolution of the LDV measurement points in comparison to PIV, the values of $L_{u}$ appear broadly in agreement with PIV, being of the order 3-4 mm on the intake side and about 2 at the spark plug location. $L_{u}$ plotted along the $z$-axis (top left graph of Figure 25) shows larger values than those along $y$. The integral length scales of $v$ showed clearly larger values in the negative $z$ direction in the PIV data of Figure 28 (bottom left graph); the LDV data of Figure 25 also show generally increased $L_{v}$ scales in the negative $z$ direction at the end of compression, of the order 8-10 $\mathrm{mm}$ (right graph, $2^{\text {nd }}$ row). However, this trend of agreement is not really holding when it comes to comparing $L_{v}$ values between PIV and LDV data along the $y$-axis. The left graph of the $2^{\text {nd }}$ row of Figure 25 show larger $L_{v}$ values in the negative $y$ direction, a trend that is not really seen in the PIV data of Figure 28 (bottom left graph); if anything, it appears to be the opposite trend despite maximum values being about $10 \mathrm{~mm}$ in both graphs. A match between LDV and PIV $L_{v}$ values was slightly better when mean velocities were used for LDV's $L_{v}$ estimation. This may be due to the sufficiently large mean velocity upstream the spark plug on the intake side from the mean tumble vortex and cannot be really associated with Taylor's hypothesis holding better. The integral length scales of $w$ in the right graph of the $3^{\text {rd }}$ row of Figure 25 display increased values of the order 6-7 $\mathrm{mm}$ in the negative $z$ direction, a trend again not present in Figure 28. The larger values of $L_{w}$ in the negative $y$ direction in Figure 25 ( $3^{\text {rd }}$ row, left graph) appear in some agreement with Figure 28 though. $L_{u}$ and $L_{w}$ scales calculated by mean velocities and LDV's time scales did not match PIV's equivalent length scales, most probably because both $u$ and $w$ featured very low mean values at ignition timing in comparison to $v$.

Analysis of the time evolution of LDV's integral length scales showed that on the lower in-cylinder plane (Figure 27) all length scales had decreased at the latest measurement timing of $50{ }^{\circ} \mathrm{CA}$ BTDC. However, on the upper horizontal plane inside the pentroof (Figure 25), scales showed that despite their general trend of decreasing up to $50{ }^{\circ} \mathrm{CA}$, they increased rapidly towards TDC after that. The most drastic increase was observed for $v$ along both $y$ and $z$-axes and a more moderate one for $u$ also for both axes. In contrast, the integral length scales of $w$ showed a continuous decrease to TDC. This indicates a redistribution of scales as the flow is squeezed inside the pentroof at the end of compression and can be critical in how the early flame kernel grows.

\section{Comparison of Integral Length Scales with other Engines and Conditions}

The spatially averaged longitudinal integral length scales of the current study, as derived by PIV at $26{ }^{\circ} \mathrm{CA}$ BTDC, were on the tumble plane $4.2 \mathrm{~mm}$ (mean of $L_{u}$ and $L_{v}$ ) and on the swirl plane $6.1 \mathrm{~mm}$ (mean of $L_{v}$ and $L_{w}$ ). At this stage it was deemed interesting to make some quantitative comparisons with other integral length scale data found in the engine literature. Quoting the different combustion engine geometries and operating conditions was also 
considered necessary. Specific effort was made to quote velocity components and axes in this section with respect to the definition adopted in the current paper in order to avoid confusion when making comparisons throughout. A summary of these scale data is presented in Table 5. The results of the present study in this table show the length scales derived by PIV. It is also reminded that, according to theory, a longitudinal integral length scale should be double the size of the respective lateral one of the same velocity component according for homogeneous isotropic turbulence. The following text elaborates further on the studies of Table 5. The exact in-cylinder locations and measurement techniques used by the different authors have been quoted explicitly in the text in order for the interested reader to make his own assessment and comparisons where required.

The seminal two-point LDV work of [63] in the centre of the clearance height $6 \mathrm{~mm}$ below the flat engine head of a disk-shaped combustion chamber was conducted at a radial location $77 \%$ of the bore radius and showed about 3 $\mathrm{mm}$ lateral length scales $40{ }^{\circ} \mathrm{CA}$ BTDC, decreasing to about $2 \mathrm{~mm}$ at TDC. This was for radially-separated tangential velocity measurements, equivalent to $v$ or $w$ of the current study since their engine combustion chamber was a very simple cylinder with side ports (2-stroke). The length scale was found to scale 10-20\% with the clearance height. The engine was run at 600 RPM, 1 bar intake, with a compression ratio of 8 and a swirl ratio of 4 . This work was expanded in [64] where compression ratios of 5.7, 7.6 and 11.4 were employed and both raw velocities and velocity data filtered by cut-off frequencies of $150-450 \mathrm{~Hz}$ were considered. Increasing the cut-off frequency led to lateral integral length scales dropping to $\sim 1 \mathrm{~mm}$ with $150 \mathrm{~Hz}, \sim 0.75 \mathrm{~mm}$ with $300 \mathrm{~Hz}$ and $\sim 0.6$ $\mathrm{mm}$ with $450 \mathrm{~Hz}$. This highlighted that the large scale motions were predominantly associated with the lower frequencies. The ensemble length scales were found to decrease to about $2-2.5 \mathrm{~mm}$ at TDC, with the higher compression ratios giving the lower values in this short range; scales were about $3-6 \mathrm{~mm}$ at $40{ }^{\circ} \mathrm{CA} \mathrm{BTDC}$. This was considered weak dependence of length scales on compression ratio. When the respective filtered data were used in the analysis, the insensitivity to compression ratio was even stronger and a lack of clear proportionality with the clearance height before and after TDC was obvious. The analysis was expanded to more lateral integral length scales in [65] using axially separated tangential components, i.e. $v$ (or $w$ ) along $x$, as well as radially separated axial components, i.e. lateral integral length scales of $u$. The lateral tangential components did not scale with clearance height around TDC but the lateral axial integral length scales were approximately proportional to clearance height, with scales decreasing from about $2 \mathrm{~mm}$ at $40{ }^{\circ} \mathrm{CA}$ BTDC to about $1-1.5 \mathrm{~mm}$ at TDC for compression ratios of 11.4 and 7.6. For a compression ratio of 5.7 this length scale remained constant at about 2.5 $\mathrm{mm}$ from $40{ }^{\circ} \mathrm{CA}$ BTDC to $20{ }^{\circ} \mathrm{CA}$ ATDC. The same length scale measured on the opposite hemi-circle of the engine bore at a radial location from the centre $46 \%$ of the bore radius, showed a relatively flat value of about 2.5 $\mathrm{mm}$ around TDC. It was quantified that, with respect to homogeneity, length scales $\sim 5 \mathrm{~cm}$ apart differed from their respective average values by $\sim 12-14 \%$ for all compression ratios (with $95 \%$ of the scales being within $21-29 \%$ of their average). Similar levels of inhomogeneity were quantified for the fluctuation intensities. The axially-separated lateral integral length scale of the tangential velocity showed similar behaviour to its radially-separated counterpart. A recent study in a similar bore disk-shaped chamber to that of [63-65] but without swirl and a compression ratio of 10.6 [78] measured integral length scales by PIV on a horizontal plane at $17^{\circ} \mathrm{CA}$ BTDC for 1500 RPM, 1 bar intake. These were found to be 6-8 $\mathrm{mm}$ for the longitudinal correlation of both $u$ and $w$ and about $4-5 \mathrm{~mm}$ for the lateral correlation. 
The scanning LDV study of [79] of both $v$ and $w$ velocity components along the $z$ axis between intake and exhaust valve in a disk-shaped chamber engine with a compression ratio of 9 and almost square bore-stoke geometry of 86 $\mathrm{mm}$ at $1200 \mathrm{RPM}$ with wide-open-throttle and a swirl ratio of 3.6, showed that the longitudinal scale of $w$ was about $7 \mathrm{~mm}$ at $30{ }^{\circ} \mathrm{CA}$ BTDC and the lateral one of $v$ about half that. These authors also commented that their autocorrelation functions appeared to asymptote to a correlation of 0.1 rather than zero at most points, and attributed this to cyclic variations in the bulk flow causing a velocity offset from one cycle to the next, thereby increasing the correlation at all separations.

Measurements by [80] in an another 2-valve disk-shaped combustion chamber using a Laser homodyne technique showed integral length scales that were fairly independent of engine speed in the range 400-1200 RPM with 1 bar intake. The lateral scale was measured and then doubled to provide estimates of the longitudinal. The longitudinal was found to decrease from about $4-5 \mathrm{~mm}$ in the early compression stroke to about $2.5 \mathrm{~mm}$ at TDC with compression ratio of 8.2 and zero swirl. The initial scale past BDC was found to be about $3 \mathrm{~mm}$ when the compression ratio was increased to 11.6 at $800 \mathrm{RPM}$, and it dropped monotonically to about $2 \mathrm{~mm}$ at TDC. With the swirl ratio increased to 2.1, the longitudinal length scales at 800 RPM, with 8.2 compression ratio increased to levels across the bore of about $4-6 \mathrm{~mm}$ at the end of compression, starting from values in the range $8-10 \mathrm{~mm}$ soon after IVC.

The study of [81] in an engine with a 2-valve disk-shaped combustion chamber of $85 \mathrm{~mm}$ bore and a compression ratio of 8 measured at 1000 RPM wide-open-throttle with a swirl ratio of 3.5 integral time scales of the order 0.5 ms near compression TDC for all components $6.5 \mathrm{~mm}$ below the engine head gasket and $16 \mathrm{~mm}$ from the centre of the bore between intake and exhaust sides. Using Taylor's hypothesis the authors derived respective longitudinal length scales of the order $1 \mathrm{~mm}$ for the axial $(u)$ and radial $(w)$ velocity components, whilst that of the tangential component ( $v$ velocity) was about $4 \mathrm{~mm}$ at TDC, having dropped rapidly from levels of about $10 \mathrm{~mm}$ at $90{ }^{\circ} \mathrm{CA}$ BTDC. Decreasing the swirl ratio to 0.9 at 1000 RPM, increased significantly the axial integral time scales to about $3 \mathrm{~ms}$ at TDC, $4.5 \mathrm{~mm}$ below the engine head and $16 \mathrm{~mm}$ away from the centre of the bore between intake and exhaust valve. The corresponding integral length scales were over $5 \mathrm{~mm}$ during the entire compression and expansion strokes. In the vicinity of the swirl centre, higher integral time scales were registered axially after TDC than at other measuring locations, with an order of magnitude of $0.5-1 \mathrm{~ms}$. The axial integral time scales showed a monotonic decrease when the swirl ratio was increased from 0.9 to 2.0, 2.4 and 3.5 at 1000 RPM, with levels ranging at TDC from of $0.5 \mathrm{~ms}$ to $3 \mathrm{~ms}$. The radial integral time scale at the lowest swirl ratio was found to scale reciprocal with the engine speed in the range 600-1500 RPM; however, in units of ${ }^{\circ} \mathrm{CA}$ these scales were the same, decreasing from about $20{ }^{\circ} \mathrm{CA}$ at $90{ }^{\circ} \mathrm{CA}$ BTDC to about $10{ }^{\circ} \mathrm{CA}$ in late compression. The corresponding radial integral length scales were found to be unaffected by engine speed, decreasing from about $8 \mathrm{~mm}$ at $90{ }^{\circ} \mathrm{CA}$ BTDC to about $5 \mathrm{~mm}$ at TDC.

The PIV work of $[3,4]$ in a pentroof engine of similar geometric characteristics to those of the current study (in terms of bore/stroke and compression ratio) at 1200 RPM, 1 bar load, and with one of the intake ports blocked to generate swirl, showed integral length scales in the range $6-10 \mathrm{~mm}$ on a horizontal plane about $12 \mathrm{~mm}$ below the cylinder head gasket at $60{ }^{\circ} \mathrm{CA}$ BTDC. The smaller values applied to $v$ and the larger to $w$. The longitudinal scales were typically about 15-30\% larger than the lateral. Operation at 600 RPM showed spatially averaged integral length scales in the range 7-9 mm, generally increasing from BDC and peaking at about $90{ }^{\circ} \mathrm{CA}$ BTDC with a 
small decrease after for the last measurement timing of $30{ }^{\circ} \mathrm{CA}$ BTDC. The differences between longitudinal and lateral scales of $w$ were of the order 15-20\%. The lateral scale of $v$ showed a fairly constant value of about 4-5 mm during compression; this was about $50-60 \%$ of the longitudinal.

Spatially averaged integral length scale measurements by PIV in [82] using a 3-valve pentroof engine of 11.1 compression ratio at $60^{\circ} \mathrm{CA} \mathrm{BTDC}$ on a horizontal plane $3 \mathrm{~mm}$ below the engine head and on the central symmetry vertical plane showed, for 1200 RPM, increasing values during compression from about $4 \mathrm{~mm}$ at BDC to about 7 $\mathrm{mm} 60{ }^{\circ} \mathrm{CA}$ BTDC for the longitudinal scales of both $v$ and $w$ and from about $3 \mathrm{~mm}$ to $6 \mathrm{~mm}$ for the lateral components. Their latest measurement timing of $30{ }^{\circ} \mathrm{CA}$ BTDC showed the scales had levelled off or decreased slightly. In contrast, the scales on the vertical symmetry plane did not show a monotonic increase during compression. For $u$, an average value of the order $7 \mathrm{~mm}$ for the longitudinal and $5 \mathrm{~mm}$ for the lateral integral length scale was quantified. For $v$, the mean longitudinal integral length scale on the tumble plane was in broad agreement with the horizontal plane, increasing from about $6 \mathrm{~mm}$ at BDC to about $8-9 \mathrm{~mm}$ at $60{ }^{\circ} \mathrm{CA}$ BTDC, whilst the lateral scale was fairly constant at about $5 \mathrm{~mm}$. The longitudinal integral scales of $v$ were larger on the intake side of the engine and shorter under the single exhaust valve, similarly to those in the current study of the 4-valve chamber, a characteristic most probably attributed to similarities in the tumble flow pattern in the two engines. The longitudinal scale of $w$ also showed similar spatial pattern to that of the current engine. However, the spatial range of scales was typically 5-10 mm, quite narrower and with larger values than those of the current study on both vertical and horizontal planes. This may be attributed to the later timing of $26{ }^{\circ} \mathrm{CA}$ BTDC used to derive length scales here.

The LDV work of $[66,67]$ in a small over-square 4-valve pentroof engine with a bore of $56 \mathrm{~mm}$ and a compression ratio of 8.5 showed relatively constant integral time scales of about $0.5 \mathrm{~ms}$ from mid compression to TDC at the centre of the bore $1 \mathrm{~mm}$ above TDC for the $v$ velocity component with both a conventional and a high tumble port at 1000 RPM (mean $v$ at mid compression was close to $5 \mathrm{~m} / \mathrm{s}$ for the tumble port and close to zero for the conventional). The time scales were about double those at $500 \mathrm{RPM}$, i.e. about the same in units of ${ }^{\circ} \mathrm{CA}$ irrespective of speed. Using the suggestion of [77] for the link between length scale and time scale, i.e. equation (20), and with a constant $C=3$, the respective integral length scales were quite small, typically less than $0.4 \mathrm{~mm}$ with the tumble port and about half that for the conventional port. The much smaller length scales than those found in other engines may be related to the smaller size of the engine. However, still, longitudinal $v$ length scales lower than $\sim 1 \%$ of the bore, or $\sim 2 \%$ of half the stroke, even less than $\sim 5 \%$ of the expected clearance height at TDC, are surprisingly small, especially when considering the $C=3$ value as well.

It is notable that the integral scales have shown generally similar values in different combustion chambers that span many years of engine design. Time scales decrease with increasing engine speed but are not affected if expressed in units of crank angle degrees. Integral length scales appear generally insensitive to engine speed. Typically the longitudinal scales scale with the bore within 5-20\%. The lateral ones are about 30-40\% smaller than the longitudinal ones, when homogeneous isotropic turbulence dictates $50 \%$ difference. This highlights the degree of inhomogeneity and anisotropy in engines. Length scales in disk-shape chamber decrease during compression and appear to scale with the clearance height close to TDC within $15-25 \%$. This feature appears to be more complicated in pentroof engines where spatially averaged length scales have shown non-monotic (but fairly constant) values axially, and increasing values horizontally during most of compression, especially in the main 
tumble direction from inlet to exhaust, with then a small decrease towards TDC. The current pentroof engine showed an even more complex behaviour with decreasing scales up to $50{ }^{\circ} \mathrm{CA}$ TDC and rapid increase towards TDC after that. The most drastic increase was for the main horizontal component of tumble from intake to exhaust side and a moderate one for the vertical component. In contrast, the second horizontal component showed continuous decrease to TDC. The presence of the bulk tumble vortex in pentroof engines and the altering geometric shape of the in-cylinder volume as the flow is gradually squeezed from a broadly generic cylindrical shape into a more irregular volume dictated by the specifics of the pentroof geometry that carries variable clearance height across, maybe associated with such differences. However, further work is needed to understand such effects and how the total pentroof chamber geometry (including piston top land shape) can be tailored to induce specific size of integral scales prior to ignition in order to facilitate combustion.

\section{CONCLUSIONS}

Air flow analysis was performed using LDV and PIV in an optical engine running at 1500 RPM, 0.5 bar intake plenum pressure. The combination of both techniques allowed high spatial and temporal resolution as the two data sets complemented each other to provide details of mean flow and turbulence characteristics, aiming ultimately for quantification of integral time scales and length scales. Two PIV planes were considered inside the pentroof: one vertical 'tumble' plane passing through the centre of the combustion chamber and one horizontal 'swirl' plane 1 $\mathrm{mm}$ below the spark plug's ground electrodes, both imaged at ignition timing. PIV was also conducted inside the cylinder at different crank angles throughout the intake and compression strokes. This was done vertically but also horizontally $10 \mathrm{~mm}$ below engine's fire-face (plane that the spray crosses during injection in the intake stroke). LDV measurements of all three components of velocity were conducted on both horizontal planes used for PIV along two axes, in order to provide detailed time history data of the flow inside the pentroof and cylinder. Filtering was also applied to LDV data in an attempt to distinguish between ensemble-averaging effects and high-/lowfrequency fluctuations about an in-cycle mean. The main conclusions of this study can be summarised as follows:

- The predominant mean flow direction $1 \mathrm{~mm}$ below the spark plug at ignition timing was from intake to exhaust side ( $v$ component), with highest velocity of $5-7 \mathrm{~m} / \mathrm{s}$ on the intake side upstream the spark plug and reduced velocities of $0-2 \mathrm{~m} / \mathrm{s}$ on the exhaust side. The vertical velocity component $u$ along the piston's motion axis and the horizontal component $w$ between exhaust and inlet side of the engine were near zero at ignition timing (the former linked to the piston's low speed close to TDC and the latter to symmetry plane effects).

- Two counter rotating swirl vortices were seen on the horizontal plane below the spark plug, with their centres of rotation below each one of the intake valves and the $y$-axis as symmetry axis.

- Velocity fluctuations quantified by the RMS of LDV data were typically between $2-5 \mathrm{~m} / \mathrm{s}$, strongest in $y$ direction. These were generally of similar order to the mean piston speed of $4.25 \mathrm{~m} / \mathrm{s}$.

- Turbulent kinetic energy during intake was up to $350 \mathrm{~m}^{2} / \mathrm{s}^{2}$, reducing during compression to $8-20 \mathrm{~m}^{2} / \mathrm{s}^{2}$. Values of $9-15 \mathrm{~m}^{2} / \mathrm{s}^{2}$ were found at the time of ignition, highest towards the exhaust side of the engine.

- When comparing the power spectra density of raw individual cycle data with that of windowed-averaged cycles using windows of $8-16^{\circ} \mathrm{CA}$, a frequency cut-off between $300-400 \mathrm{~Hz}$ was identified as suitable to calculate an in-cycle mean velocity by low-pass filtering. This correlated with the highest frequencies found in the FFT of the ensemble-averaged velocity data and intake runner pressure fluctuations. 
- Decreasing the cut-off frequency gradually to $100 \mathrm{~Hz}$ demonstrated the degree of cyclic contribution to highfrequency turbulent fluctuations and low-frequency cyclic ones. A low cut-off frequency returned individual cycle mean velocities more akin to traditional ensemble-averaging. The cut-off frequency affected the intake stroke more than the compression, as variations in the ensemble-averaged data were higher during intake.

- Low-frequency fluctuations at ignition timing were of the order of 2-3 m/s (largest for $v$ ). High-frequency fluctuations were of the order of $1-2 \mathrm{~m} / \mathrm{s}$, similar in all directions.

- The cycle-resolved turbulent kinetic energy was about $3-4 \mathrm{~m}^{2} / \mathrm{s}^{2}$, only $25 \%$ of that derived by typical ensemble averaging. The resulting turbulence intensity was $1.4-1.6 \mathrm{~m} / \mathrm{s}$, lower than half the mean piston speed.

- The integral time scales obtained by classic ensemble averaging were about $15^{\circ} \mathrm{CA}$, indicating that a flame would experience about two integral timescales during the critical stage of early flame kernel development from ignition timing to 5-10\% mass fraction burned. In contrast, time scales in the early intake stroke were of the order 5-10 ${ }^{\circ} \mathrm{CA}$, indicating that, for injection durations typical of stoichiometric combustion, the spray during injection would experience about 1-3 integral times scales depending on fuel type.

- The autocorrelation function derived by the high-frequency velocity components returned very short time scales of the order $0.5{ }^{\circ} \mathrm{CA}$. These were not considered a proper reflection of expected integral time scales of turbulence.

- Integral length scales calculated by PIV at ignition timing inside the pentroof were for the swirl view between 4-10 mm, larger in $y$ - than $z$-direction, hence they scaled to the cylinder bore by about 5-12\%. Integral length scales on the tumble view were 1-5 mm for the vertical component (lowest under the protruding spark plug), scaling with the equivalent clearance height at ignition timing by about $7-30 \%$. The respective horizontal component showed integral length scales of 3-7 mm.

- Integral length scales derived from LDV's integral time scales multiplied by RMS velocities showed similar range of values to the length scales derived by PIV. However, positions of largest scales did not always match with PIV.

- The time evolution of LDV's integral length scales showed that on the lower in-cylinder plane all scales had decreased at the latest measurement timing of $50{ }^{\circ} \mathrm{CA}$ BTDC. However, on the upper horizontal plane inside the pentroof, some scales showed that despite their general trend of decreasing up to $50{ }^{\circ} \mathrm{CA}$, they increased rapidly towards TDC after that. The most drastic increase was for $v$ (horizontal component of tumble) and a moderate one for $u$ (vertical component). In contrast, the scales of $w$ showed continuous decrease to TDC. The degree of this redistribution of scales at the end of compression can be quite critical for the early flame kernel development.

- At the intersection of the tumble and swirl planes, the 3-component PIV TKE was about 10-20\% lower than that obtained by the 2-component averaged estimation of the third component and generally in closer agreement with LDV's TKE during the cycle. LDV characterised about $10 \%$ larger velocities in absolute magnitude than those obtained by PIV.

Parallel work focused on quantifying the integral length scales by PIV in fuelled cycles and studying their modulation by injecting different types of hydrocarbons and alcohols and subsequent effects on the flame front itself during the early stages of combustion $[83,84]$; the interested reader is guided to these publications for further 
analysis. Differences between PIV and LDV highlight the need for further analysis of the two techniques when applied to in-cylinder flows with steep gradients and unsteadiness. Issues of into-plane motion of seeding particles may require active adjustment of Laser pulse separation for better dynamic resolution. Issues of velocity bias, related to more fast particles being statistically captured over typical LDV phase-averaging processes of many cycles, may also require closer analysis in complex engine flows than normally considered. Future work would be interesting in the area of comparing high-speed PIV and LDV data, preferably obtained simultaneously with suitable gating of the two measurement systems over the same number of samples. Furthermore, simultaneous calculation of time scales and length scales by high-speed PIV data would give unique new information on the degree of proportionality between temporal and spatial correlations in engines and their effects on combustion.

\section{ACKNOWLEDGMENTS}

The authors would like to thank Alasdair Cairns, Dave OudeNijeweme and Paul Freeland of MAHLE Powertrain, Ltd., UK, for financial and technical support over the duration of this study.

\section{REFERENCES}

1. Reuss, D.L., Adrian, R.J., Landreth, C.C., French, D.T. and Fansler, T.D., "Instantaneous Planar Measurements of Velocity and Large-Scale Vorticity and Strain Rate in an Engine Using Particle-Image Velocimetry”, SAE Paper 890616.

2. Reuss, D.L., "Cyclic Variability of Large-Scale Turbulent Structures in Directed and Undirected IC Engine Flows", SAE Paper 2000-01-0246, 2000.

3. Li, Y., Zhao, H., Peng, Z. and Ladommatos, N., "Particle Image Velocimetry Measurement of In-Cylinder Flow in Internal Combustion Engines - Experiment and Flow Structure Analysis", Proceedings of IMechE, Part D, Journal of Automobile Engineering, Vol. 216, pp. 65-81, 2002.

4. Li, Y., Zhao, H. and Ladommatos, N., "Analysis of Large-Scale Flow Characteristics in a Four-Valve Spark Ignition Engine", Proceedings of IMechE, Part D, Journal of Mechanical Engineering Science, Vol. 216, pp. 923-938, 2002.

5. Burluka, A.A., El-Dein Hussin, A.M.T.A, Ling, Z.-Y. and Sheppard, C.G.W., "Effects of Large-Scale Turbulence on Cyclic Variability in Spark Ignition Engine”, Experimental Thermal and Fluid Science, Vol. 43, pp. 13-22, 2012.

6. Lacour, C. and Pera, C., "An Experimental Database Dedicated to the Study and Modelling of Cyclic Variability in Spark-Ignition Engines with LES”, SAE Paper 2011-01-1282, 2011.

7. Müller, S.H.R., Böhm, B., Gleißner, M., Grzeszik, R., Arndt, S. and Dreizler, A., "Flow Field Measurements in an Optically Accessible Direct-Injection Spray-Guided Internal Combustion Engine using High-speed PIV”, Experiments in Fluids, Vol. 48, pp. 281-290, 2010.

8. Karhoff, D.-C., Bücker, I., Laas, M. and Schröder, W., "Time-Resolved Sterescopic PIV Measurements of Cyclic Variations in an Internal Combustion Engine", $10^{\text {th }}$ International Symposium on Particle Image Velocimetry - PIV13, Delft, The Netherlands, July 1-3, 2013.

9. Baum, E., Peterson, B., Böhm, B. and Dreizler, A., "On the Validation of LES Applied to Internal Combustion Engine Flows: Part 1: Comprehensive Experimental Database”, Flow, Turbulence and Combustion, Vol. 92, pp. 269-297, 2014. 
10. Justham, T., Jarvis, S., Garner, C.P., Hargrave, G.K. Clarke, A. and Richardson, D., "Single Cylinder Motored SI IC Engine Intake Runner Flow Measurement using Time Resolved Digital Particle Image Velocimetry", SAE Paper 2006-01-1043, 2006.

11. Jarvis, S., Justham, T., Clarke, A., Garner, C.P., Hargrave, G.K., Richardson, D., "Motored SI IC Engine InCylinder Flow Field Measurement Using Time Resolved Digital PIV for Characterisation of Cyclic Variation", SAE Paper 2006-01-1044, 2006.

12. Rimmer, J.E.T., Long, E.J., Garner, C.P., Hargrave, G.K., Richardson, D. and Wallace, S., "The influence of single and multiple injection strategies on in-cylinder flow and combustion within a DISI engine", SAE paper 2009-01-0660, 2009.

13. Müller, S.H.R., Arndt, S. and Dreizler, A., “Analysis of the In-Cylinder Flow Field/Spray Injection Interaction within a DISI IC Engine using High-Speed PIV”, SAE Paper 2011-01-1288, 2011.

14. Disch, C., Kubach, H., Spicher, U., Pfeil, J., Altenschmidt, F. and Schaupp, U., "Investigations of SprayInduced Vortex Structures during Multiple Injections of a DISI Engine in Stratified Operation Using HighSpeed-PIV”, SAE Paper 2013-01-0563, 2013.

15. Zeng, W., Sjöberg, M. and Reuss, D.L., "PIV Examination of Spray-Enhanced Swirl flow for Combustion Stabilization in a Spray-Guided Stratified-Charge Direct-Injection Spark-Ignition Engine", International Journal of Engine Research, Vol. 16, pp. 306-322, 2014.

16. Peterson, B., Reuss, D.L. and Sick, V., "On the Ignition and Flame Development in a Spray-Guided DirectInjection Spark-Ignition Engine", Combustion and Flame, Vol. 161, pp. 240-255, 2014.

17. Peters, N., "The turbulent burning velocity for large-scale and small-scale turbulence", Journal of Fluid Mechanics, Vol. 384, pp. 107-32, 1999.

18. Aleiferis, P.G., Serras-Pereira, J. and Richardson, D., "Characterisation of flame development with ethanol, butanol, iso-octane, gasoline and methane in a direct-injection spark-ignition engine", Fuel, Vol. 109, pp. 256278, 2013.

19. Aleiferis, P.G., van Romunde, Z.R., Larson, G., Lawes, M and Sheppard, C.G.W., "On the Effect of Ambient Turbulence and Thermodynamic Conditions on Fuel Spray Development for Direct-Injection Spark-Ignition Engines”, Flow, Turbulence and Combustion, Vol. 95, pp. 29-60, 2015.

20. Nomura, T., Takahashi, Y., Ishima, T., Obokata, T., "LDA and PIV Measurements and Numerical Simulation on In-Cylinder Flow under Steady State Flow Condition", 12 ${ }^{\text {th }}$ Int. Symposium on Application of Laser Techniques to Fluid Mechanics, Lisbon, Portugal, Paper 17-4, 2004.

21. Huijen, V., Somers, L.M.T, Baert, R.S.G., de Goey, L.P.H., Olbricht, C., Sadiki, A., and Janicka, J., "Study of Turbulent Flow Structures of a Practical Steady Engine Head Flow Using Large-Eddy Simulations”, ASME Journal of Fluids Engineering, Vol. 128, pp. 1181-1191, 2006.

22. Ishima, T., Obokata, T., Nomura, T. and Takahashi, Y., "Analysis of In-Cylinder Flow by Means of LDA, PIV and Numerical Simulation under Steady State Flow Condition”, SAE Paper 2008-01-1063, 2008.

23. Pitcher, G., Binjuwair, S., Picton-Turbervill, T., Wood, A., Wigley, G. and Hollis, D., "LDA and PIV Analyses and Comparison of In-Cylinder Flow Structures under Steady State Condition", $15^{\text {th }}$ Int. Symposium on Application of Laser Techniques to Fluid Mechanics, Lisbon, Portugal, Paper 1801, 2010. 
24. Malcolm, J.S., Aleiferis, P.G., Todd, A.R. and Cairns, A., Hume, A., Blaxill, H., Hoffmann, H. and Rueckauf, J., "A Study of Blended Alcohol Fuels in a New Optical Spark-Ignition Engine”, International Conference on Internal Combustion Engines: Performance, Fuel Economy and Emissions, December 2007, IMechE, London, UK, pp. 223-234, 2007.

25. Aleiferis, P.G., Malcolm, J.S., Todd, A.R., Cairns, A., and Hoffmann, H., "An Optical Study of Spray Development and Combustion of Ethanol, iso-Octane and Gasoline Blends in a DISI Engine”, SAE Paper 2008-01-0073, 2008.

26. Malcolm, J. S., Behringer, M., Aleiferis, P. G., Mitcalf, J. and OudeNijeweme, D., "Characterisation of Flow Structures in a Direct-Injection Spark-Ignition Engine using PIV, LDV and CFD”, SAE Paper 2011-01-1290, 2011.

27. Malcolm, J.S., "Alcohol Fuel Effects on Mixture Preparation and Combustion in SI Engines”, PhD Thesis, University College London, 2015.

28. Raffel, M., Willert, C., Kompenhans, J., "Particle Image Velocimetry - A Practical Guide", $2^{\text {nd }}$ Edition Springer, 2007.

29. Westerweel, J., "Fundamentals of Digital Particle Image Velocimetry," Measurement Science and Technology, Vol. 8, 1379-1392 (1997).

30. Melling, A., "Tracer Particles and Seeding for Particle Image Velocimetry", Measurement Science and Technology, Vol. 8, pp. 1406-1416, 1997.

31. Adrian, R.J., "Dynamic Ranges of Velocity and Spatial Resolution of Particle Image Velocimetry", Measurement Science and Technology, Vol. 8, pp. 1393-1398, 1997.

32. Keane, R. and Adrian, R.J., "Optimization of particle image velocimeters. I. Double pulsed systems", Measurement Science and Technology, Vol. 1, 1202-1215, 1990.

33. Luff, J., Drouillard, T., Rompage, A., Linne, M. and Hertzberg, J. "Experimental uncertainties associated with particle image velocimetry (PIV) based velocity algorithms” Experiments in Fluids 26, 36-54, 1999.

34. Megerle, M. Sick, V. and Reuss, D.L., "Measurement of digital particle image velocimetry precision using electro-optically created particle-image displacements", Measurement Science and Technology, Vol. 13, $997-$ $1005,2002$.

35. Lazar, E., DeBlauw, B. Glumac, N., Dutton, C. and Elliott, G., “A Practical Approach to PIV Uncertainty Analysis", AIAA Paper 2010-4355.

36. Okamoto, K., Nishio, S., Saga, T. and Kobayashi, T., "Standard images for particle-image velocimetry", Measurement Science and Technology, Vol. 11, pp. 685-691, 2000.

37. Reuss, D.L., Megerle, M. and Sick, V. "Particle-image velocimetry measurement errors when imaging through a transparent engine cylinder," Measurement Science and Technology, Vol. 13, 1029-1035, 2002.

38. Zeng, W., Sjöberg, M. and Reuss, D.L., "Using PIV Measurements to Determine the Role of the In-Cylinder Flow Field for Stratified DISI Engine Combustion”, SAE Paper 2014-01-1237.

39. Fajardo, C. and Sick, V., "Development of a High-Speed UV Particle Image Velocimetry Technique and Application for Measurements in Internal Combustion Engines", Experiments in Fluids, vol. 46, pp. 43-53, 2009. 
40. Durst F., Melling A., and Whitelaw J.H., "Principles and Practice of Laser-Doppler Anemometry", $2^{\text {nd }}$ Ed., Academic Press, London, 1981.

41. Albrecht, H.-E., Damaschke, N., Borys, M. and Tropea, C., "Laser Doppler and Phase Doppler Measurement Techniques", Springer, 2002.

42. Dimotakis P., "Single scattering particle Laser Doppler measurements of turbulence", Paper 10, AGARD Conference No. 193, Applications of Non-Intrusive Instrumentation in Fluid Flow Research, 1976.

43. Durao D.F.G., Laker J. and Whitelaw J.H., "Bias effects in Laser Doppler anemometry", Journal of Physics E, Scientific Instruments, Vol. 13, pp. 442-445, 1980.

44. Yanta W.J. and Smith R.A., "Measurements of turbulent transport properties with a Laser Doppler velocimeter", AIAA $11^{\text {th }}$ Aerospace Science Meeting, Washington, D.C., 1978.

45. Melling, A., "Investigation of Flow in non-circular ducts and other configurations by Laser Doppler Anemometry", PhD Thesis, Imperial College of Science and Technology, University of London, 1975.

46. Vafidis, C., “Aerodynamics of Reciprocating Engines”, PhD Thesis, Imperial College of Science, Technology and Medicine, University of London, 1985.

47. Morse, A.P., "The Effect of Crank Angle Broadening on Laser-Doppler Measurements in Reciprocating Engines", Imperial College of Science and Technology, Mechanical Engineering Department Report FS/77/18, 1977.

48. Glover, A. R., "Towards bias-free estimates of turbulence in engines", $3^{\text {rd }}$ Int. Symp. on Applications of Laser Anemometry to Fluid Mechanics, Lisbon, 5.3, 1986.

49. Hall, M. J.; Bracco, E V. and Santavicca, D. A., "Cycle resolved velocity and turbulence measurements in an IC engine with combustion”, SAE Paper 860320, 1986.

50. Liou, T.-M. and Santavicca, D. A., "Cycle resolved turbulence measurements in a ported engine with and without swirl”, SAE Paper 830419, 1983.

51. Liou, T.-M.; Santavicca, D. A., "Cycle resolved LDV measurements in a motored IC engine”, ASME Journal of Fluids Engineering, Vol. 107, pp. 232-240, 1985.

52. Vafidis, C., "Influence of induction swirl and piston configuration on air flow in a four-stroke model engine", Proc. IMechE, Part C, Journal of Mechanical Engineering Science, Vol. 198, pp. 71-79, 1984.

53. Vafidis, C., Vorropoulos, G. and Whitelaw, J. H., "Effects of intake port and combustion chamber geometry on in-cylinder turbulence in a motored reciprocating engine", Proceedings of Symposium on Fluid Flow and Heat Transfer in Reciprocating Machinery, Boston/MA, ASME-FED 62, 9-15, 1987.

54. Witze, P. O.; Martin, J. K., "Cyclic-variation bias in spark ignition engine turbulence measurements. $2^{\text {nd }}$ Int. Symp. On Applications of Laser Anemometry to Fluid Mechanics, Lisbon, 9.4, 1984.

55. Witze, P. O.; Martin, J. K.; Borgnakke, C., "Conditionally-sampled velocity and turbulence measurements in a spark ignition engine", Combustion Science and Technology, Vol. 36, pp. 301-317, 1986.

56. Lock, J.A. and Schock, H.J., "Incident Beam Polarization for Laser Doppler Velocimetry Employing a Sapphire Cylindrical Window”, Applied Optics, Vol. 24, pp. 1987-1995, 1985.

57. Lowe, M.L. and Kutt, P.H., "Refraction through Cylindrical Tubes”, Experiments in Fluids, Vol. 13, pp. 315 320, 1992. 
58. Doukelis, A., Founti, M., Mathioudakis, K. and Papailiou, K., "Evaluation of Beam Refraction Effects in a 3D Laser Doppler Anemometry System for Turbomachinery Applications", Measurement Science and Technology, Vol. 7, pp. 922-931, 1996.

59. Zhao, H. and Ladommatos, N., "Engine Combustion Instrumentation and Diagnostics", Society of Automotive Engineers, U.S.A., 2001.

60. Freudenhammer, D., Peterson, B., Ding, C.P., Boehm, B. and Grundman, S., "The Influence of Cylinder Head Geometry Variations on the Volumetric Intake Flow Captured by Magnetic Resonance Velocimetry", SAE Paper 2015-01-1697, 2015.

61. Freudenhammer, D., Baum, E., Peterson, B., Böhm, B., Jung, B. and Grundman S., "Volumetric Intake Flow Measurements of an IC Engine using Magnetic Resonance Velocimetry", Experiments in Fluids, Vol. 55, Article No. 1724, 2014.

62. Abraham, P., Reuss, D. and Sick, V., "High-Speed Particle Image Velocimetry Study of In-Cylinder Flows with Improved Dynamic Range”, SAE Paper 2013-01-0542, 2013.

63. Fraser, R.A., Felton, P.G., Bracco, F.V. and Santavicca, D.A., "Preliminary Turbulence Length Scale Measurements in a Motored IC Engines", SAE Paper 860021, 1986.

64. Fraser, R.A. and Bracco, F.V., "Cycle-Resolved LDV Integral Length Scale Measurements in an IC Engine", SAE Paper 880381, 1988.

65. Fraser, R. and Bracco, F., "Cycle-Resolved LDV Integral Length Scale Measurements Investigating Clearance Height Scaling, Isotropy, and Homogeneity in an I.C. Engine”, SAE Paper 890615, 1989.

66. Kang, K.Y. and Baek, Je H., "Tumble flow and turbulence characteristics in a small four-valve engine", SAE Paper 960265, 1996.

67. Kang, K. Y., and Baek, J. H., "Turbulence characteristics of tumble flow in a four-valve engine”, Experimental Thermal and Fluid Science Vol. 18, pp. 231-243, 1998.

68. Liao, S. Y., Jiang, D. M., and Cheng, Q., "Turbulent time-frequency spectral structures and the extraction of the desired turbulence component", Proceedings of IMechE, Part D, J. Automotive Engineering, Vol. 218, pp. 1025-1033, 2004.

69. Enotiadis, A.C., Vafidis, C and Whitelaw, J.H., "Interpretation of cyclic flow variations in motored internal combustion engines”, Experiments in Fluids, Vol. 10, pp. 77-86, 1990.

70. Fansler, T. D., and French, D., "Cycle-Resolved Laser Velocimetry Measurements in a Reentrant-Bowl-inPiston Engine", SAE Paper 880377, 1988.

71. Ball, W. F., Pettifer, H. F., and Waterhouse, C.N. 1983, "Laser Doppler Velocimeter Measurements of Turbulence in a Direct Injection Diesel Combustion Chamber”, IMechE Paper C52/83.

72. Rask, R.B., "Comparison of Windowed, Smooth-Ensemble and Cycle-by-Cycle Data Reduction techniques for Laser Doppler Anemometer Measurements of In-Cylinder Velocity", ASME Symposium on Fluid Mechanics of Combustion systems, pp. 11-20, 1981.

73. Liou, T. M., and Santavicca, D. A., "Cycle Resolved LDV Measurements in a Motored IC Engine", Transactions of ASME, Vol. 107, pp. 232-240, 1985.

74. Benedict, L H, Nobach, H, and Tropea, C., "Estimation of turbulent velocity spectra from laser Doppler data", Meas. Sci. Technol. Vol. 11, pp. 1089-1104, 2000. 
75. Catania, A.E., and Mittica, A., "Extraction Techniques and Analysis of Turbulence Quantities from In-Cylinder Velocity Data", ASME J. Eng. Gas Turbines Power, Vol. 111, pp. 466-478, 1989.

76. Johansson, B. and Soderberg, F., "The Effect of Valve Strategy on In-Cylinder Flow and Combustion", SAE Paper 960582, 1996.

77. Tabaczynski, R.J., “Turbulence measurements and modelling in reciprocating engines - An overview”, Paper No. C51/83, IMechE, 1983.

78. Burluka, A.A., El-Dein Hussin, A.M.T.A., Ling, Z.-Y., and Sheppard, C.G.W., "Effects of large-scale turbulence on cyclic variability in spark-ignition engine", Experimental Thermal and Fluid Science, Vol. 43, pp. 13-22, 2012.

79. Glover, A.R., Hundleby, G.E. and Hdded, O, "The development of scanning LDA for the measurement of turbulence in engines", SAE Paper, 880378, 1988.

80. Ikegami, M., Shioji, M. and Nishimoto, K., "Turbulence intensity and spatial integral scale during compression and expansion strokes in a four-cycle reciprocating engine”, SAE Paper 870372, 1987.

81. Dimopoulos, P. and Boulouchos, K., "Turbulent flow filed characteristics in a motored reciprocating engine", SAE Paper 972833, 1997.

82. Li, Y., Zhao, H., Leach, B., Ma, T. and Ladommatos, N., "Characterization of an in-cylinder flow structure in a high-tumble spark-ignition engine”, International Journal of Engine Research, Vol. 5, pp. 375-399, 2004.

83. Aleiferis, P.G. and Behringer, M.K., "Flame Front Analysis of Ethanol, Butanol, iso-Octane and Gasoline in a Spark-Ignition Engine Using Laser Tomography and Integral Length Scale Measurements", Combustion and Flame, Vol. 162, pp. 4533-4552, 2015.

84. Aleiferis, P.G, and Behringer, M.K., "Modulation of Integral Length Scales of Turbulence in an Optical SI Engine by Direct Injection of Gasoline, iso-Octane, Ethanol and Butanol Fuels”, Fuel, in print, 2016. 


\section{LIST OF TABLES}

Table 1. Engine Specifications.

Table 2. PIV Settings.

Table 3. LDV Settings.

Table 4. Dirichlet -3 dB limit.

Table 5. Integral Length Scales.

\section{LIST OF FIGURES}

Figure 1. View through the pentroof side of the research engine's optical liner and through the piston crown.

Figure 2. PIV and LDV measurement positions. Two horizontal layers were measured along the $y$-and $z$-axis at a vertical $(x)$ level $-3 \mathrm{~mm}$ (above the fire-face) and $+10 \mathrm{~mm}$ (below the fire-face).

Figure 3. Top: PIV image of an individual cycle for the tumble plane motion at $26{ }^{\circ} \mathrm{CA}$ BTDC. Image width 36 $\mathrm{mm}$, height $18 \mathrm{~mm}$. Bottom: PIV image of an individual cycle for the swirl plane motion at $26^{\circ} \mathrm{CA}$ BTDC on $x=-3$ $\mathrm{mm}$ plane. Visible diameter $56 \mathrm{~mm}$.

Figure 4. Tumble mean flow field and TKE as obtained by PIV at $26^{\circ} \mathrm{CA}$ BTDC.

Figure 5. Swirl mean flow field and TKE as obtained by PIV at $26^{\circ} \mathrm{CA}$ BTDC on $x=-3 \mathrm{~mm}$ plane.

Figure 6. Vertical velocity $u, u^{\prime}$ and horizontal velocity $v, v^{\prime}$ at the centre of the cylinder $3 \mathrm{~mm}$ above the fire-face $(x=-3 \mathrm{~mm})$ as obtained by LDV.

Figure 7. Ensemble averaged velocities $u, v$ and $w$ (left) and fluctuation components $u^{\prime}, v^{\prime}$ and $w^{\prime}$ (right) vs. ${ }^{\circ} \mathrm{CA}$ at $3 \mathrm{~mm}$ above the fire-face $(x=-3 \mathrm{~mm})$ along the $y$-axis as obtained by LDV.

Figure 8. Ensemble averaged velocities $u, v$ and $w$ (left) and fluctuation components $u^{\prime}, v^{\prime}$ and $w^{\prime}$ (right) vs. ${ }^{\circ} \mathrm{CA}$ at $3 \mathrm{~mm}$ above the fire-face $(x=-3 \mathrm{~mm})$ along the $z$-axis as obtained by LDV.

Figure 9. Ensemble averaged velocities $u, v$ and $w$ (left) and fluctuation components $u^{\prime}, v^{\prime}$ and $w^{\prime}$ (right) vs. ${ }^{\circ} \mathrm{CA}$ at $3 \mathrm{~mm}$ above the fire-face $(x=-3 \mathrm{~mm})$ along the $y$-axis at the end of compression as obtained by LDV.

Figure 10. Ensemble averaged velocities $u, v$ and $w$ (left) and fluctuation components $u^{\prime}, v^{\prime}$ and $w^{\prime}$ (right) vs. ${ }^{\circ} \mathrm{CA}$ at $3 \mathrm{~mm}$ above the fire-face $(x=-3 \mathrm{~mm})$ along the $z$-axis at the end of compression as obtained by LDV.

Figure 11. TKE and turbulence intensity (from ensemble averaged RMS) vs. ${ }^{\circ} \mathrm{CA}$ at $3 \mathrm{~mm}$ above fire-face ( $x=-3$ $\mathrm{mm}$ ) during compression along $y$-axis (left) and $z$-axis (right) as obtained by LDV.

Figure 12. Tumble and swirl mean flow fields as obtained by PIV at various crank angles on $x=10 \mathrm{~mm}$ plane.

Figure 13. Ensemble averaged velocities $u, v$ and $w$ (left) and fluctuation components $u^{\prime}, v^{\prime}$ and $w^{\prime}$ (right) vs. ${ }^{\circ} \mathrm{CA}$ at $10 \mathrm{~mm}$ below the fire-face $(x=10 \mathrm{~mm})$ along the $y$-axis as obtained by LDV.

Figure 14. Ensemble averaged velocities $u, v$ and $w$ (left) and fluctuation components $u^{\prime}, v^{\prime}$ and $w^{\prime}$ (right) vs. ${ }^{\circ} \mathrm{CA}$ at $10 \mathrm{~mm}$ below the fire-face $(x=10 \mathrm{~mm})$ along the $z$-axis as obtained by LDV.

Figure 15. Ensemble averaged velocities $u$ and $v$ (left) and turbulent kinetic energy (right) vs. ${ }^{\circ} \mathrm{CA}$ at $10 \mathrm{~mm}$ below the fire-face at position $4 \mathrm{~mm}$ as obtained by LDV and PIV. Top: $320-40{ }^{\circ} \mathrm{CA}$ BTDC, Bottom: Enlarged 180-40 ${ }^{\circ} \mathrm{CA}$ BTDC.

Figure 16. Frequency analysis of individual cycles and ensemble averaged cycles (left) to find the cut-off frequency for the cycle based analysis. In-cycle mean velocities are shown for different thresholds (right).

Figure 17. Effect of the cut-off frequency on the in-cycle mean velocity (top left), the ensemble averaged mean velocity (bottom left), the high-frequency turbulence intensity (top right) and the low-frequency turbulence intensity (bottom right).

Figure $18.400 \mathrm{~Hz}$ cut-off frequency analysis at $x=-3 \mathrm{~mm}$ along the $y$-axis. Low-pass mean velocities are given in the left column of graphs for $u, v$ and $w$ velocities in the first second and third row, respectively. High- and lowfrequency fluctuations are given in the middle and right columns accordingly. 
Figure 19. $400 \mathrm{~Hz}$ cut-off Frequency analysis at $x=-3 \mathrm{~mm}$ along the $z$-axis. Low-pass mean velocities are given in the left column of graphs for $u, v$ and $w$ velocities in the first second and third row, respectively. High- and lowfrequency fluctuations are given in the middle and right columns accordingly.

Figure 20. TKE and turbulence intensity during compression stroke at $x=-3 \mathrm{~mm}$ from $400 \mathrm{~Hz}$ high-frequency fluctuation along $y$-axis (left) and $z$-axis (right).

Figure 21. Autocorrelation functions at 300 and $26{ }^{\circ} \mathrm{CA}$ BTDC. High-frequency only considerations are given in solid coloured lines without marker and indicate very low time scales, reducing for higher cut-off frequencies. The autocorrelation for the combined high- and low-frequency fluctuations for various cut-offs returned autocorrelation functions (circular marker) very similar to the traditional ensemble averaging approach (black line).

Figure 22. Autocorrelation function against ${ }^{\circ} \mathrm{CA}$ ATDC at $x=-3, y=0, z=0 \mathrm{~mm}$ for the traditional ensemble averaged approach and a $200 \mathrm{~Hz}$ cut-off high-frequency analysis.

Figure 23. Integral time scales along $y$ - and $z$-axis at $x=-3 \mathrm{~mm}$, LDV.

Figure 24. Integral time scales along $y$-and $z$-axis at $x=10 \mathrm{~mm}, \mathrm{LDV}$.

Figure 25. Integral length scales along $y$ - and $z$-axis at $x=-3 \mathrm{~mm}$, from integral time scale and ensemble averaged fluctuation, LDV.

Figure 26. Integral length scales along $y$-and $z$-axis at $x=10 \mathrm{~mm}$, from integral time scale and ensemble averaged mean velocity, LDV.

Figure 27. Integral length scales along $y$-and $z$-axis at $x=10 \mathrm{~mm}$, from integral time scale and ensemble averaged fluctuation, LDV.

Figure 28. Integral length scale maps as obtained by PIV at $26{ }^{\circ} \mathrm{CA}$ BTDC. 
Table 1. Engine Specifications.

\begin{tabular}{ll}
\hline Engine Parameter & Value \\
\hline Bore $[\mathrm{mm}] \times$ Stroke $[\mathrm{mm}]$ & $82.5 \times 88.9$ \\
\hline Compression Ratio & $9.8: 1$ \\
\hline Connection Rod Length $[\mathrm{mm}]$ & 165.2 \\
\hline Number of Valves & 2 Inlet, 2 Exhaust \\
\hline Inlet Valve Opening (IVO) & $10.5^{\circ} \mathrm{CA}$ BTDC Intake \\
Inlet Valve, Closing (IVC) & $124.5^{\circ}$ BTDC Compression \\
\hline Exhaust Valve Opening (EVO) & $118^{\circ} \mathrm{CA}$ ATDC Compression \\
Exhaust Valve Closing (EVC) & $1{ }^{\circ} \mathrm{CA}$ ATDC Intake \\
\hline
\end{tabular}

Table 2. PIV Settings.

\begin{tabular}{ll}
\hline Parameter & Value \\
\hline Laser Wavelength $[\mathrm{nm}]$ & 532 \\
\hline Beam Diameter $(90 \%)[\mathrm{mm}]$ & 7 \\
\hline Beam Divergence $\left(1 / \mathrm{e}^{2}\right)[\mathrm{mrad}]$ & $\leq 5$ \\
\hline Pointing Stability $(90 \%)[\mu \mathrm{rad}]$ & $\leq 100$ \\
\hline Pulse Duration $(\mathrm{FWHM})[\mathrm{ns}]$ & 9 \\
\hline Energy Stability (peak to peak) $[\%]$ & \pm 6 \\
\hline Timing Jitter (WERT Q-switch trigger) [ns] & \pm 1 \\
\hline Laser Sheet Thickness [mm] & $0.5-1$ \\
\hline Pulse Separation $[\mu \mathrm{s}]$ & 10,5 (swirl, tumble) \\
\hline Camera Resolution [pixels], Pixel Size $[\mu \mathrm{m}]$ & $2048 \times 2048,7.4$ \\
\hline Lens & Nikon 60 mm f/2.8 \\
\hline Interrogation Area [Pixels] & $32 \times 32,50 \%$ Overlap \\
\hline Seed Density [seeding particles/interrogation window] & $10-20$ \\
\hline Cross Correlation, Grid Engine & FFT, Nyquist \\
\hline Peak Engine and Spot Mask & Gaussian
\end{tabular}

Table 3. LDV Settings.

\begin{tabular}{lcc}
\hline Parameter & Channel 1 & Channel 2 \\
\hline Wavelength $[\mathrm{nm}]$ & 514.5 & 488 \\
\hline Beam Diameter [mm], Waist $[\mu \mathrm{m}]$ & $1.77,92.5$ & $1.77,87.8$ \\
\hline Beam Separation $[\mathrm{mm}]$ & 20 & 20 \\
\hline Transmitter Focal Length $[\mathrm{mm}]$ & 250 & 250 \\
\hline Beam Half Angle $\left[^{\circ}\right]$ & 2.3 & 2.3 \\
\hline Receiver Focal Length Front, Back lens $[\mathrm{mm}]$ & 300,250 & 300,250 \\
\hline Slit Aperture $[\mu \mathrm{m}]$ & 150 or 25 & 150 or 25 \\
\hline Fringe Spacing $[\mu \mathrm{m}]$, Number of Fringes & $6.43,14$ & $6.1,14$ \\
\hline Measurement Volume diameter $[\mu \mathrm{m}]$ & 93 & 88 \\
\hline Measurement Volume length $[\mathrm{mm}]$ & 2.3 & 2.2 \\
\hline Bragg Cell Frequency $[\mathrm{MHz}]$ & 40 & 40
\end{tabular}


Table 4. Dirichlet -3 dB limit.

\begin{tabular}{cc}
\hline Window Size & $\mathbf{- 3 ~ d B ~ l i m i t ~}[\mathbf{H z}]$ \\
\hline $1\left[{ }^{\circ} \mathrm{CA}\right]$ & 4000 \\
\hline $2\left[{ }^{\circ} \mathrm{CA}\right]$ & 2000 \\
\hline $4\left[{ }^{\circ} \mathrm{CA}\right]$ & 1000 \\
\hline $8\left[{ }^{\circ} \mathrm{CA}\right]$ & 600 \\
\hline $12\left[{ }^{\circ} \mathrm{CA}\right]$ & 350 \\
\hline $16\left[{ }^{\circ} \mathrm{CA}\right]$ & 250 \\
\hline $20\left[{ }^{\circ} \mathrm{CA}\right]$ & 200 \\
\hline
\end{tabular}

Table 5. Integral Length Scales.

\begin{tabular}{|c|c|c|c|c|c|c|c|c|c|}
\hline Study & Present & [63-65] & [78] & [79] & [80] & [81] & {$[66,67]$} & {$[3,4]$} & [82] \\
\hline Engine & $\begin{array}{l}\text { 4-valve } \\
\text { pentroof }\end{array}$ & $\begin{array}{l}\text { 2-port } \\
\text { disk }\end{array}$ & $\begin{array}{l}\text { 2-port } \\
\text { disk }\end{array}$ & 2-valve disk & 2-valve disk & 2-valve disk & $\begin{array}{l}\text { 4-valve } \\
\text { pentroof }\end{array}$ & $\begin{array}{l}\text { 4-valve } \\
\text { pentroof }\end{array}$ & $\begin{array}{l}\text { 3-valve } \\
\text { pentroof }\end{array}$ \\
\hline Bore $[\mathrm{mm}]$ & 82.5 & 82.6 & 80 & 85.7 & 102 & 85 & 56.5 & 80 & 80 \\
\hline Stroke [mm] & 88.9 & 114.3 & 110 & 86 & 106 & 92 & 49.5 & 89 & 89 \\
\hline Compression & $9.8: 1$ & $7.6-11.4$ & $10.6: 1$ & $9: 1$ & $8.2-11.6: 1$ & $8: 1$ & $8.5: 1$ & $10: 1$ & $11: 1$ \\
\hline Tumble & Yes & - & - & - & - & - & Low, & Yes & 2.6 \\
\hline Swirl & - & 4 & 0 & 3.6 & $0,2.1$ & $3.5,0.9$ & - & Yes & - \\
\hline Speed [RPM] & 1500 & 600 & 1200 & 1200 & $800-1200$ & $600-1500$ & 1000 & 1200,600 & 1200 \\
\hline Intake [bar] & 0.5 & 1.0 & 1.0 & 1.0 & 1.0 & 1.0 & 1.0 & 1.0 & 1.0 \\
\hline $\begin{array}{l}\text { Length Scale } \\
\text { Longitudinal } \\
{[\mathrm{mm}]}\end{array}$ & $\begin{array}{c}u: 1-5 \\
v: 3-7,4-10 \\
w: 4-8\end{array}$ & - & $\begin{array}{l}v: 6-8 \\
w: 6-8\end{array}$ & $w: 6.9$ & - & $\begin{array}{c}u: 1,5 \\
v: 10-4 \\
w: 3-1,8-5\end{array}$ & $v: 0.2-0.4$ & $\begin{array}{l}v: 7-10,7-8 \\
w: 8-10,6-9\end{array}$ & $\begin{array}{c}u: 7 \\
v: 4-7,6-8 \\
w: 4-7\end{array}$ \\
\hline $\begin{array}{l}\text { Length Scale } \\
\text { Lateral } \\
{[\mathrm{mm}]}\end{array}$ & - & $\begin{array}{c}u: 2-1 \\
v \text { or } w: 3-2\end{array}$ & $\begin{array}{l}v: 4-5 \\
w: 4-5\end{array}$ & $v: 3.4$ & $v$ or $w: 3-1$ & - & - & $\begin{array}{c}v: 5-8,4 \\
w: 6-7,5-8\end{array}$ & $\begin{array}{c}u: 5 \\
v: 3-6,5 \\
w: 3-6\end{array}$ \\
\hline
\end{tabular}



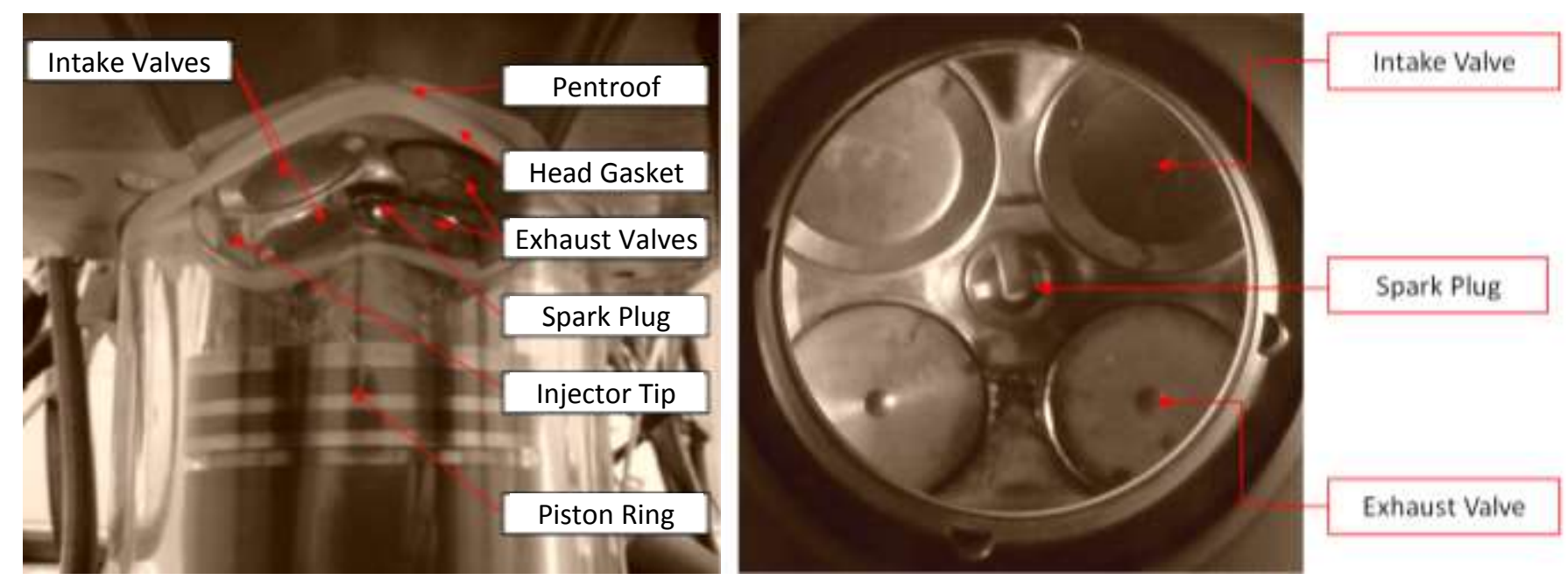

Figure 1. View through the pentroof side of the research engine's optical liner and through the piston crown.
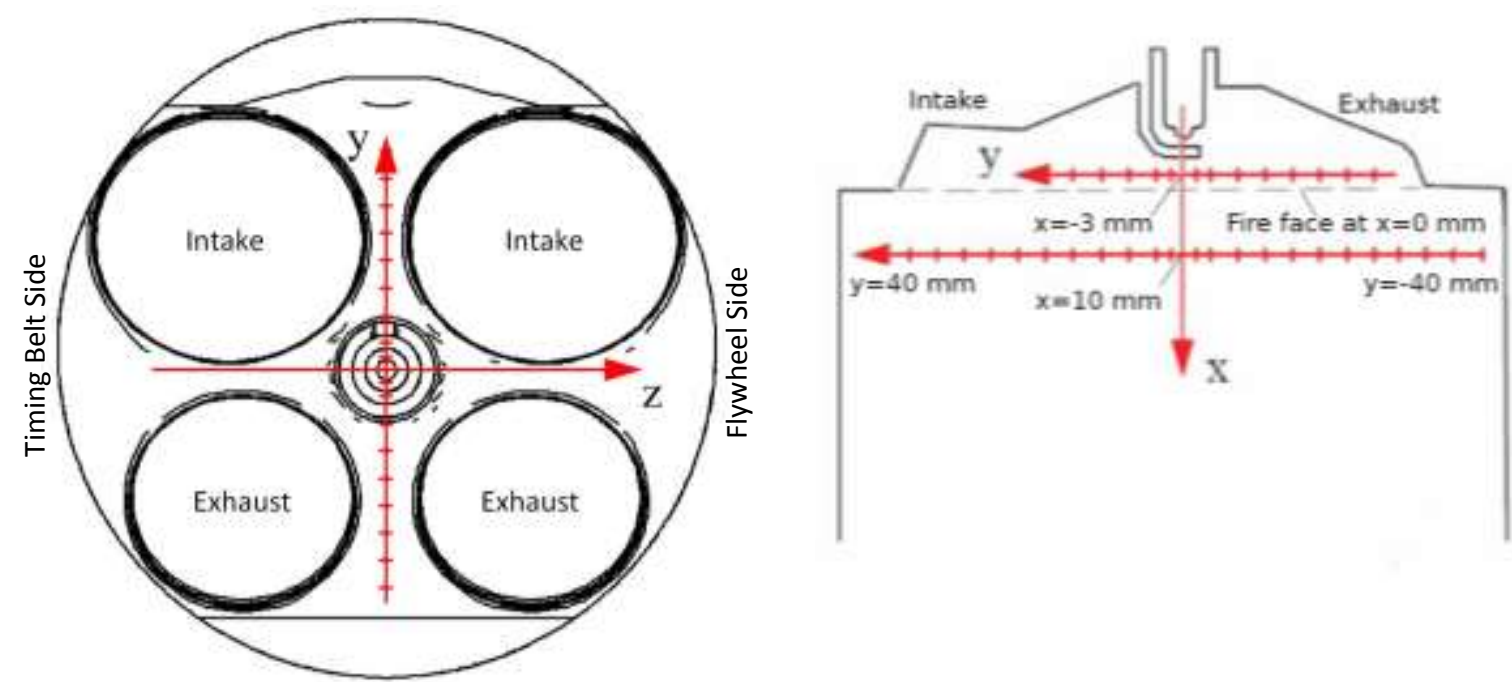

Figure 2. PIV and LDV measurement positions. Two horizontal layers were measured along the $y$-and $z$-axis at a vertical $(x)$ level $-3 \mathrm{~mm}$ (above the fire-face) and $+10 \mathrm{~mm}$ (below the fire-face). 


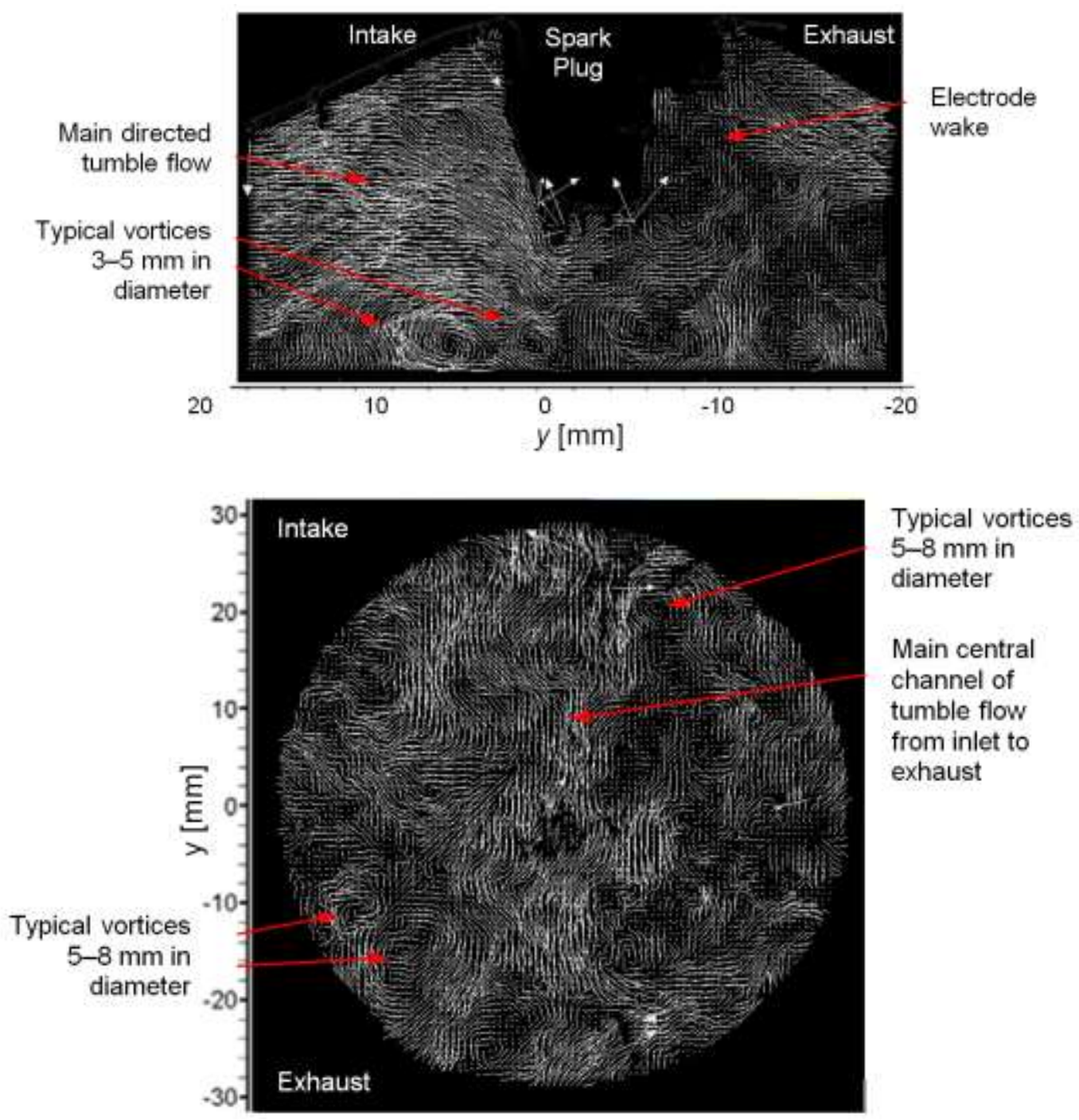

Figure 3. Top: PIV image of an individual cycle for the tumble plane motion at $26{ }^{\circ} \mathrm{CA}$ BTDC. Image width $36 \mathrm{~mm}$, height $18 \mathrm{~mm}$. Bottom: PIV image of an individual cycle for the swirl plane motion at $26{ }^{\circ} \mathrm{CA}$ BTDC on $x=-3 \mathrm{~mm}$ plane. Visible diameter $56 \mathrm{~mm}$ 

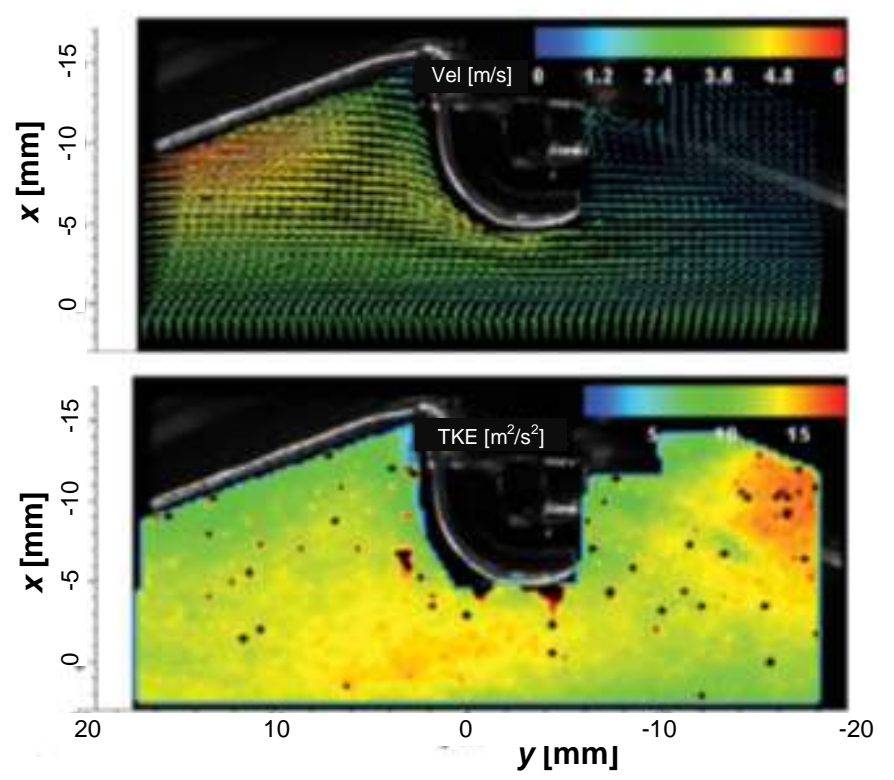

Figure 4. Tumble mean flow field and TKE as obtained by PIV at $26{ }^{\circ} \mathrm{CA}$ BTDC.

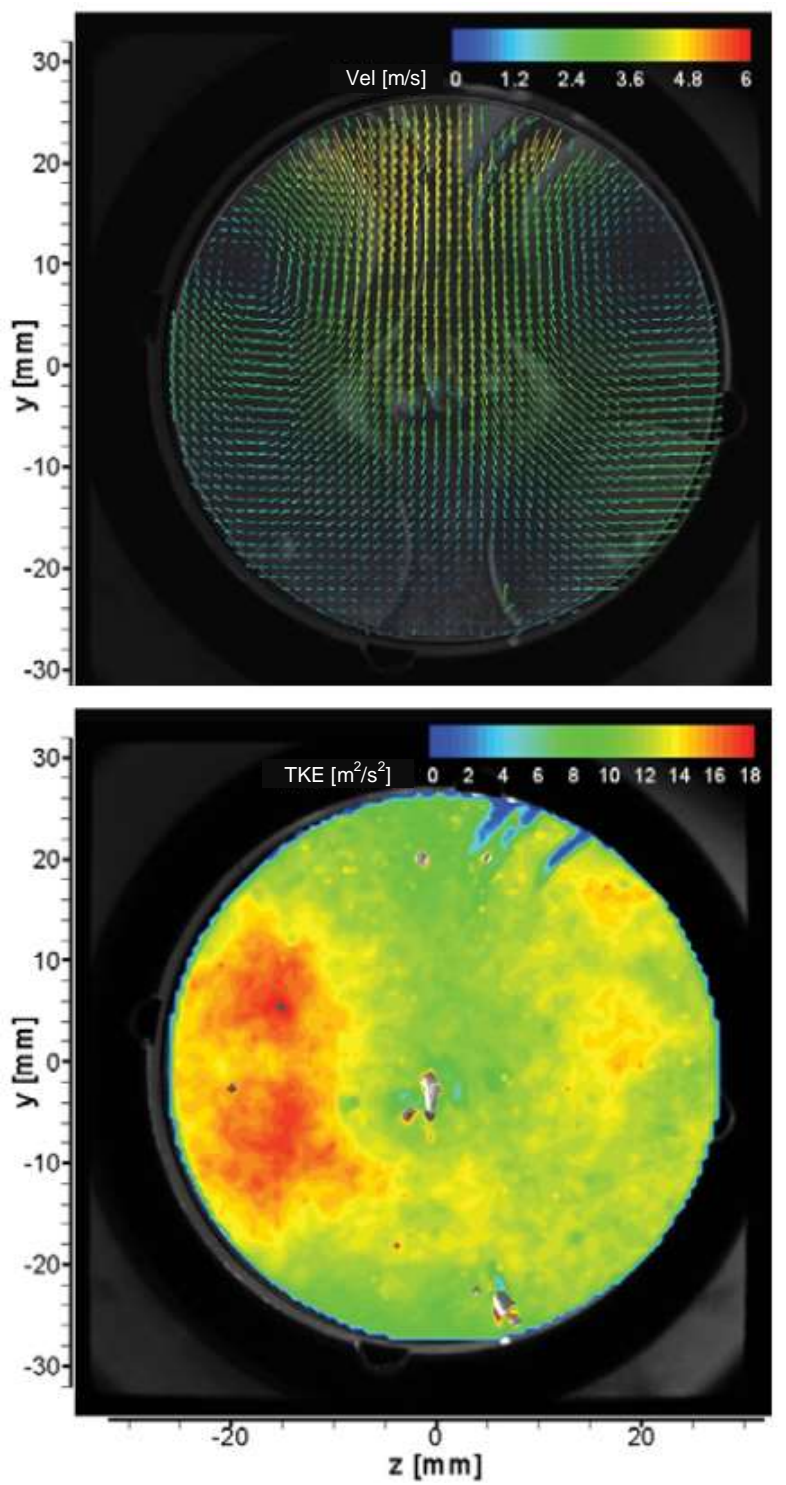

Figure 5. Swirl mean flow field and TKE as obtained by PIV at $26{ }^{\circ} \mathrm{CA}$ BTDC on $x=-3 \mathrm{~mm}$ plane. 

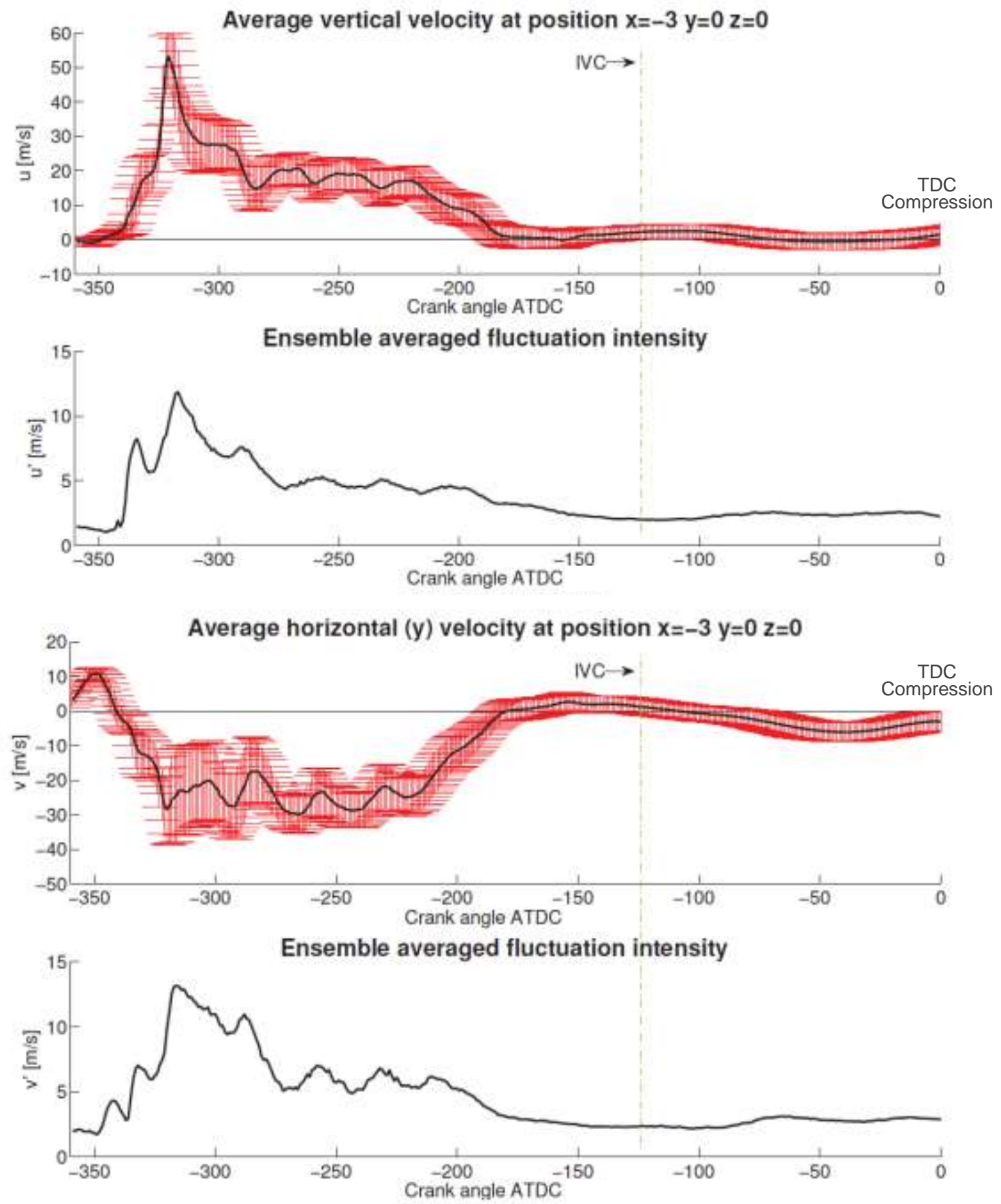

Figure 6. Vertical velocity $u, u^{\prime}$ and horizontal velocity $v, v^{\prime}$ at the centre of the cylinder $3 \mathrm{~mm}$ above the fireface $(x=-3 \mathrm{~mm})$ as obtained by LDV. 

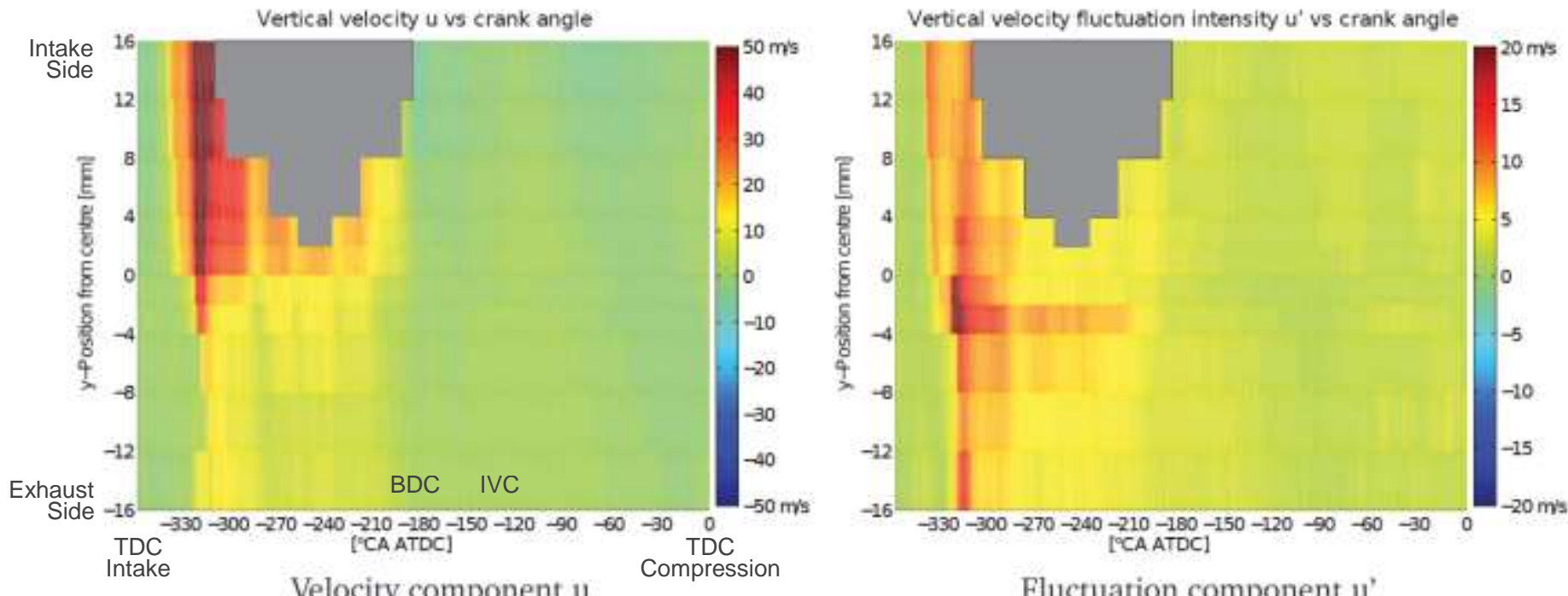

Velocity component u

Fluctuation component u'

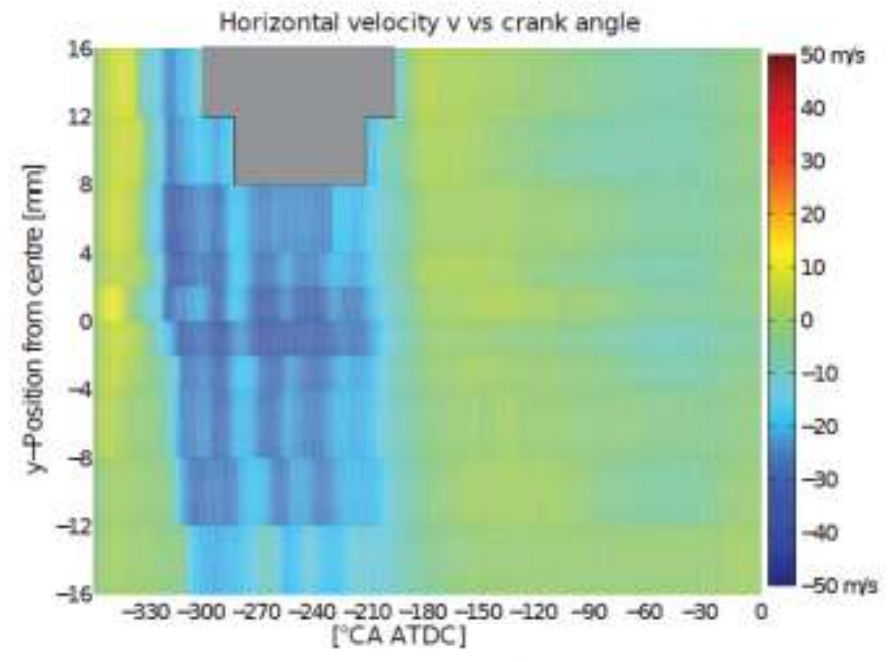

Velocity component $\mathrm{v}$

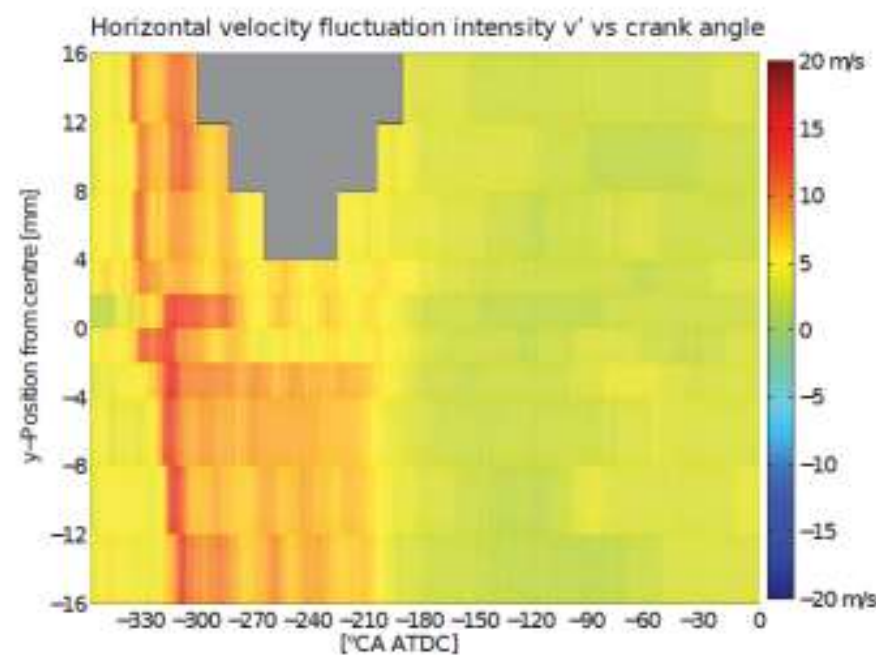

Fluctuation component $v^{\prime}$

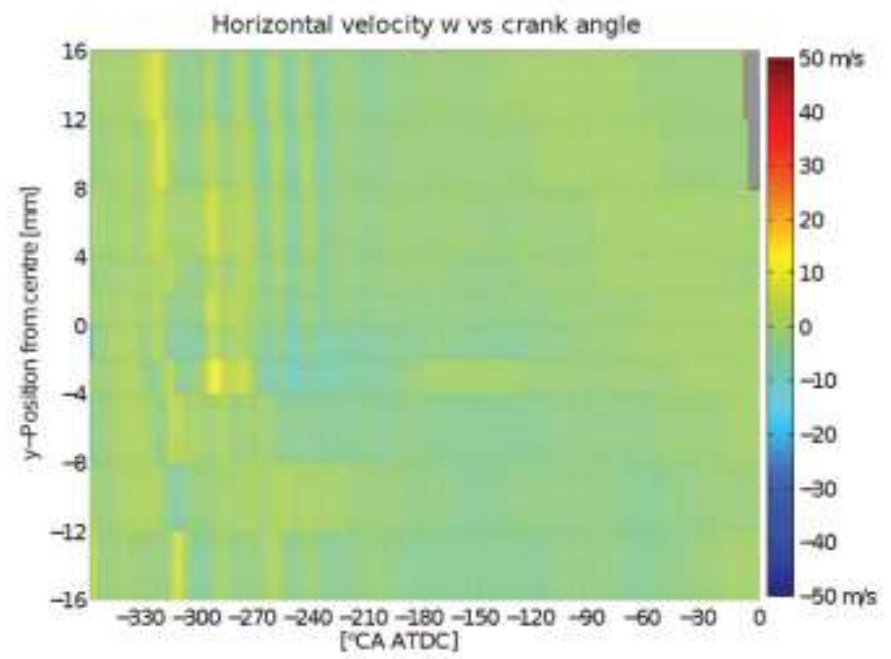

Velocity component $w$

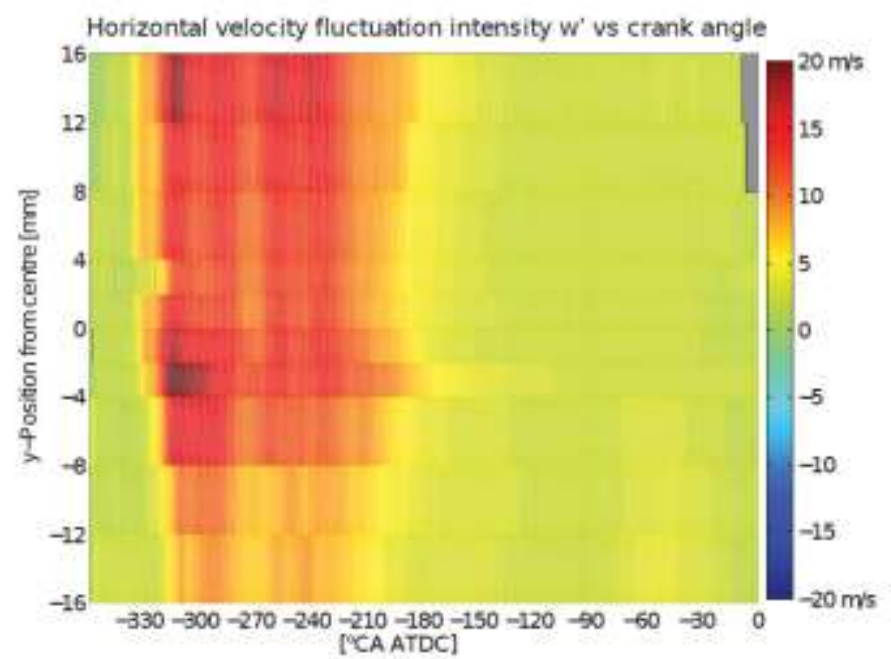

Fluctuation component w'

Figure 7. Ensemble averaged velocities $u, v$ and $w$ (left) and fluctuation components $u^{\prime}, v^{\prime}$ and $w^{\prime}$ (right) vs. ${ }^{\circ} \mathrm{CA}$ at $3 \mathrm{~mm}$ above the fire-face $(x=-3 \mathrm{~mm})$ along the $y$-axis as obtained by LDV. 


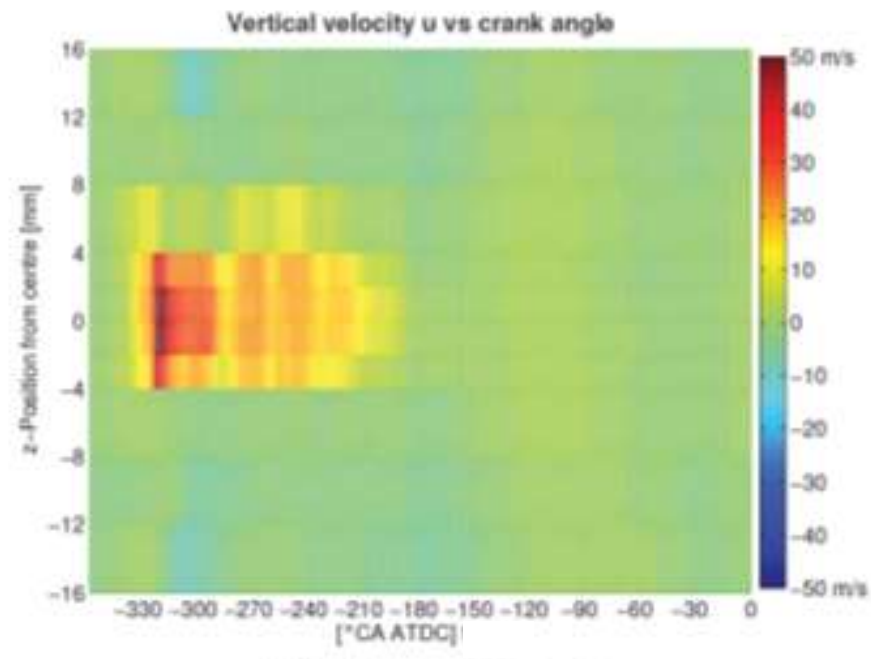

Velocity component $\mathrm{u}$

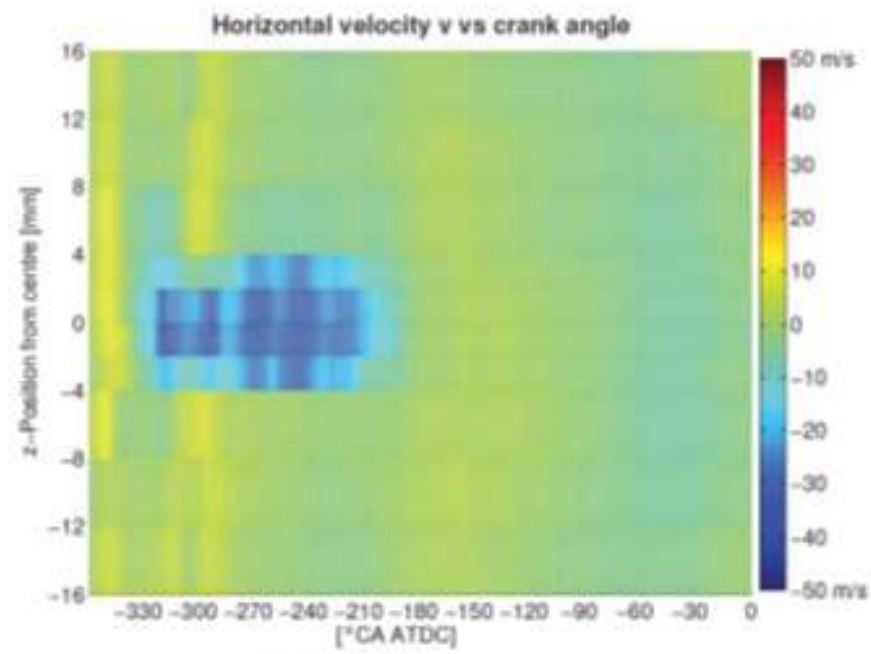

Velocity component $v$

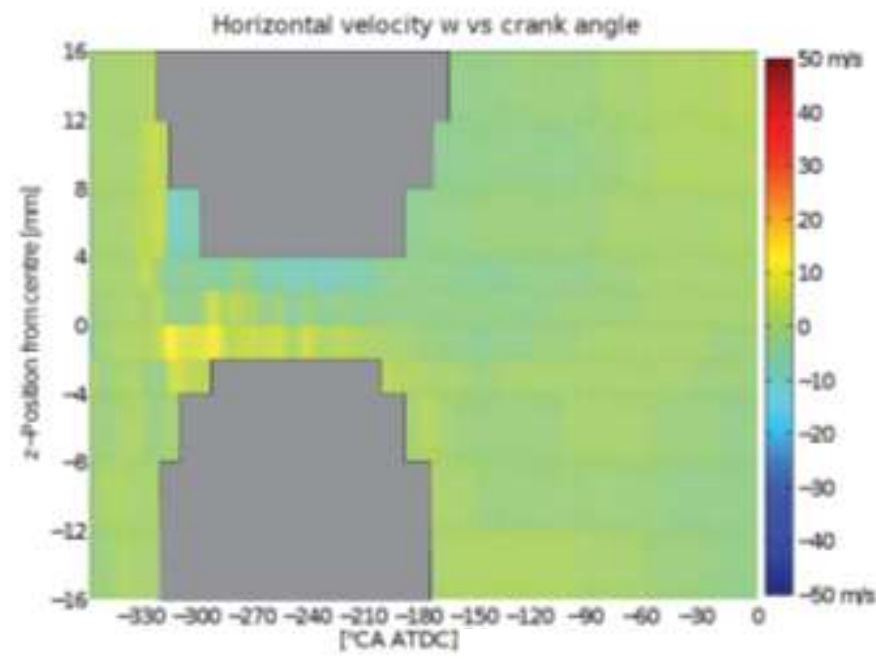

Velocity component $w$

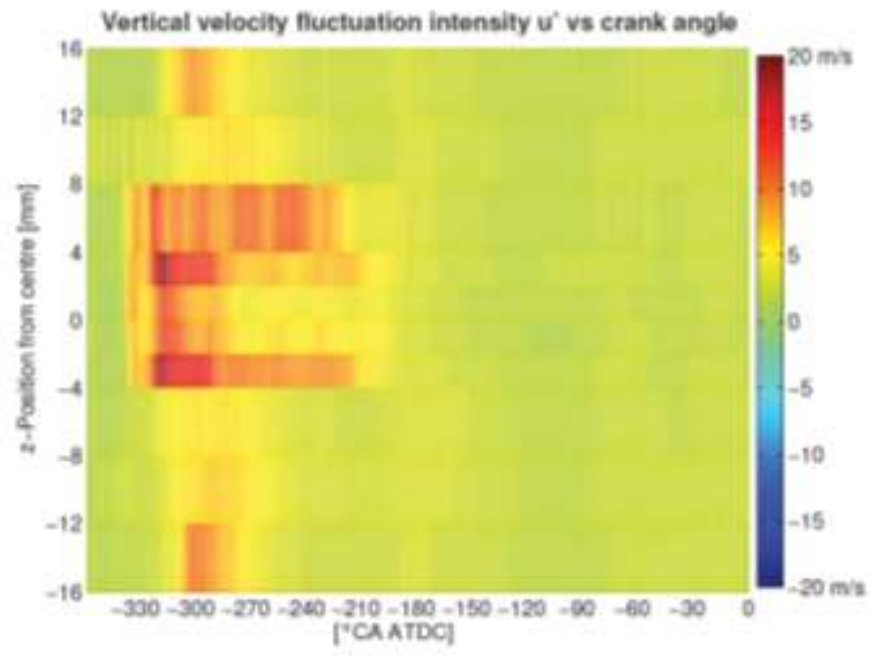

Fluctuation component $u^{\prime}$

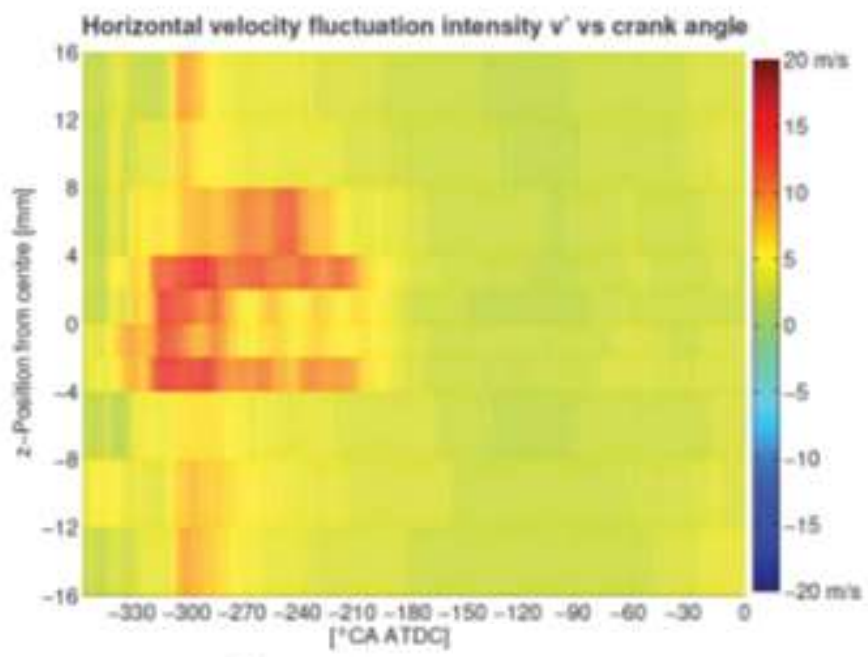

Fluctuation component $v^{\prime}$

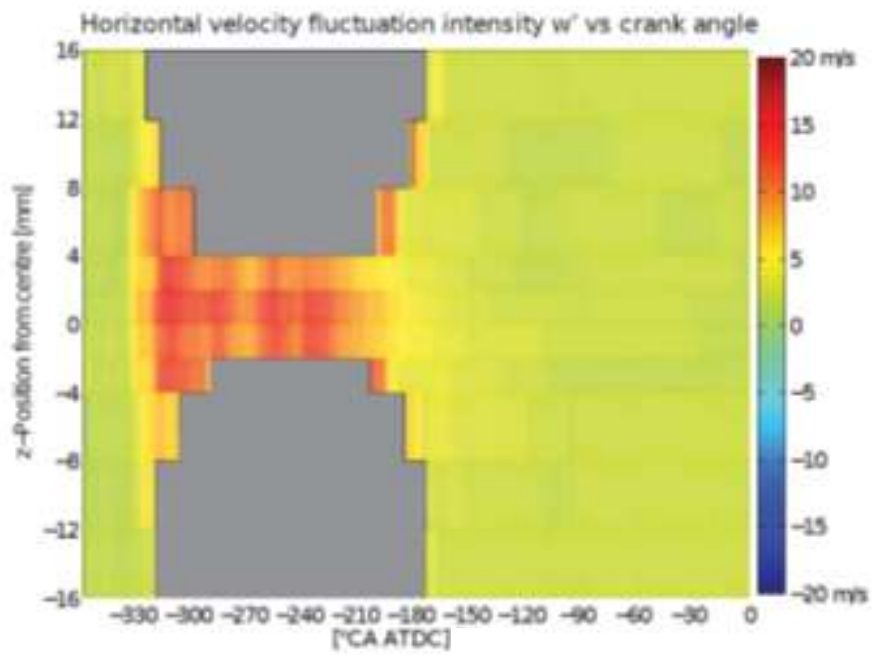

Fluctuation component $w^{\prime}$

Figure 8. Ensemble averaged velocities $u, v$ and $w$ (left) and fluctuation components $u^{\prime}, v^{\prime}$ and $w^{\prime}$ (right) vs. ${ }^{\circ} \mathrm{CA}$ at $3 \mathrm{~mm}$ above the fire-face $(x=-3 \mathrm{~mm})$ along the $z$-axis as obtained by LDV. 


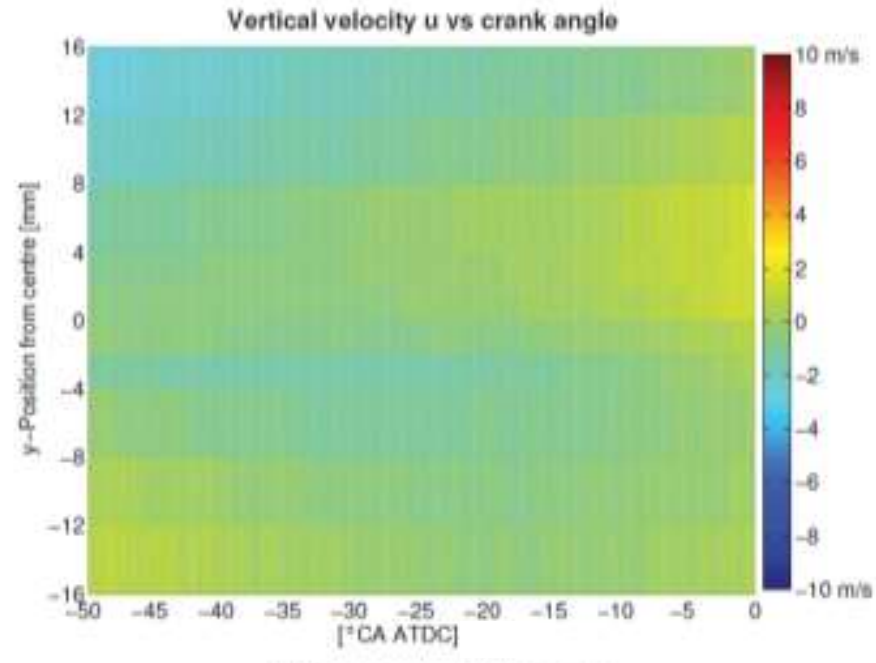

Velocity component u

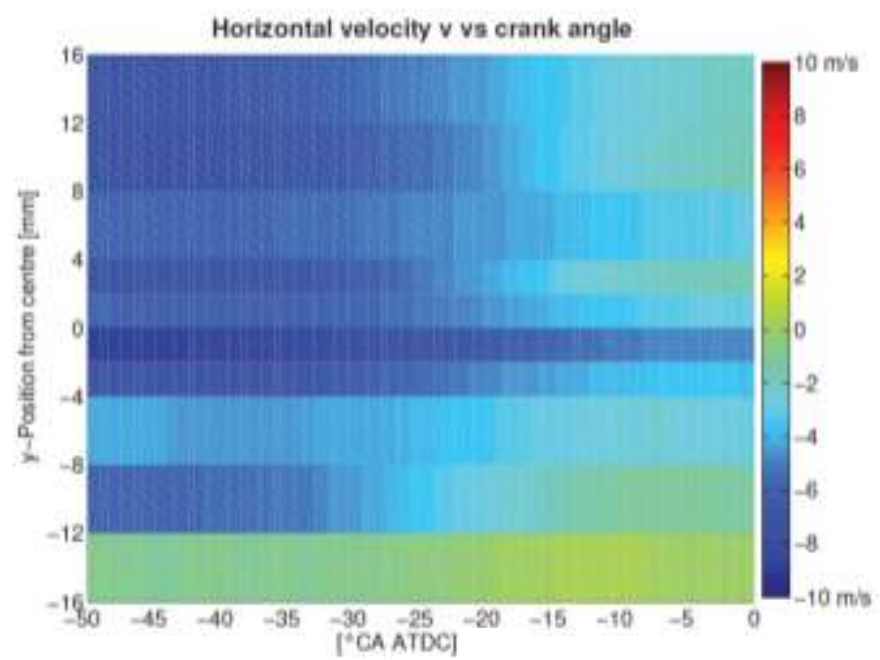

Velocity component $\mathrm{v}$

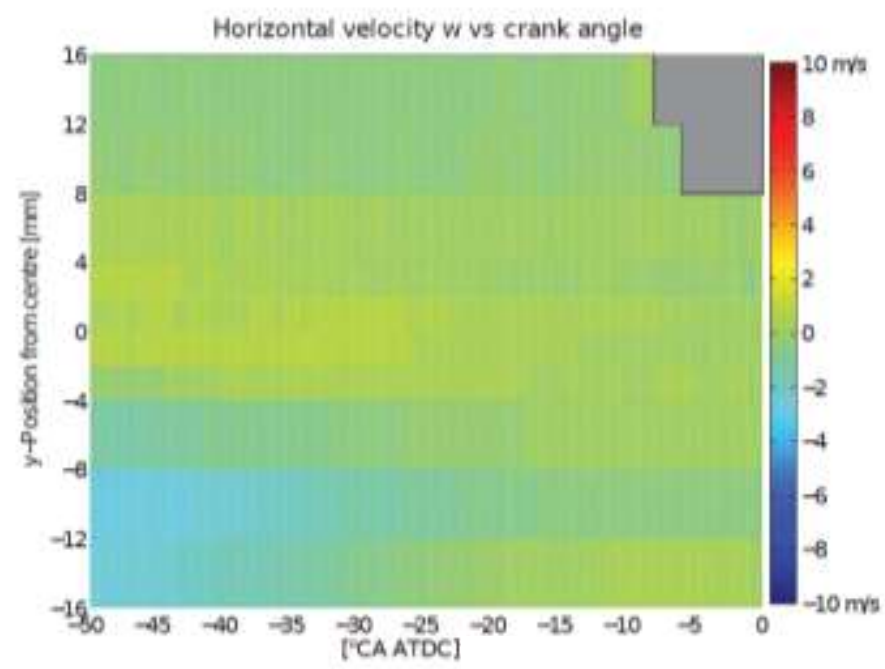

Velocity component $w$

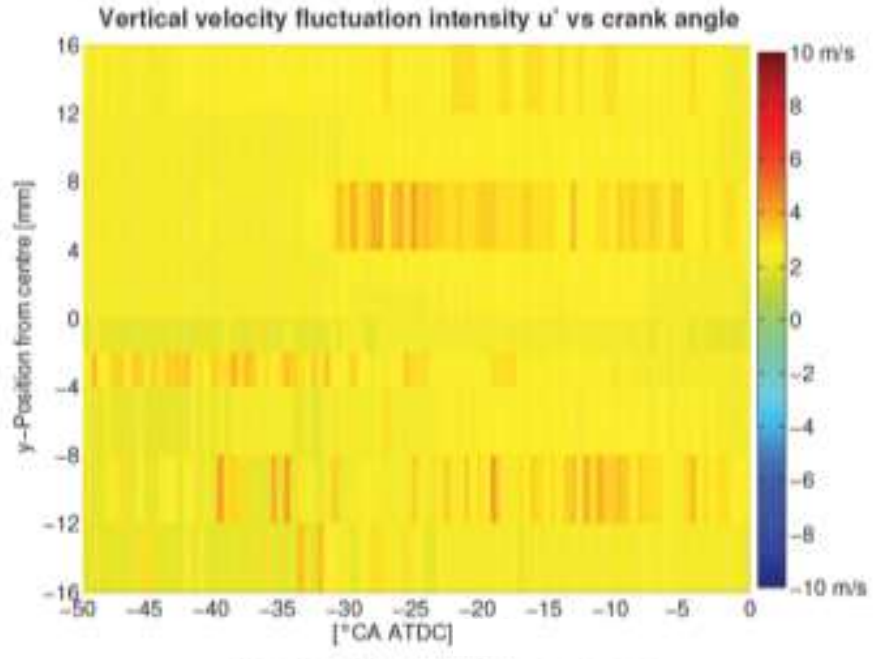

Fluctuation component u'

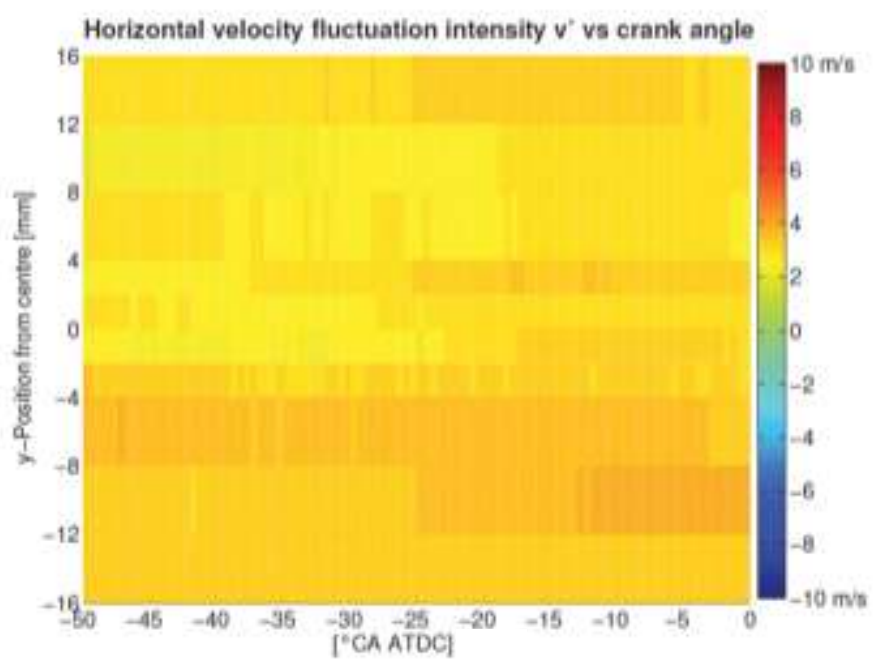

Fluctuation component $\mathrm{v}^{\prime}$

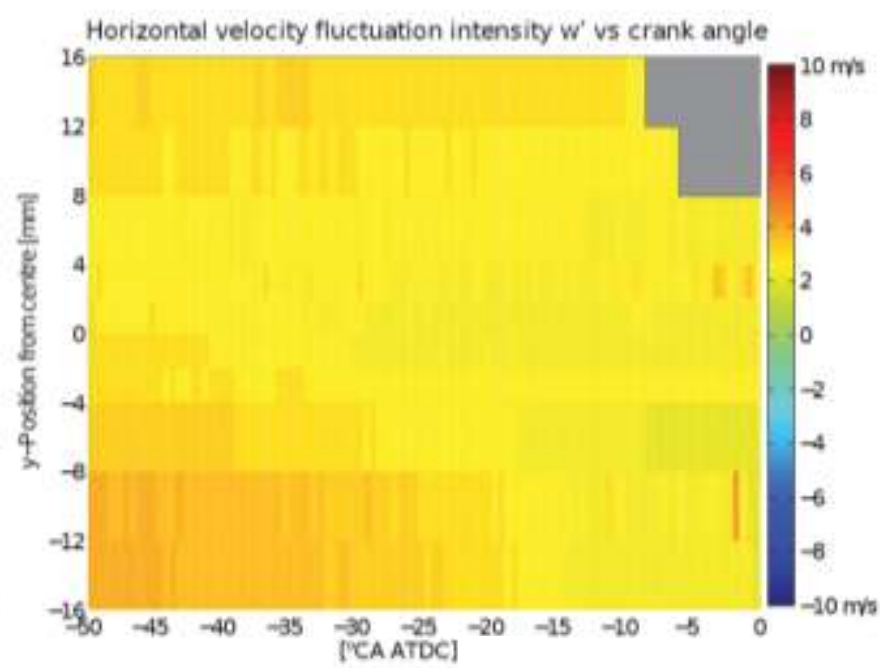

Fluctuation component $w^{\prime}$

Figure 9. Ensemble averaged velocities $u, v$ and $w$ (left) and fluctuation components $u^{\prime}, v^{\prime}$ and $w^{\prime}$ (right) vs. ${ }^{\circ} \mathrm{CA}$ at $3 \mathrm{~mm}$ above the fire-face $(x=-3 \mathrm{~mm})$ along the $y$-axis at the end of compression as obtained by LDV. 


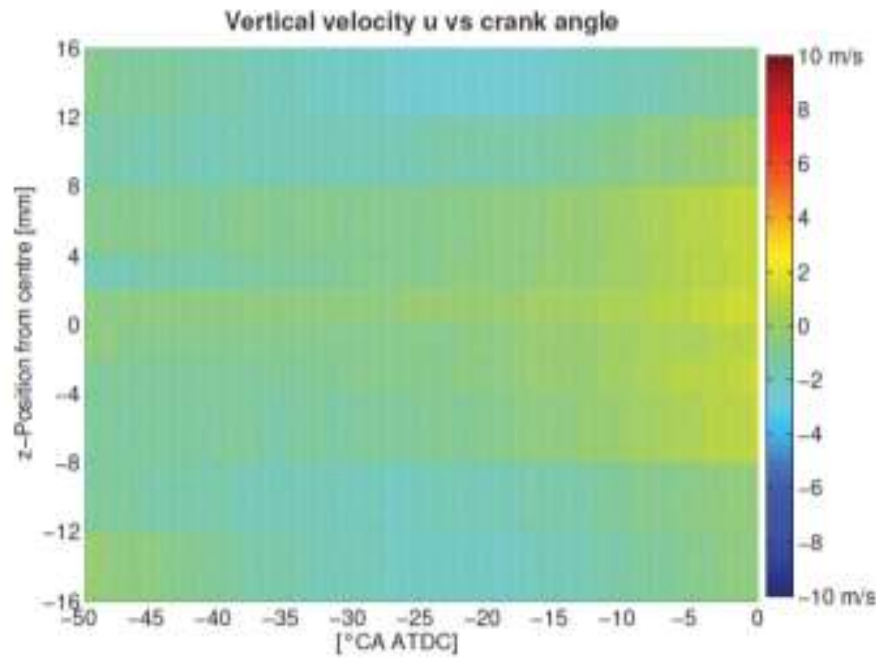

Velocity component u

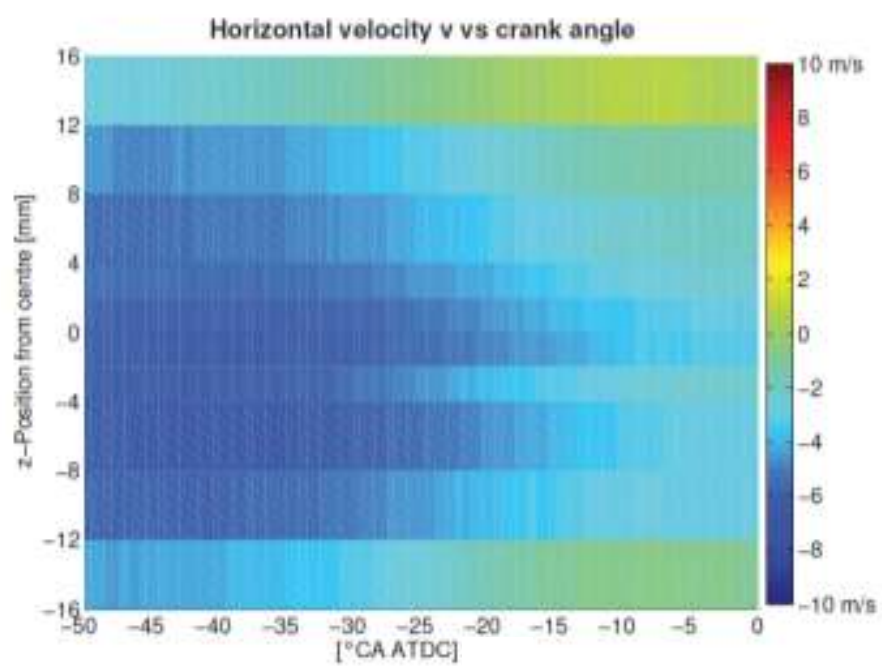

Velocity component $\mathrm{v}$

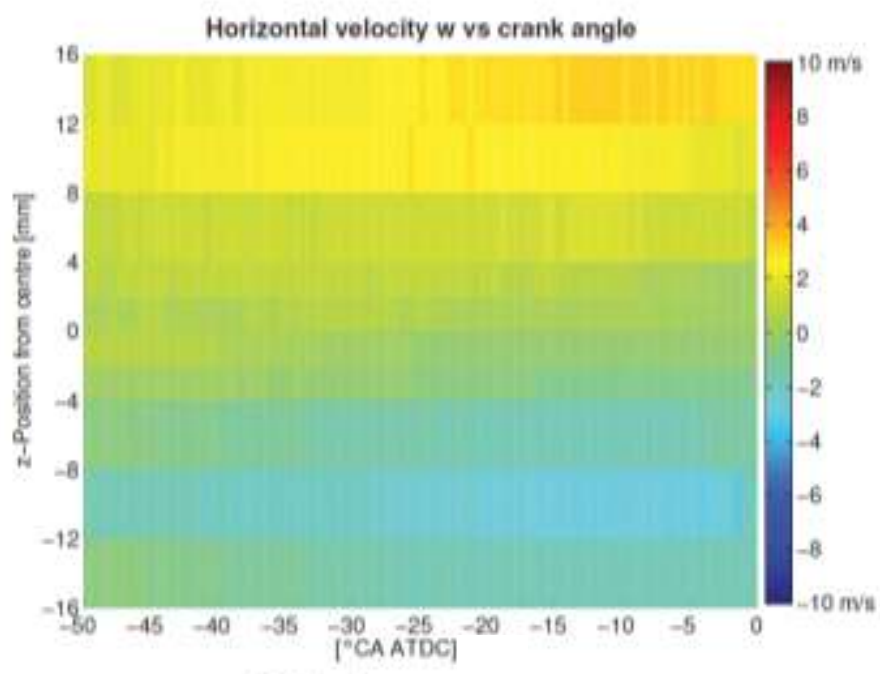

Velocity component $w$

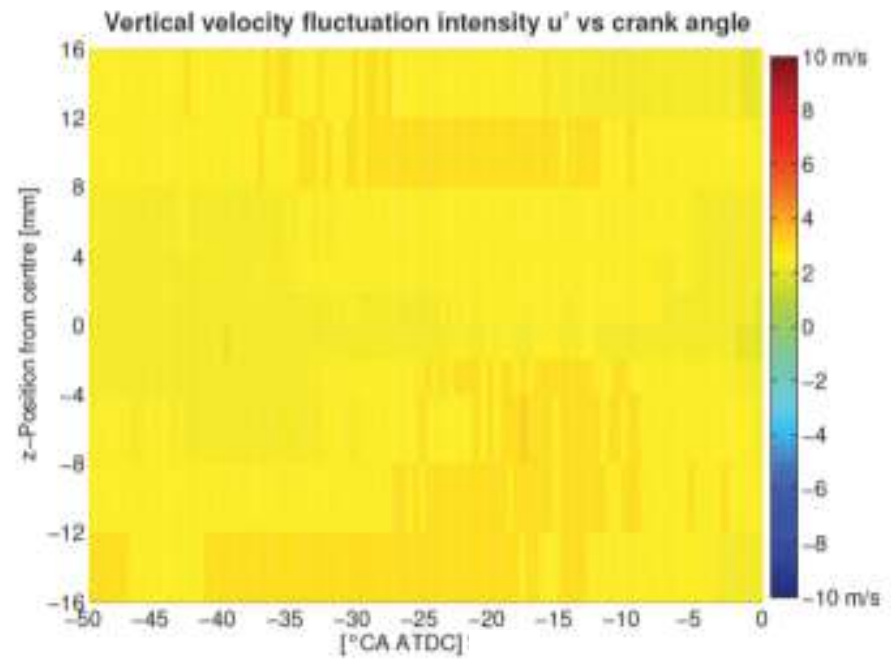

Fluctuation component u'

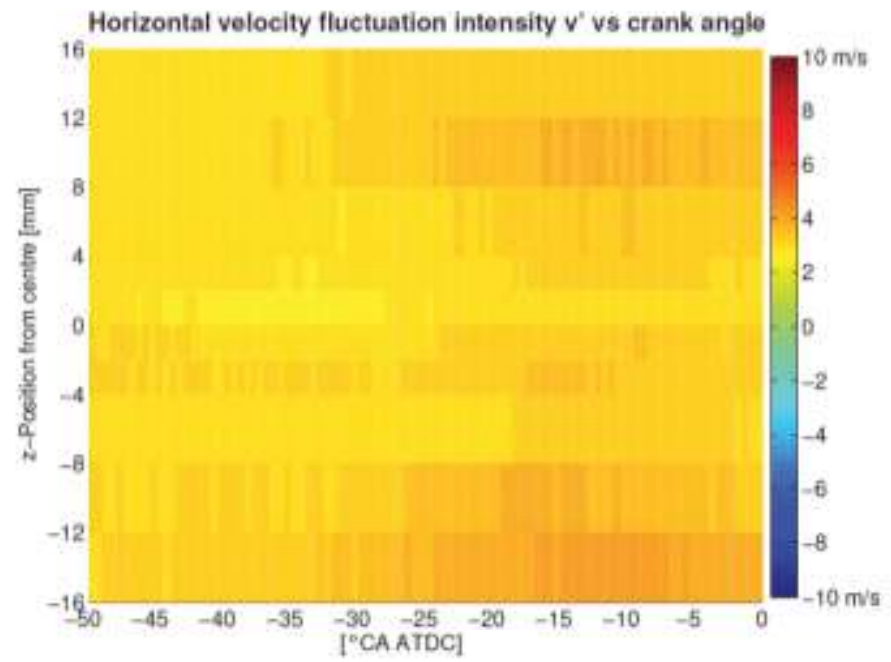

Fluctuation component $v^{\prime}$

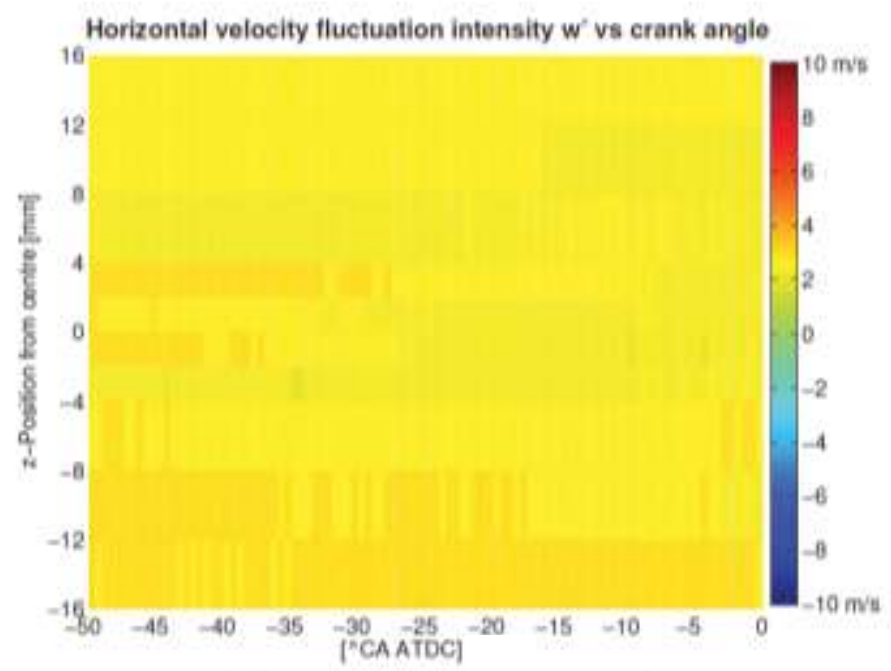

Fluctuation component $w^{\prime}$

Figure 10. Ensemble averaged velocities $u, v$ and $w$ (left) and fluctuation components $u^{\prime}, v^{\prime}$ and $w^{\prime}$ (right) vs. ${ }^{\circ} \mathrm{CA}$ at $3 \mathrm{~mm}$ above the fire-face $(x=-3 \mathrm{~mm})$ along the $z$-axis at the end of compression as obtained by LDV. 

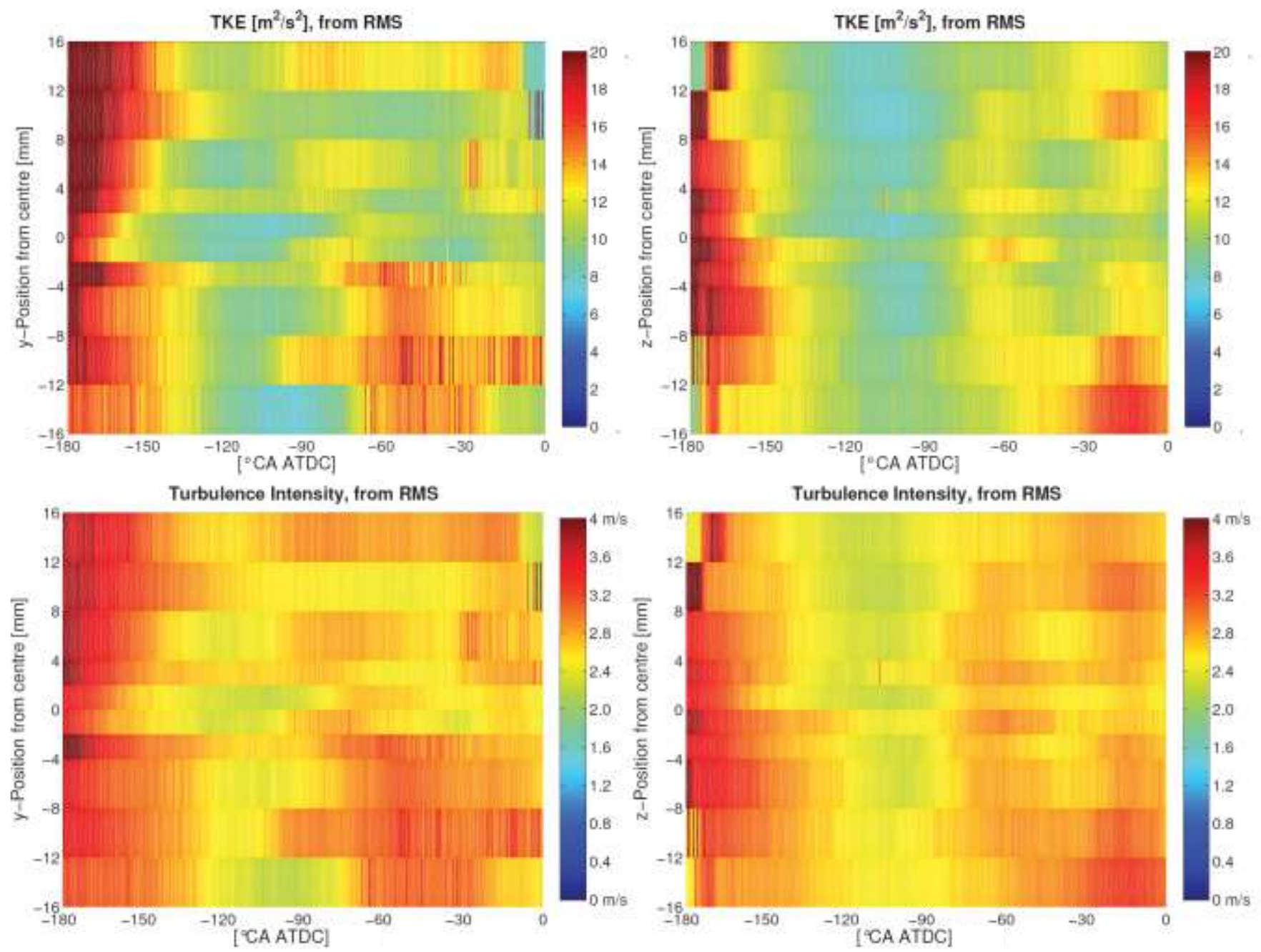

Figure 11. TKE and turbulence intensity (from ensemble averaged RMS) vs. ${ }^{\circ} \mathrm{CA}$ at $3 \mathrm{~mm}$ above fire-face $(x=-3 \mathrm{~mm})$ during compression along $y$-axis (left) and $z$-axis (right) as obtained by LDV. 

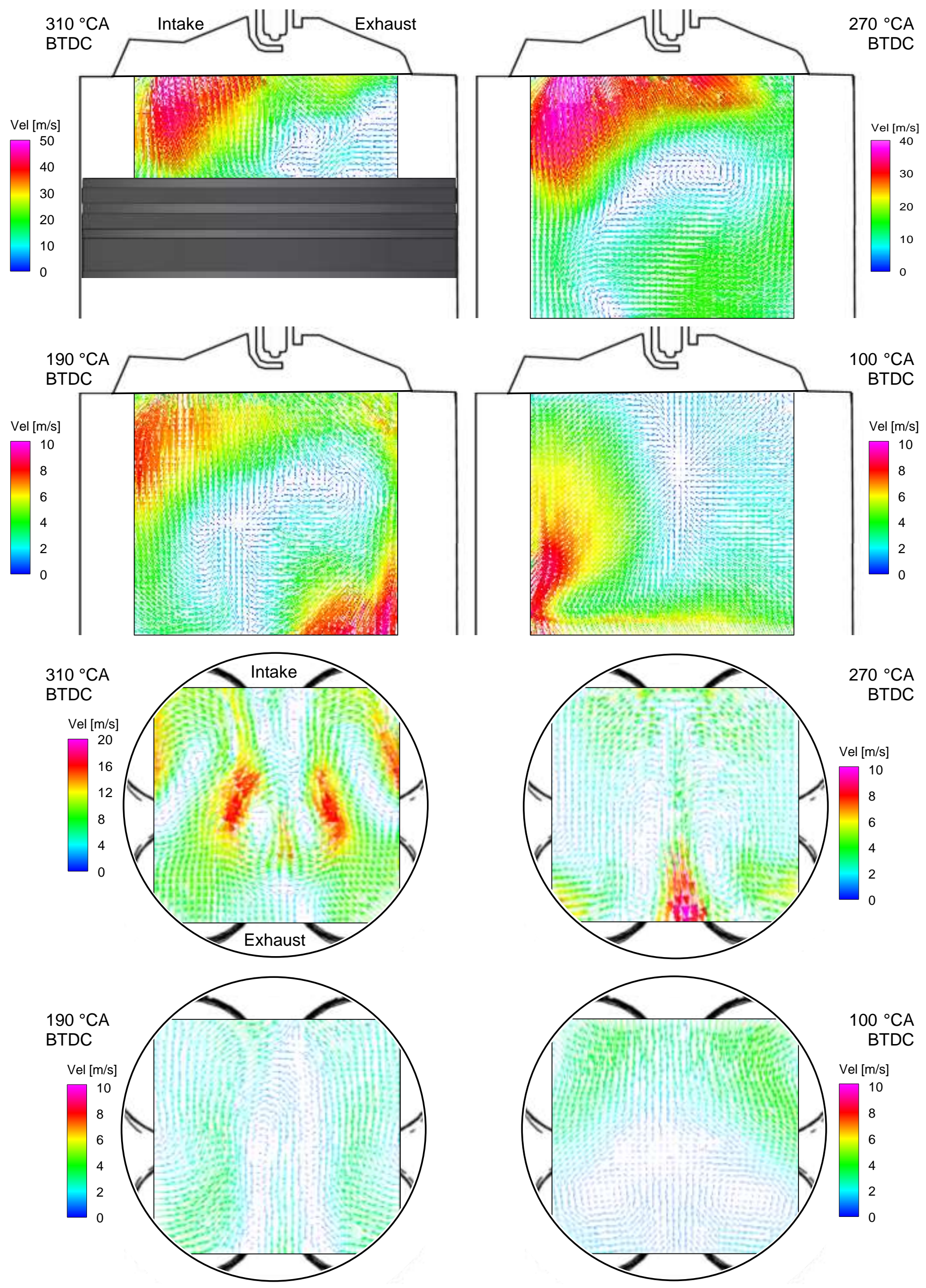

Figure 12. Tumble and swirl mean flow fields as obtained by PIV at various crank angles on $x=10 \mathrm{~mm}$ plane. 


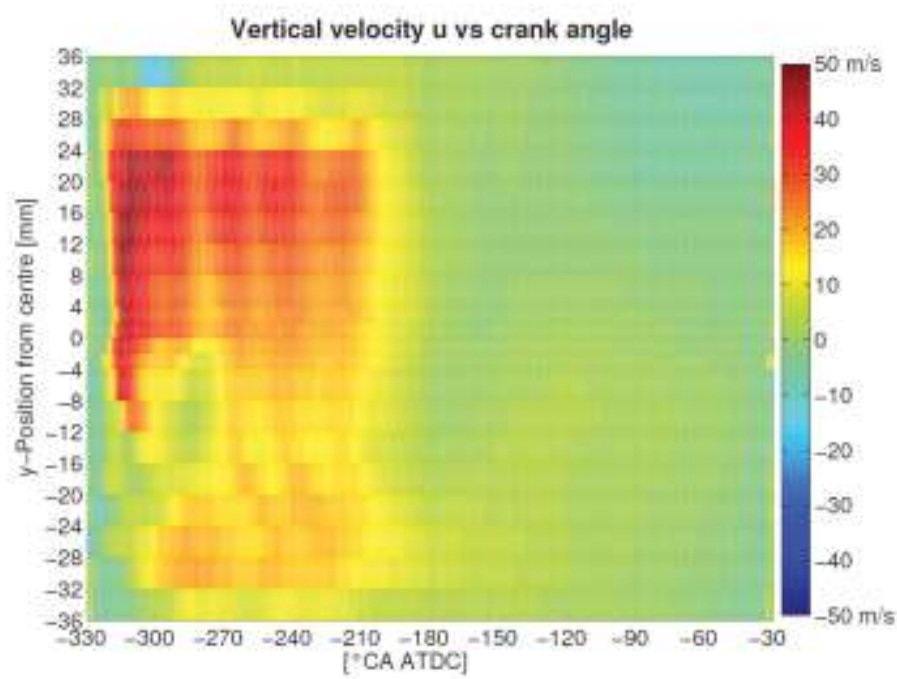

Velocity component u

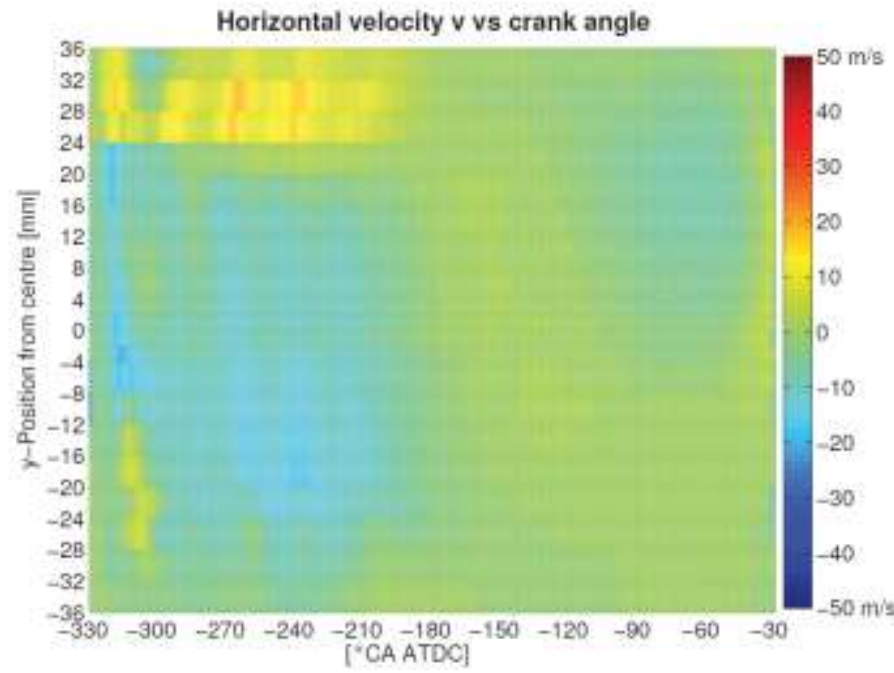

Velocity component $\mathrm{v}$

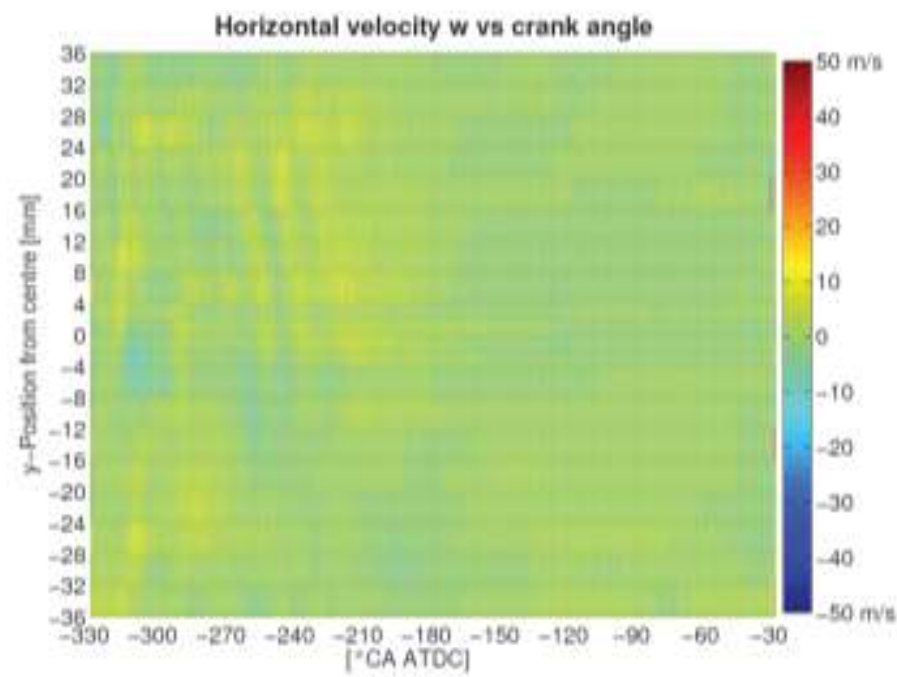

Velocity component $w$

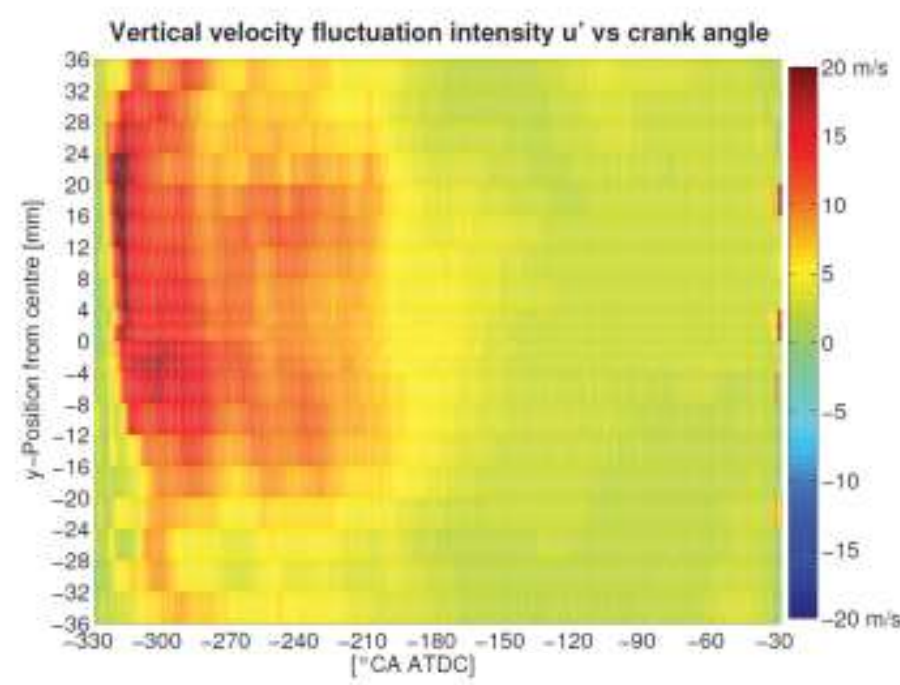

Fluctuation component $\mathrm{u}^{\prime}$

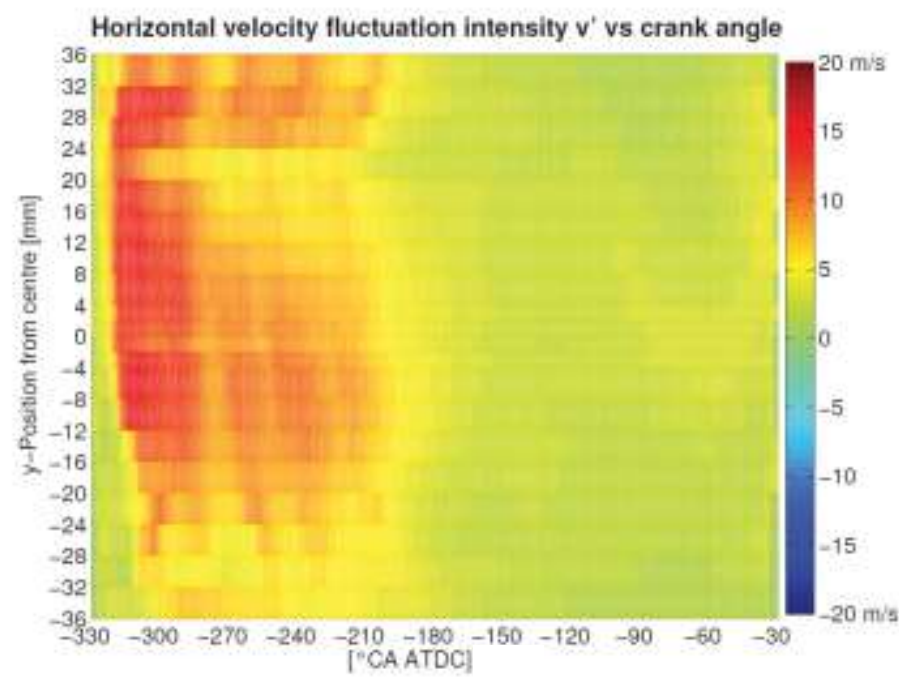

Fluctuation component $v^{\prime}$

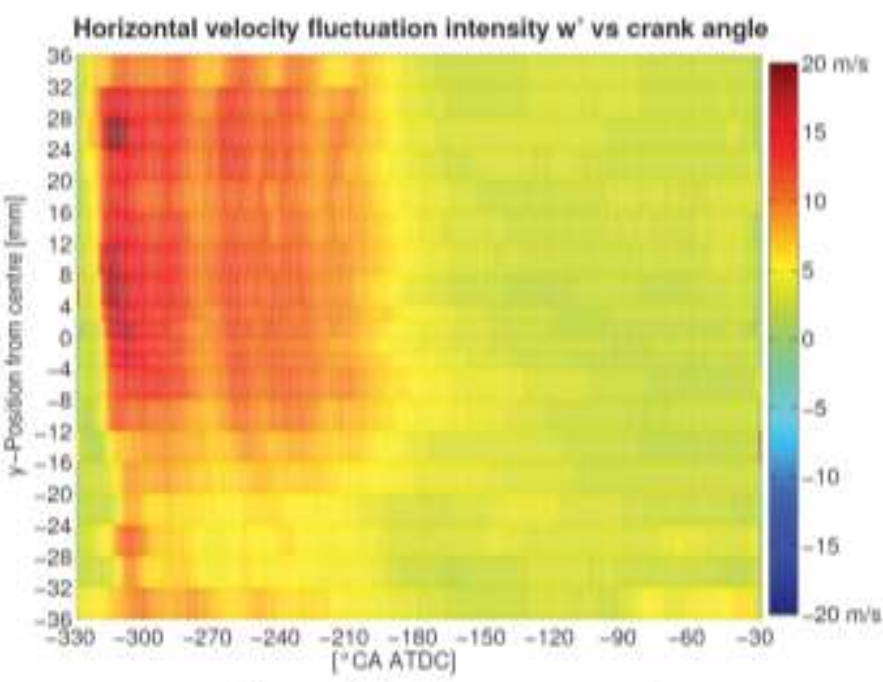

Fluctuation component $w^{\prime}$

Figure 13. Ensemble averaged velocities $u, v$ and $w$ (left) and fluctuation components $u^{\prime}, v^{\prime}$ and $w^{\prime}$ (right) vs. ${ }^{\circ} \mathrm{CA}$ at $10 \mathrm{~mm}$ below the fire-face $(x=10 \mathrm{~mm})$ along the $y$-axis as obtained by LDV. 


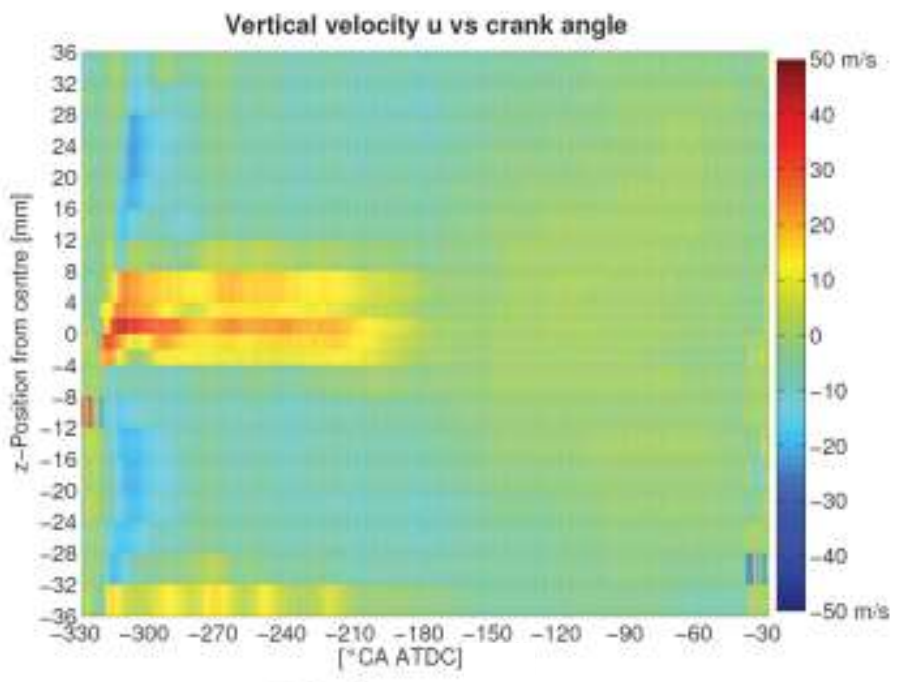

Velocity component u

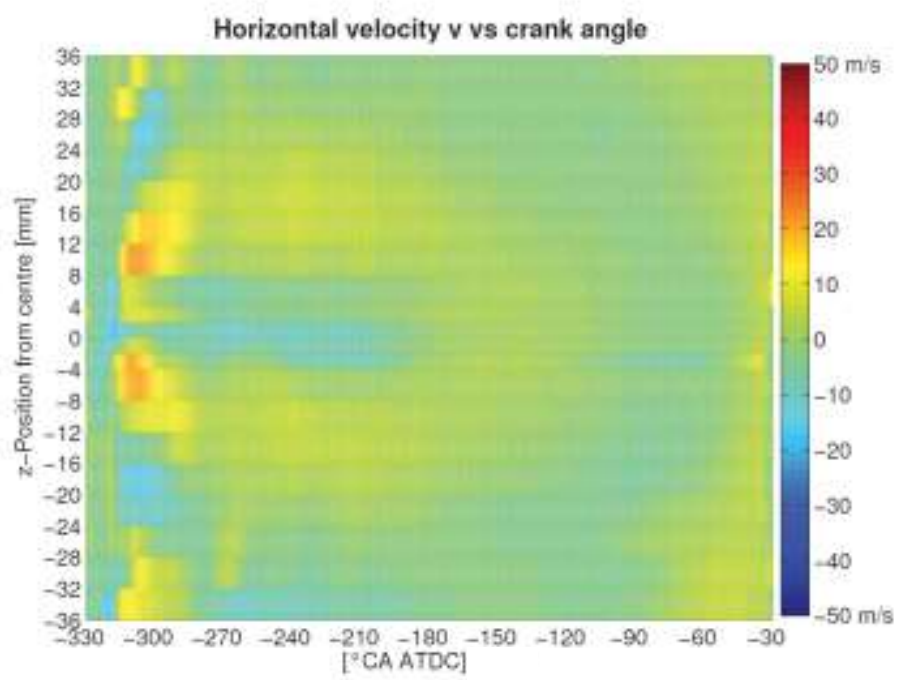

Velocity component $\mathrm{v}$

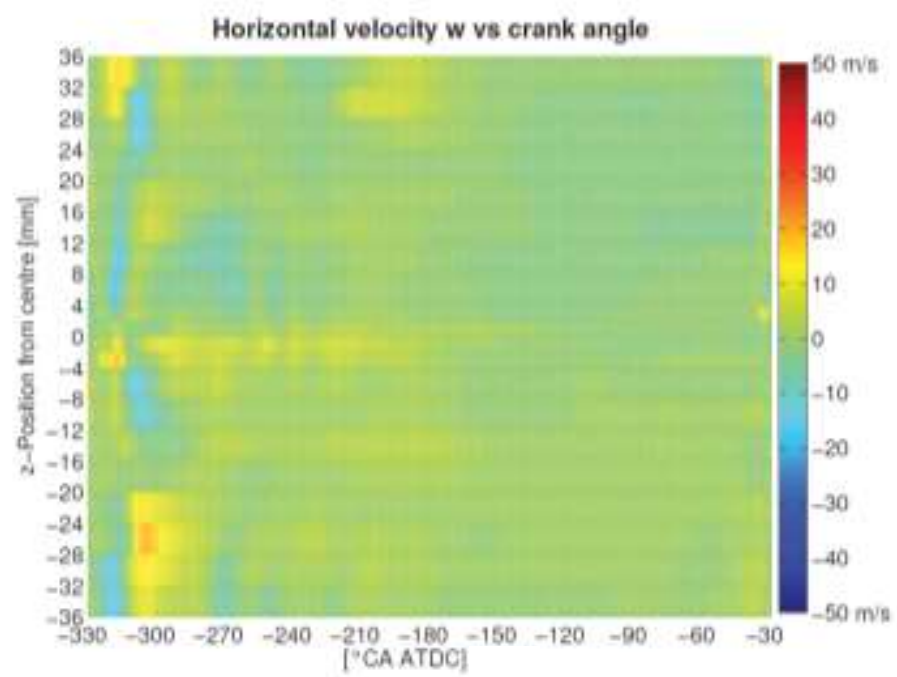

Velocity component $w$

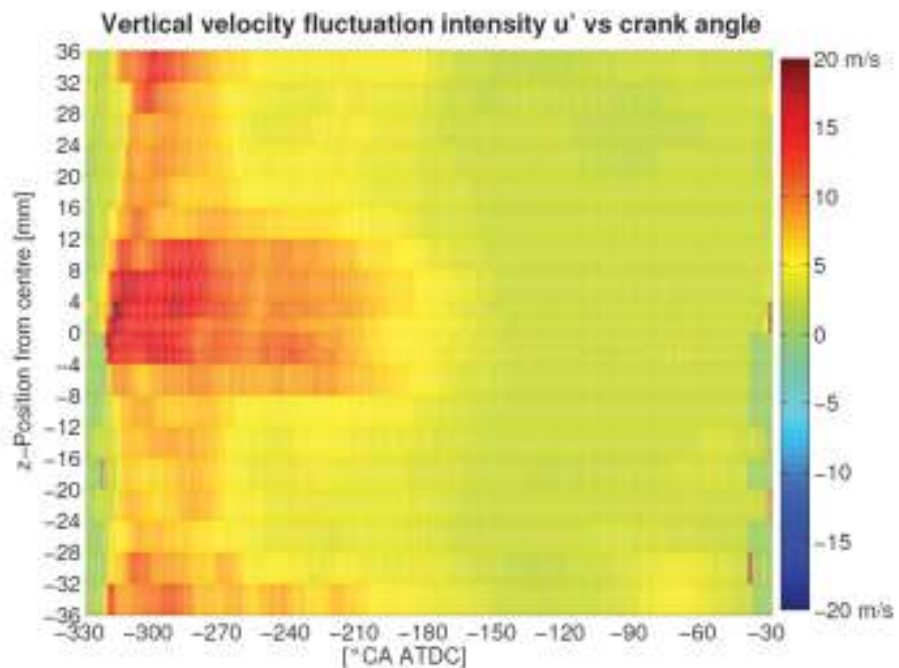

Fluctuation component $u^{\prime}$

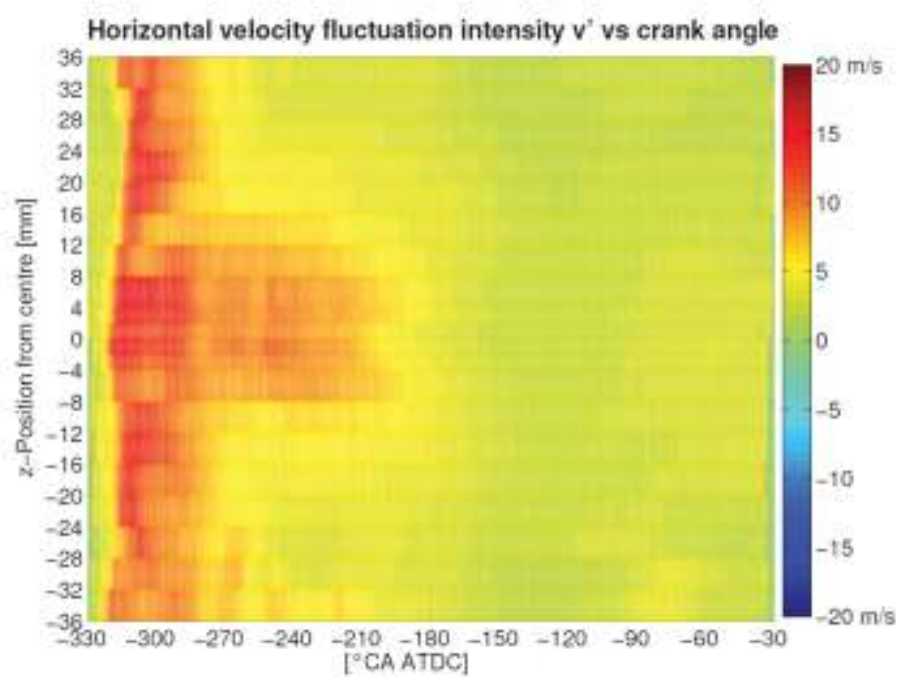

Fluctuation component $v^{\prime}$

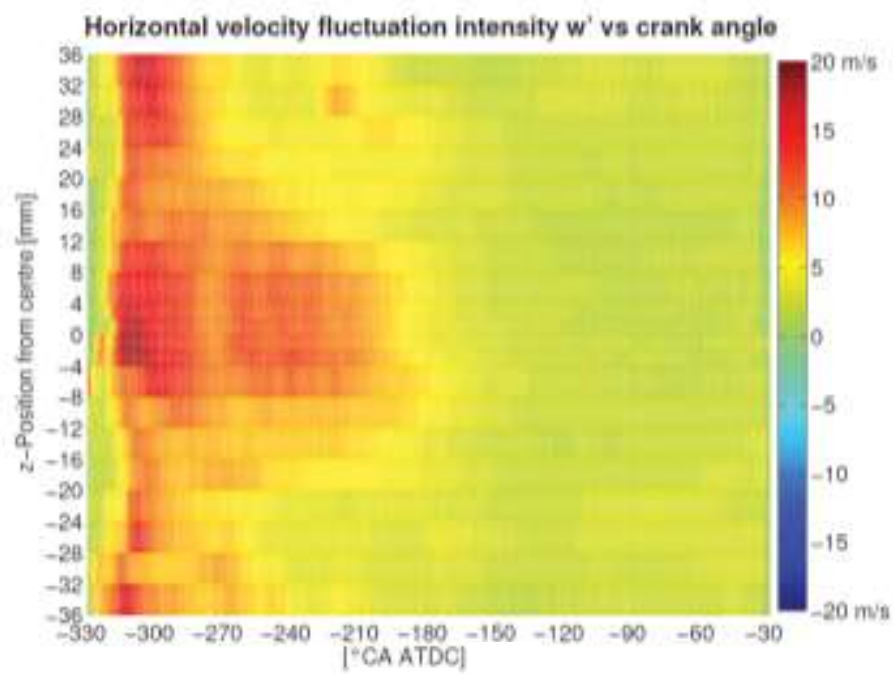

Fluctuation component $w^{\prime}$

Figure 14. Ensemble averaged velocities $u, v$ and $w$ (left) and fluctuation components $u^{\prime}, v^{\prime}$ and $w^{\prime}$ (right) vs. ${ }^{\circ} \mathrm{CA}$ at $10 \mathrm{~mm}$ below the fire-face $(x=10 \mathrm{~mm})$ along the $z$-axis as obtained by LDV. 

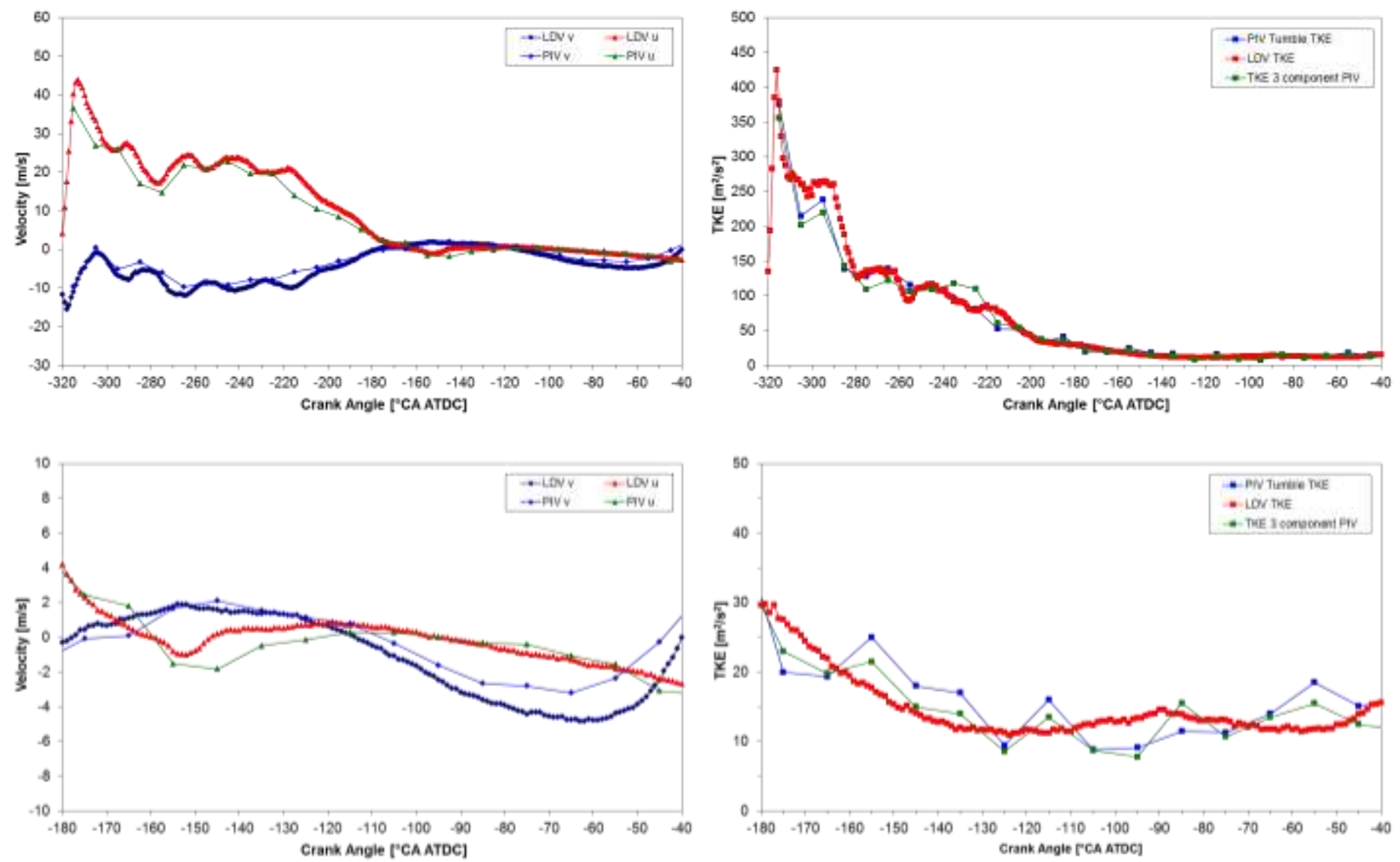

Figure 15. Ensemble averaged velocities $u$ and $v$ (left) and turbulent kinetic energy (right) $v s .{ }^{\circ} \mathrm{CA}$ at $10 \mathrm{~mm}$ below the fire-face at position $4 \mathrm{~mm}$ as obtained by LDV and PIV. Top: 320-40 ${ }^{\circ} \mathrm{CA}$ BTDC, Bottom: Enlarged 180-40 ${ }^{\circ} \mathrm{CA}$ BTDC. 
PSD

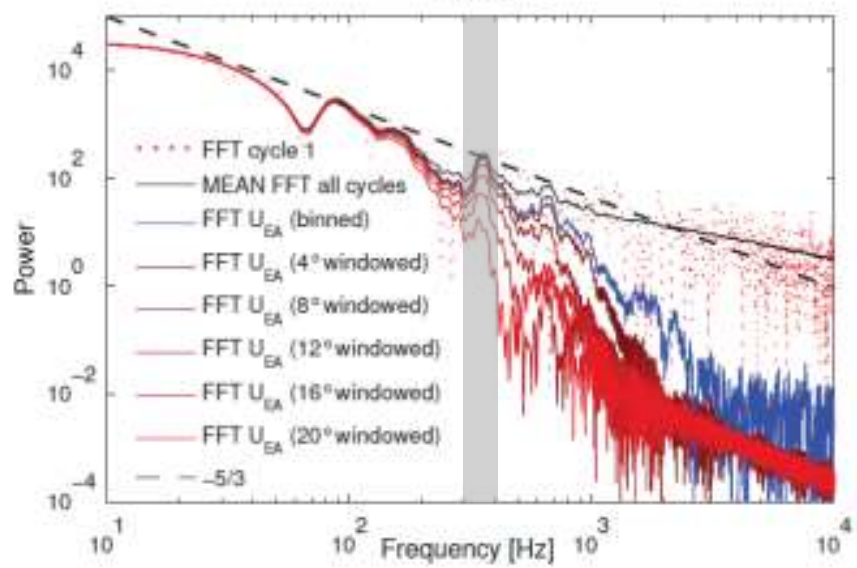

Individual Cycle and Intra-Cycle Mean

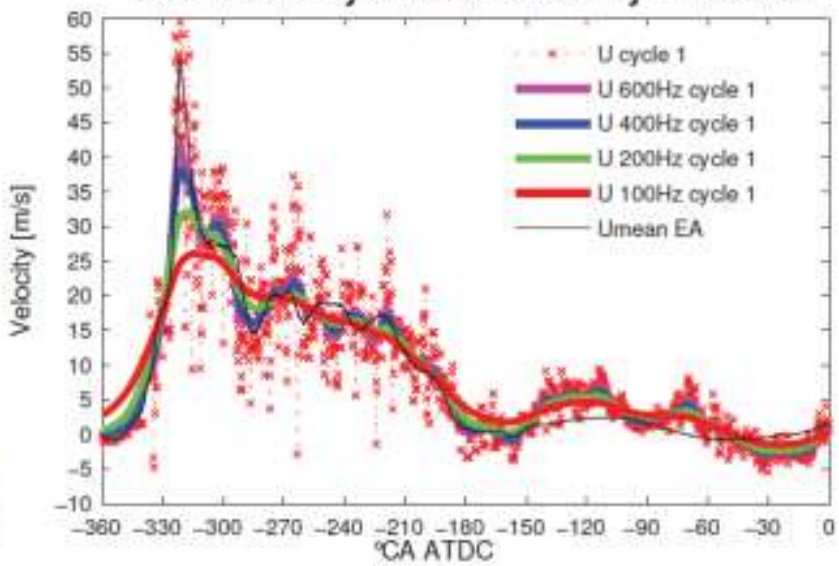

Figure 16. Frequency analysis of individual cycles and ensemble averaged cycles (left) to find the cut-off frequency for the cycle based analysis. In-cycle mean velocities are shown for different thresholds (right).

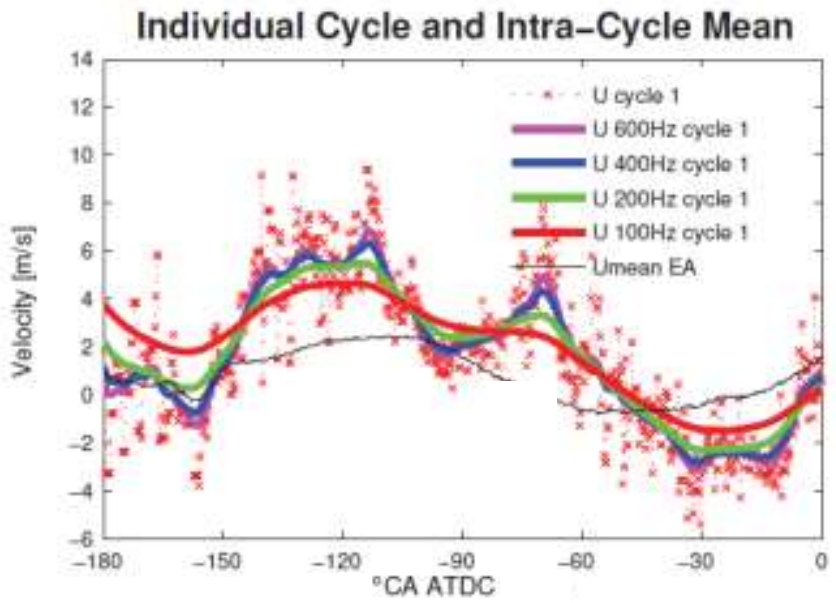

Ensemble Averages of Intra-Cycle Means

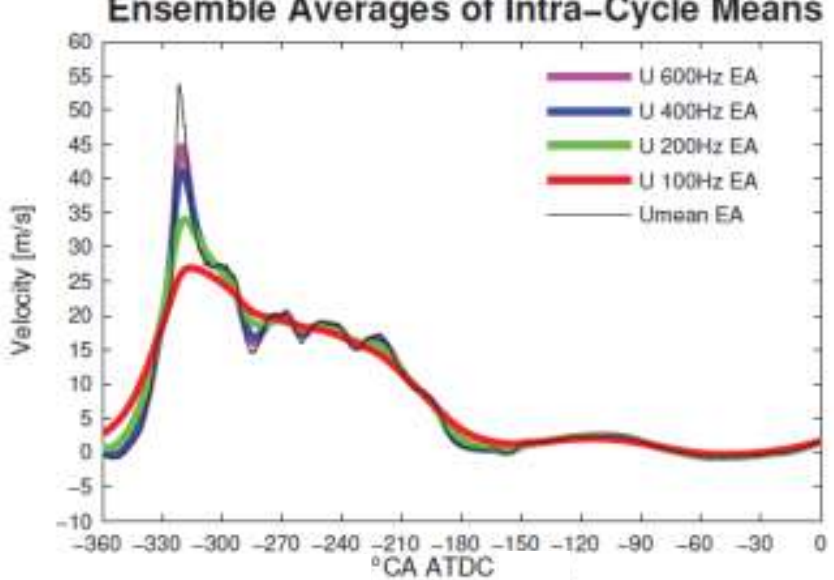

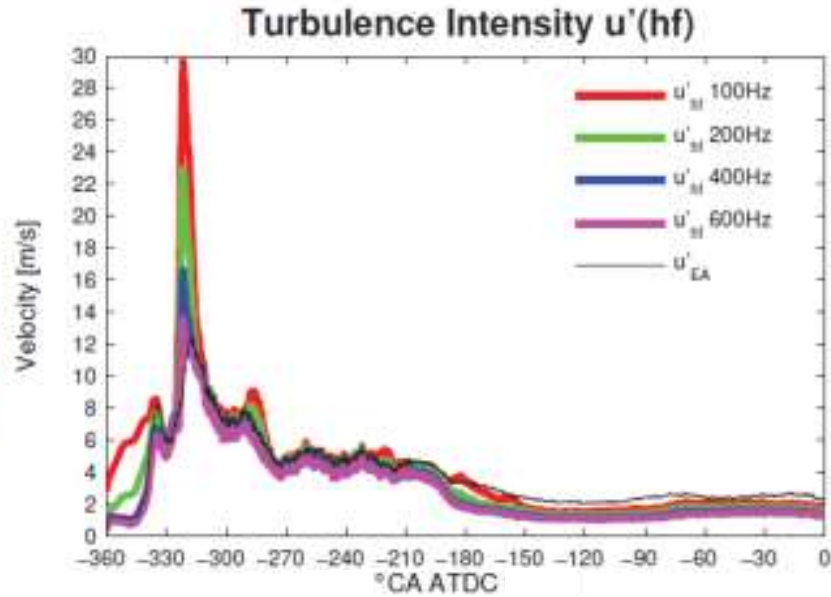

Low Frequency Fluctuation Intensity u'(If)

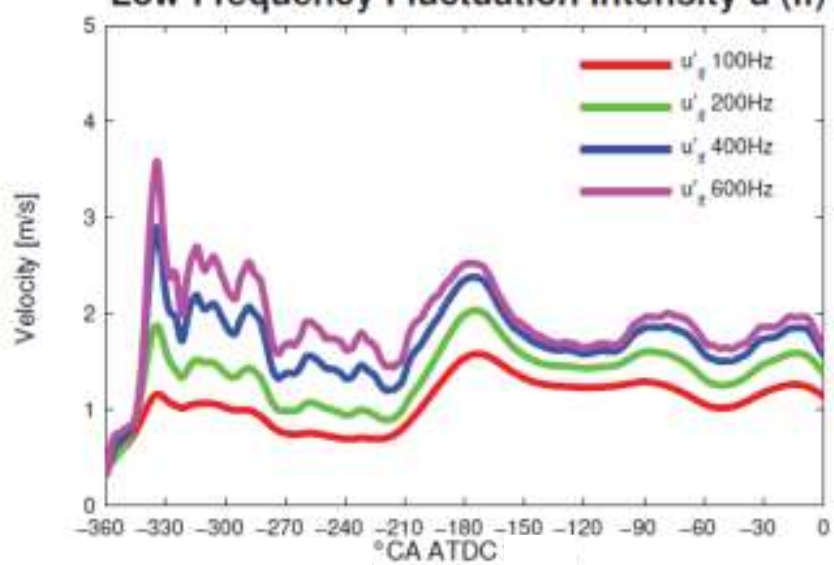

Figure 17. Effect of the cut-off frequency on the in-cycle mean velocity (top left), the ensemble averaged mean velocity (bottom left), the high-frequency turbulence intensity (top right) and the low-frequency turbulence intensity (bottom right). 

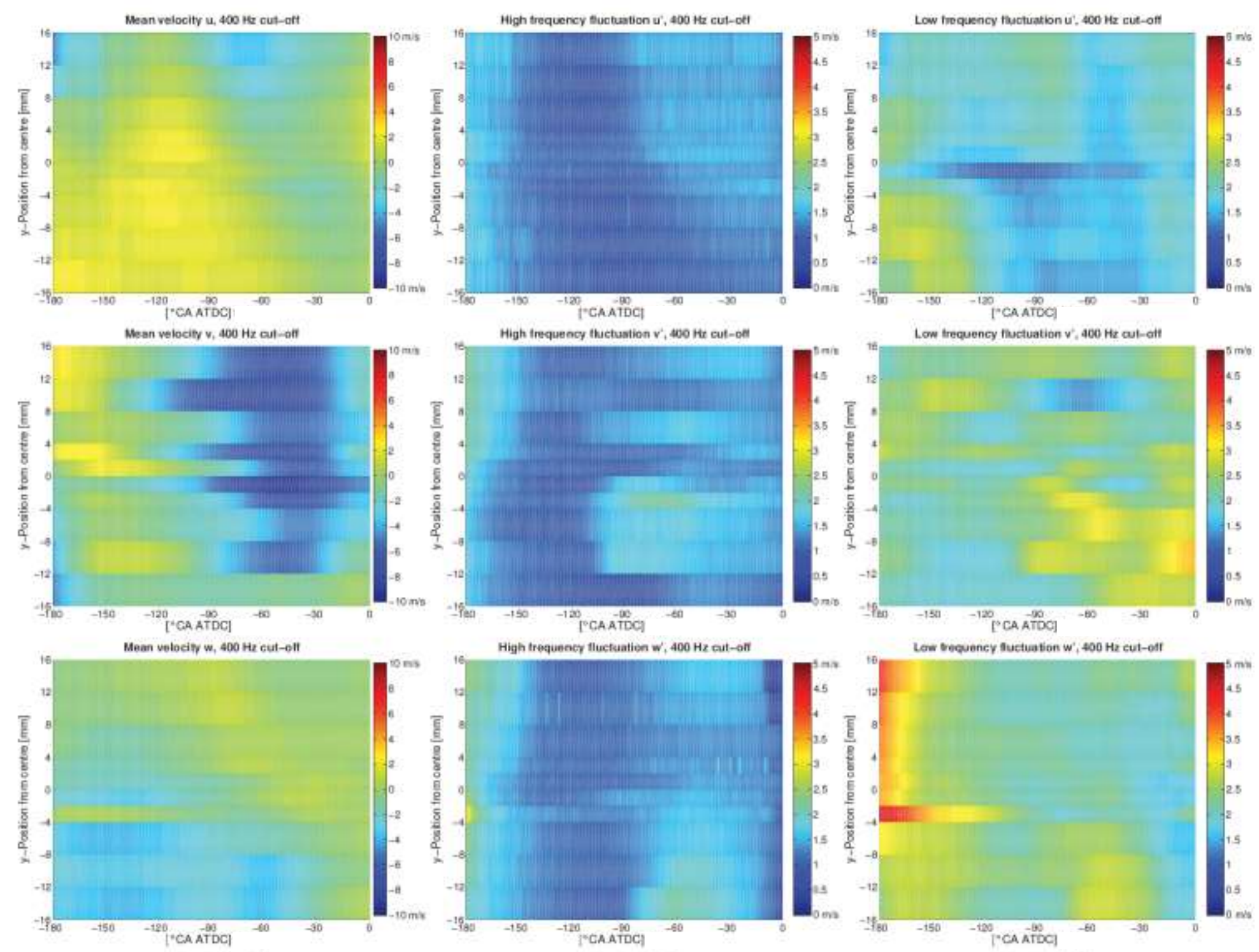

Figure 18. $400 \mathrm{~Hz}$ cut-off frequency analysis at $x=-3 \mathrm{~mm}$ along the $y$-axis. Low-pass mean velocities are given in the left column of graphs for $u, v$ and $w$ velocities in the first second and third row, respectively. High- and low-frequency fluctuations are given in the middle and right columns accordingly. 

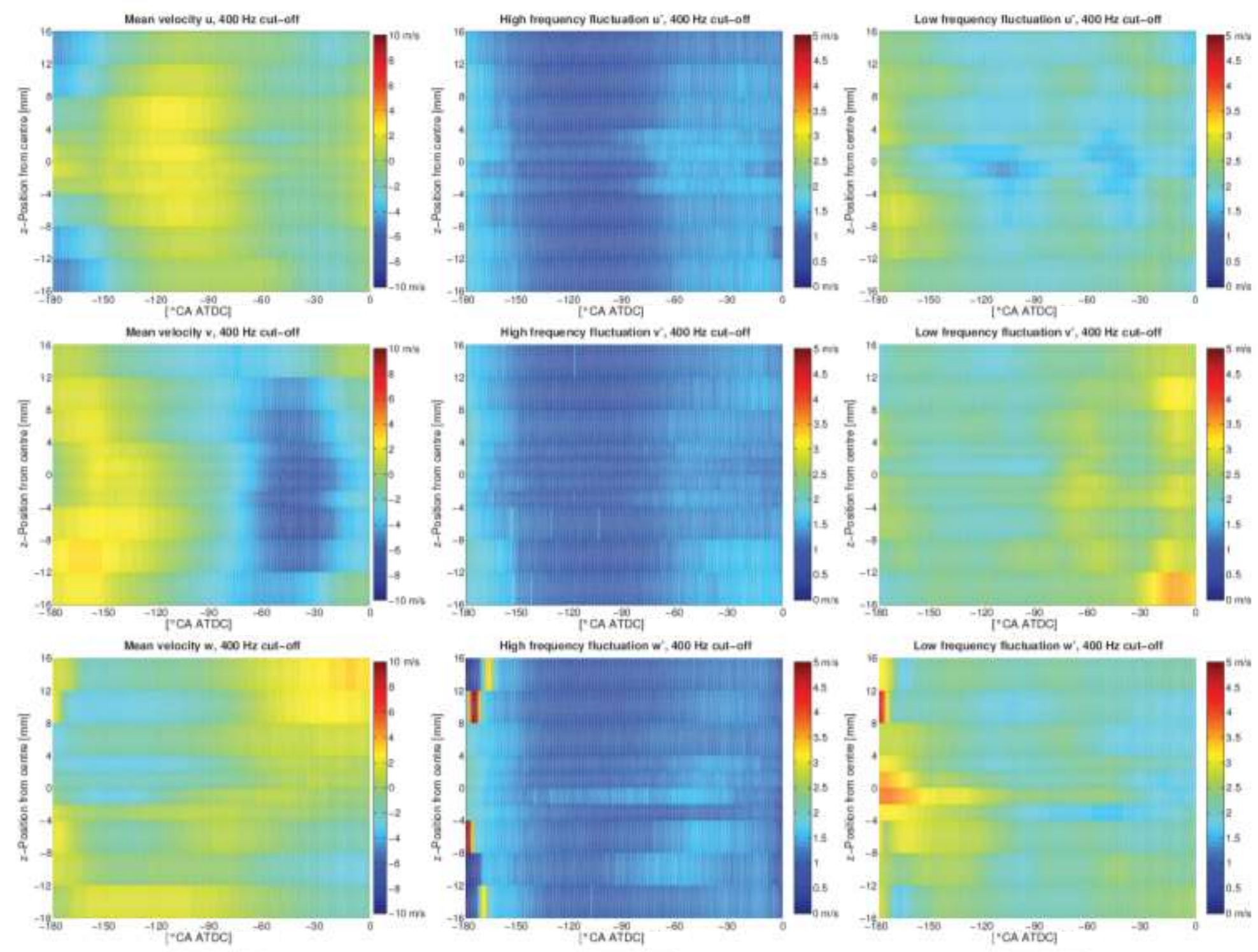

Figure 19. $400 \mathrm{~Hz}$ cut-off Frequency analysis at $x=-3 \mathrm{~mm}$ along the $z$-axis. Low-pass mean velocities are given in the left column of graphs for $u, v$ and $w$ velocities in the first second and third row, respectively. High- and low-frequency fluctuations are given in the middle and right columns accordingly. 

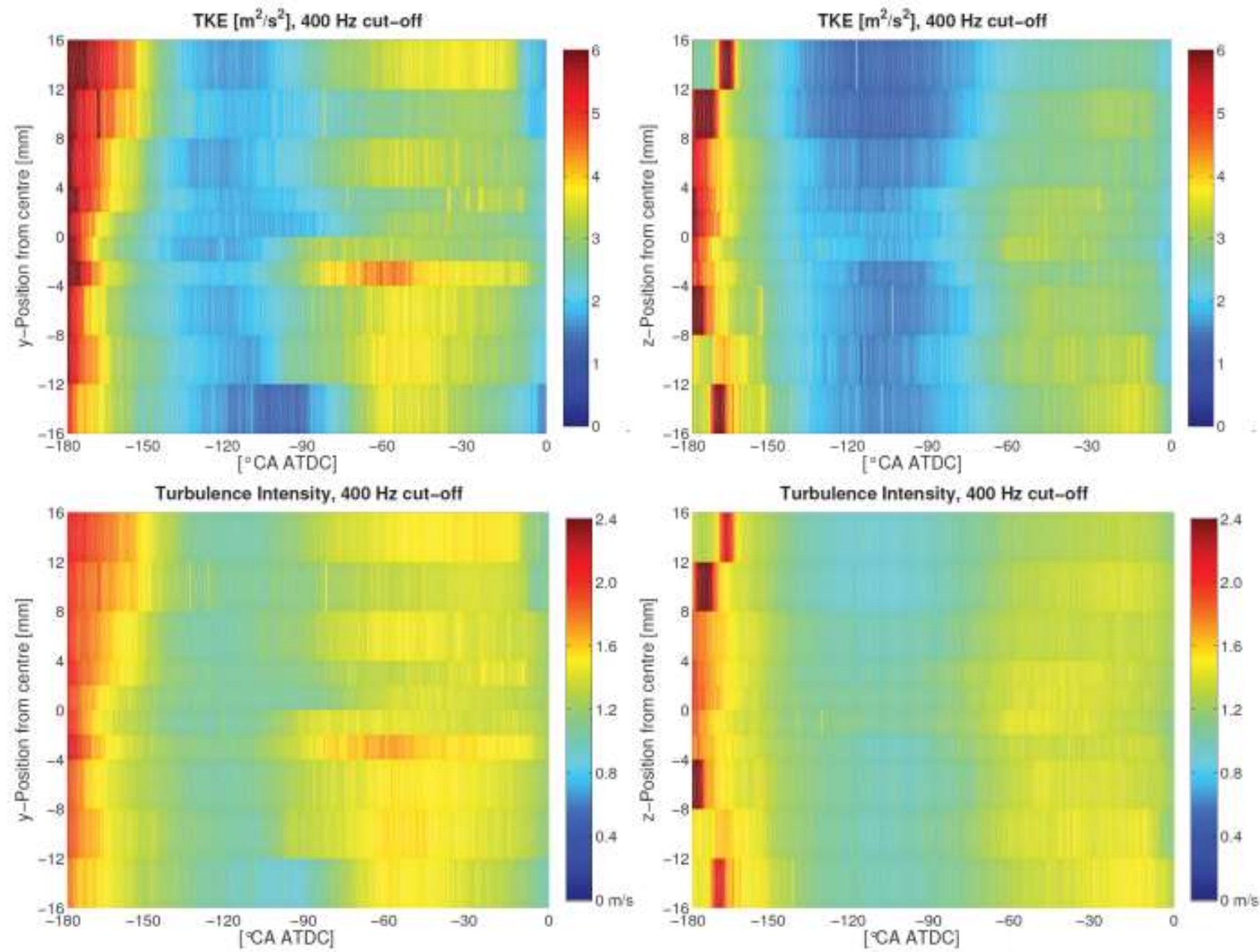

Figure 20. TKE and turbulence intensity during compression stroke at $x=-3 \mathrm{~mm}$ from $400 \mathrm{~Hz}$ highfrequency fluctuation along $y$-axis (left) and $z$-axis (right). 

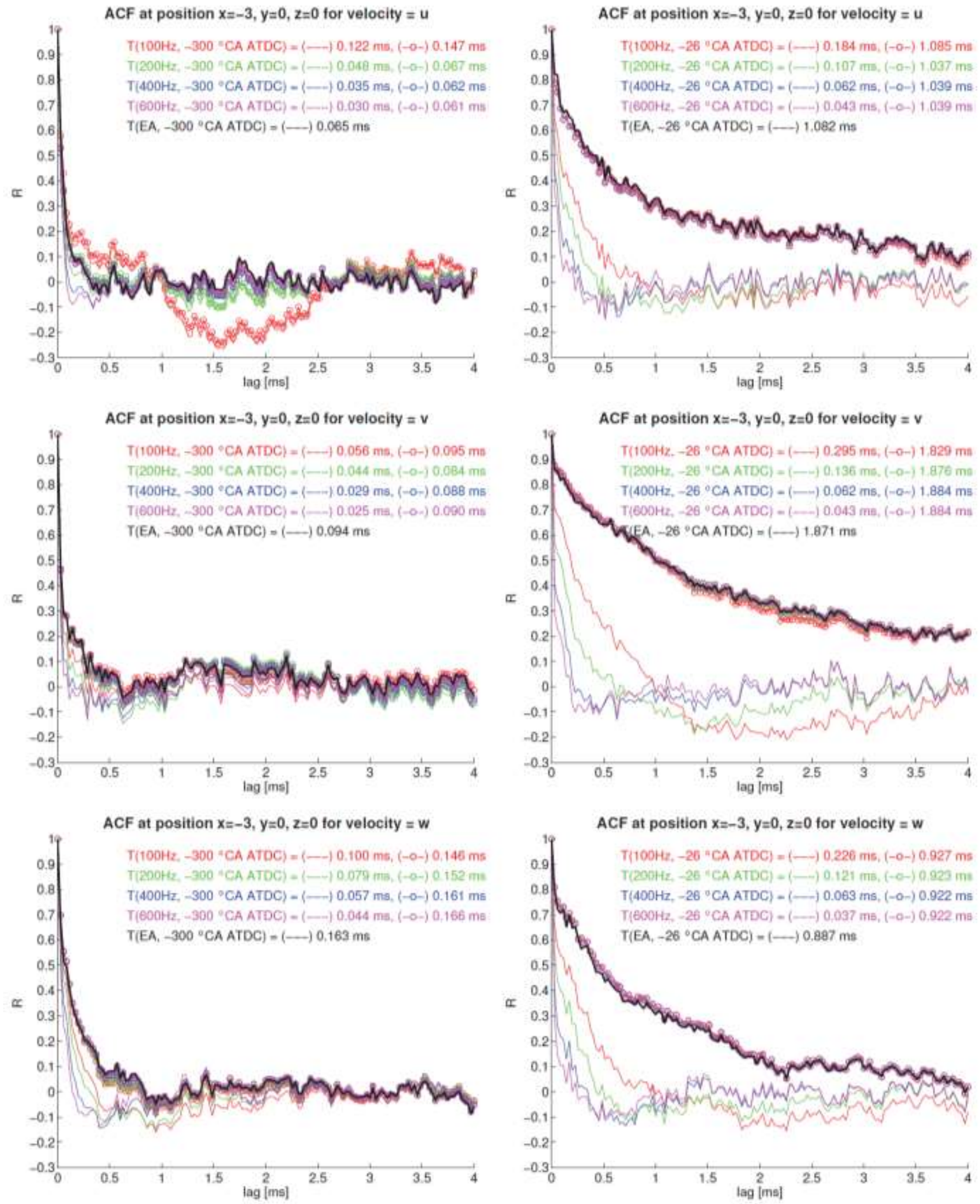

Figure 21. Autocorrelation functions at 300 and $26{ }^{\circ} \mathrm{CA}$ BTDC. High-frequency only considerations are given in solid coloured lines without marker and indicate very low time scales, reducing for higher cut-off frequencies. The autocorrelation for the combined high- and low-frequency fluctuations for various cut-offs returned autocorrelation functions (circular marker) very similar to the traditional ensemble averaging approach (black line). 


\section{Traditional EA}
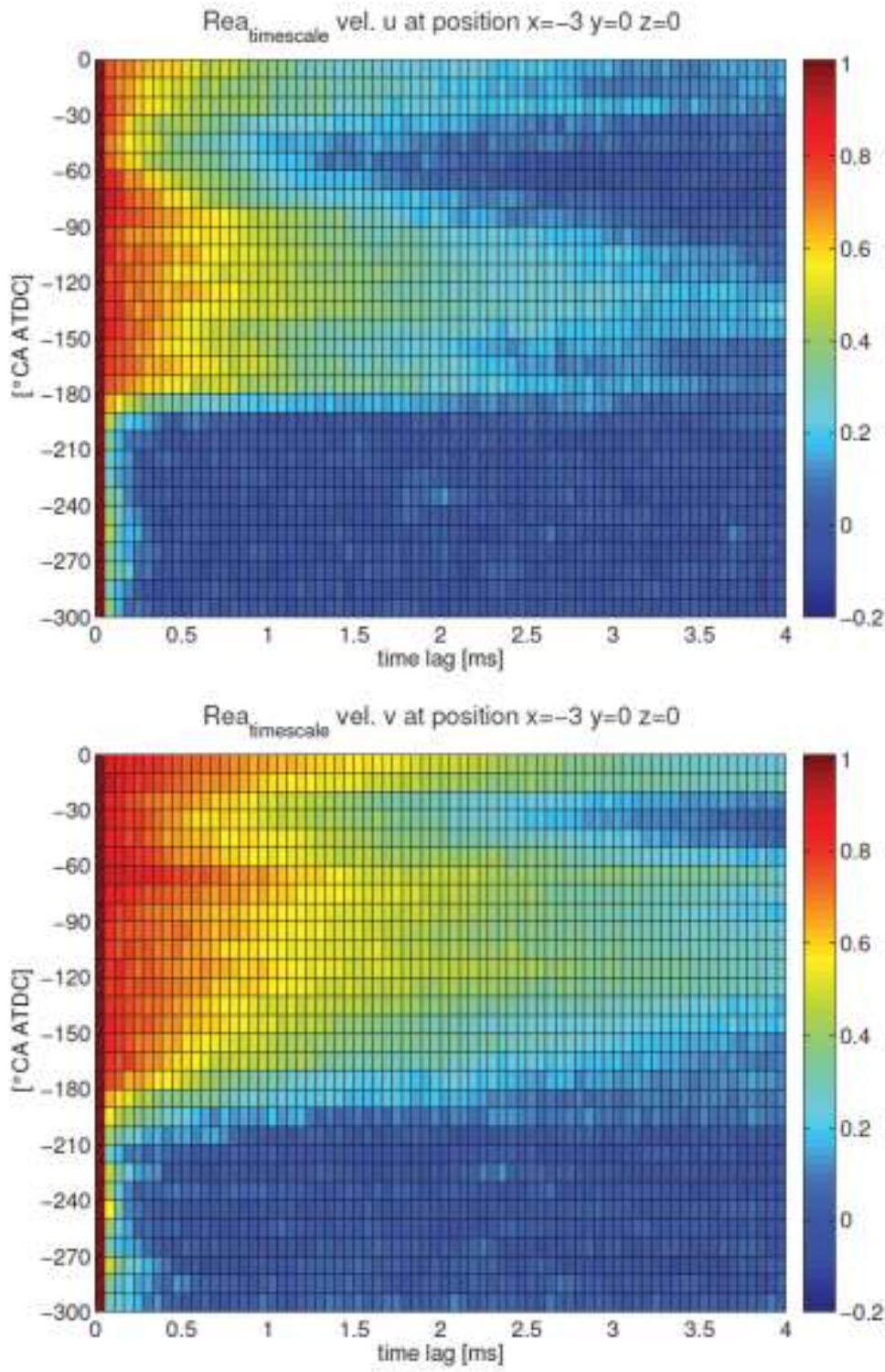

Rea $_{\text {timoscalo }}$ vel. $w$ at position $x=-3 \quad y=0 \quad z=0$

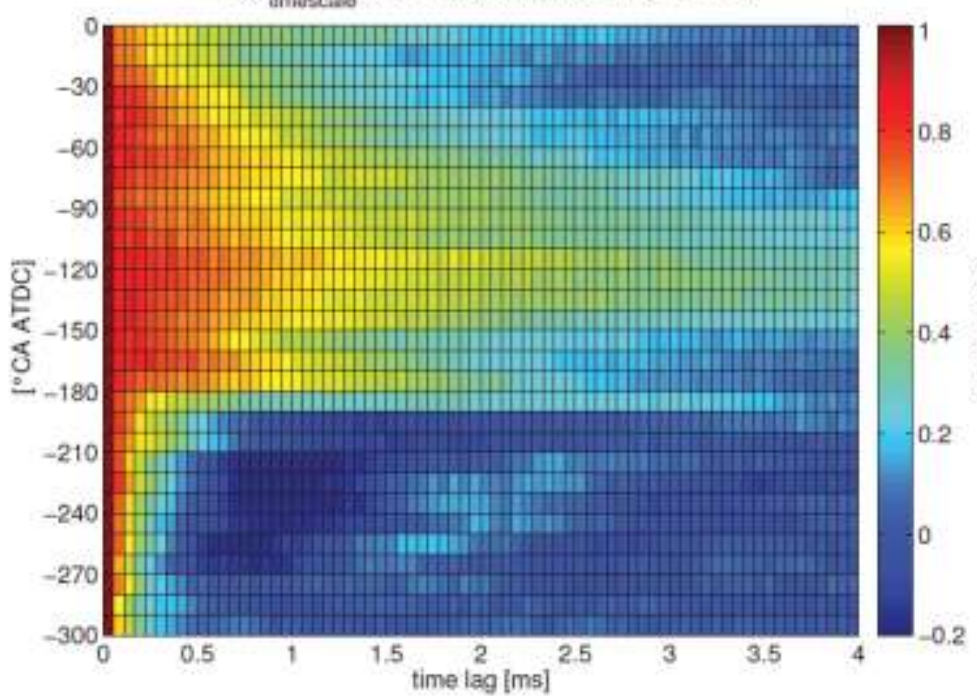

$200 \mathrm{~Hz}$ Frequency Cut-Off

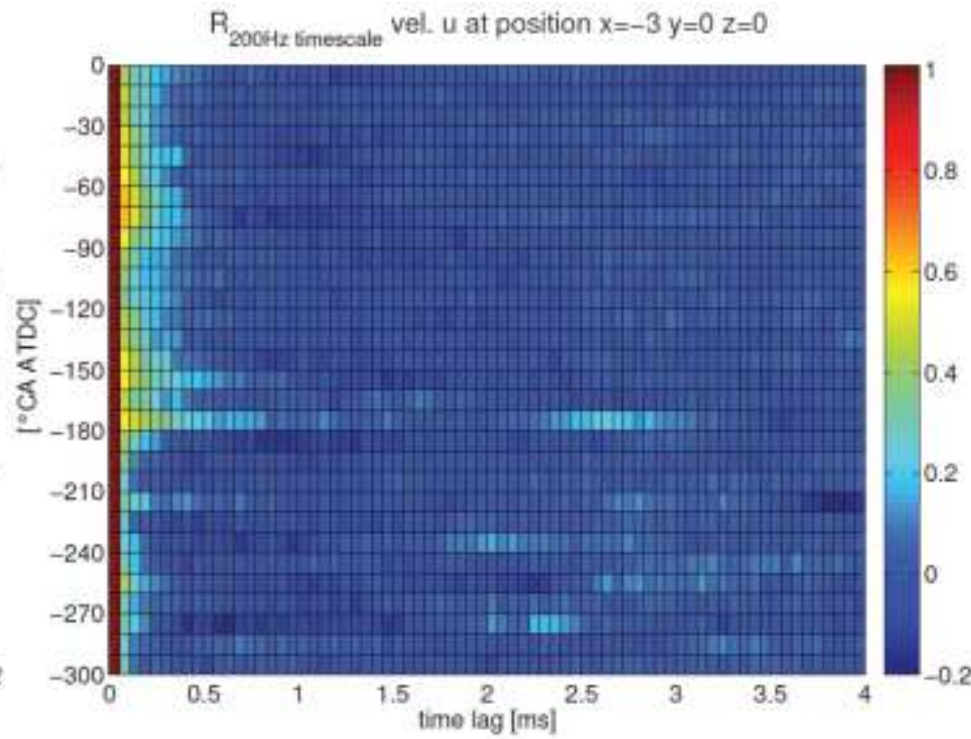

$R_{200 H \text { timescale }}$ vel. $v$ at position $x=-3 y=0 \quad z=0$

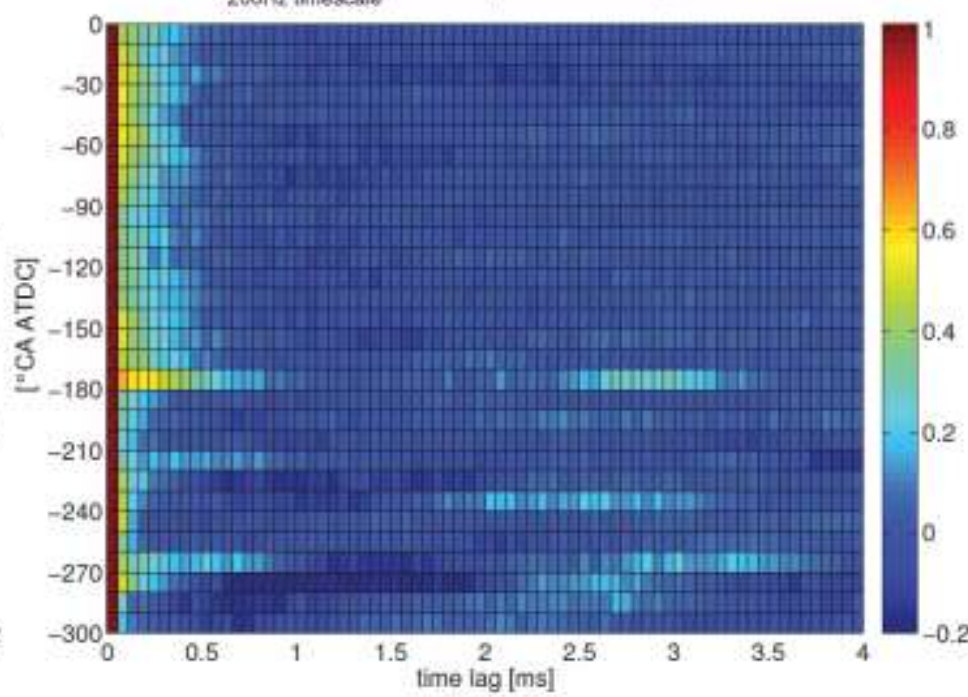

$R_{200 \mathrm{~Hz} \text { timescaio }}$ vel, w at position $x=-3$ y $=0 \quad z=0$

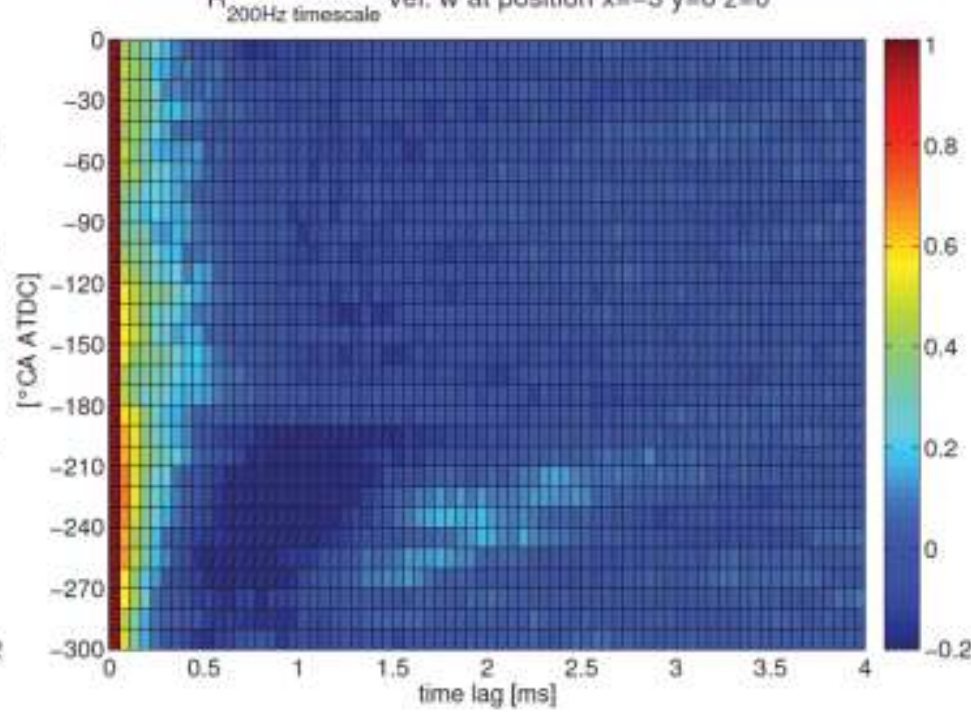

Figure 22. Autocorrelation function against ${ }^{\circ} \mathrm{CA}$ ATDC at $x=-3, y=0, z=0 \mathrm{~mm}$ for the traditional ensemble averaged approach and a $200 \mathrm{~Hz}$ cut-off high-frequency analysis. 
$\mathrm{x}=-3 \mathrm{~mm}, \mathrm{z}=0$, along $\mathrm{y}$-axis
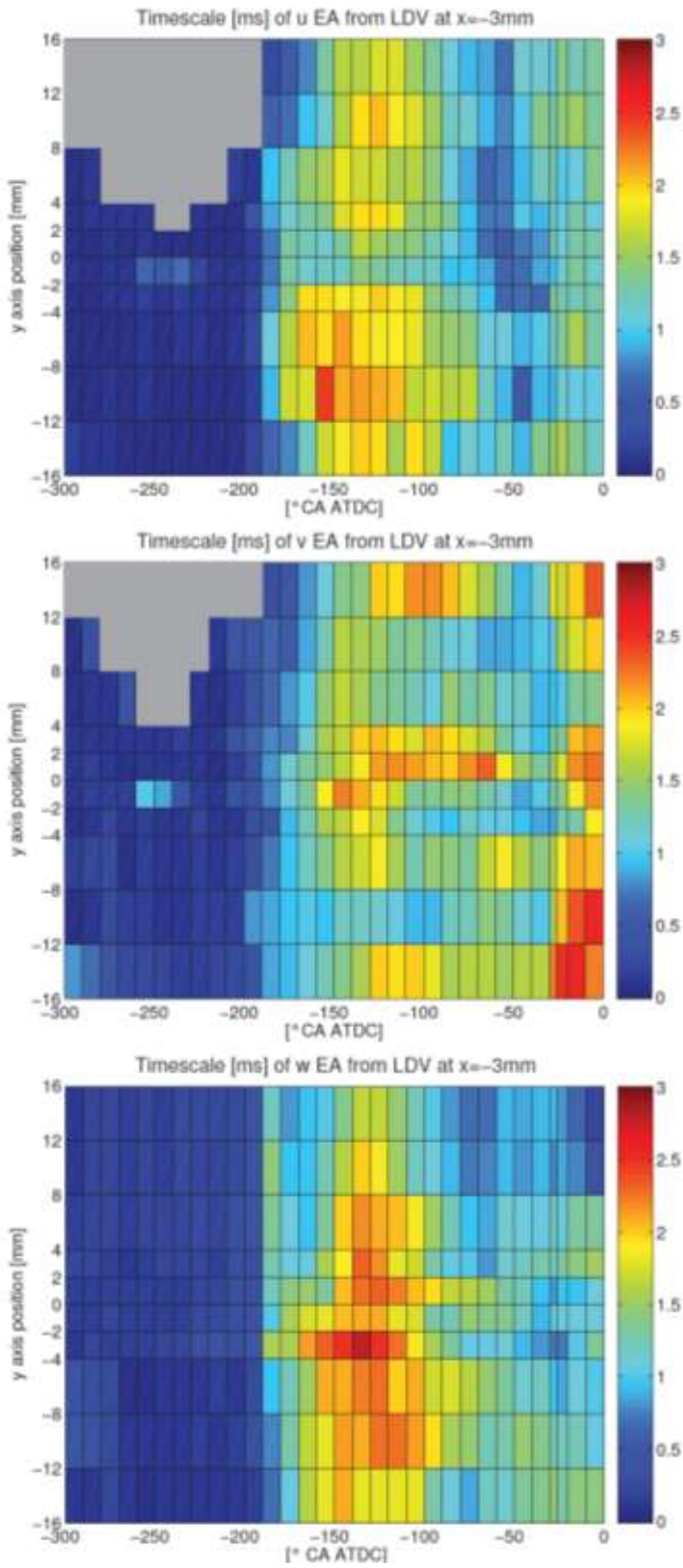

$x=-3 \mathrm{~mm}, \mathrm{y}=0$, along $\mathrm{z}$-axis

Timescale [ms] of $u$ EA from LDV at $x=-3 \mathrm{~mm}$
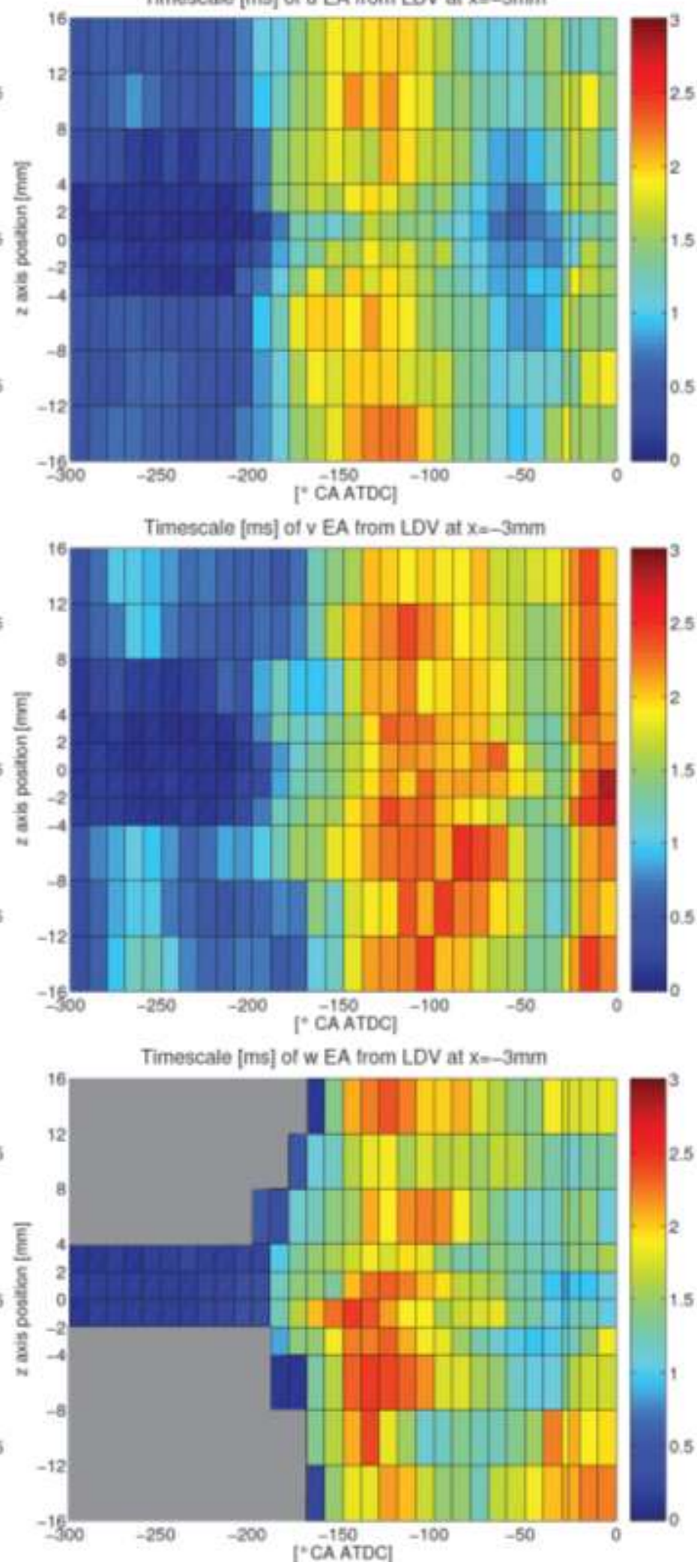

Figure 23. Integral time scales along $y$ - and $z$-axis at $x=-3 \mathrm{~mm}$, LDV. 
$\mathrm{x}=10 \mathrm{~mm}, \mathrm{z}=0$, along $\mathrm{y}$-axis

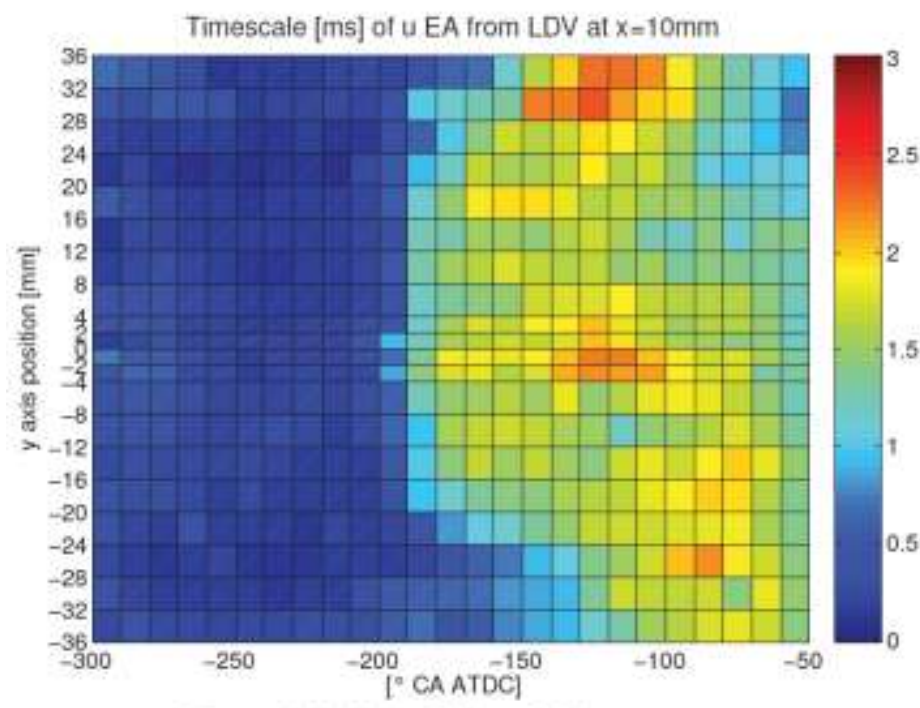

Timescale [ms] of $v$ EA from LDV at $x=10 \mathrm{~mm}$

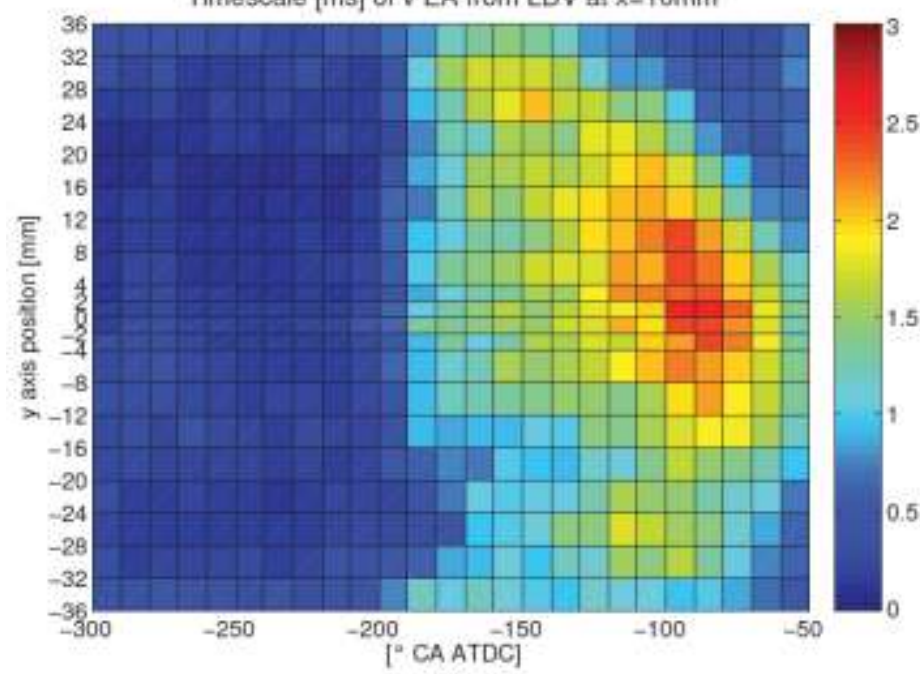

Timescale [ms] of $w$ EA from LDV at $x=10 \mathrm{~mm}$

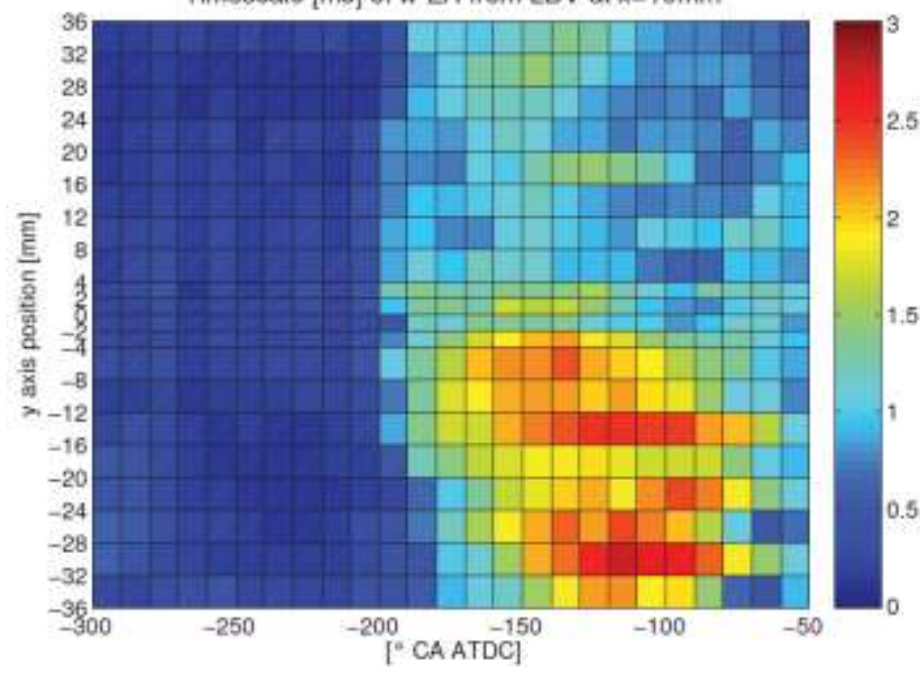

$\mathrm{x}=10 \mathrm{~mm}, \mathrm{y}=0$, along $\mathrm{z}$-axis

Timescale [ms] of u EA from LDV at $x=10 \mathrm{~mm}$

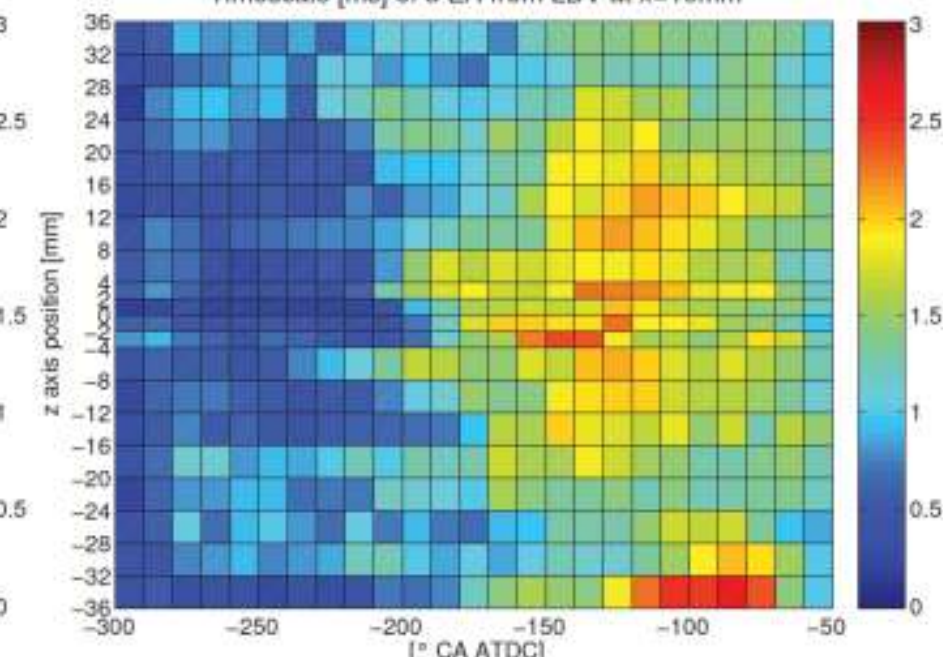

Timescale [ms] of $v$ EA from LDV at $x=10 \mathrm{~mm}$

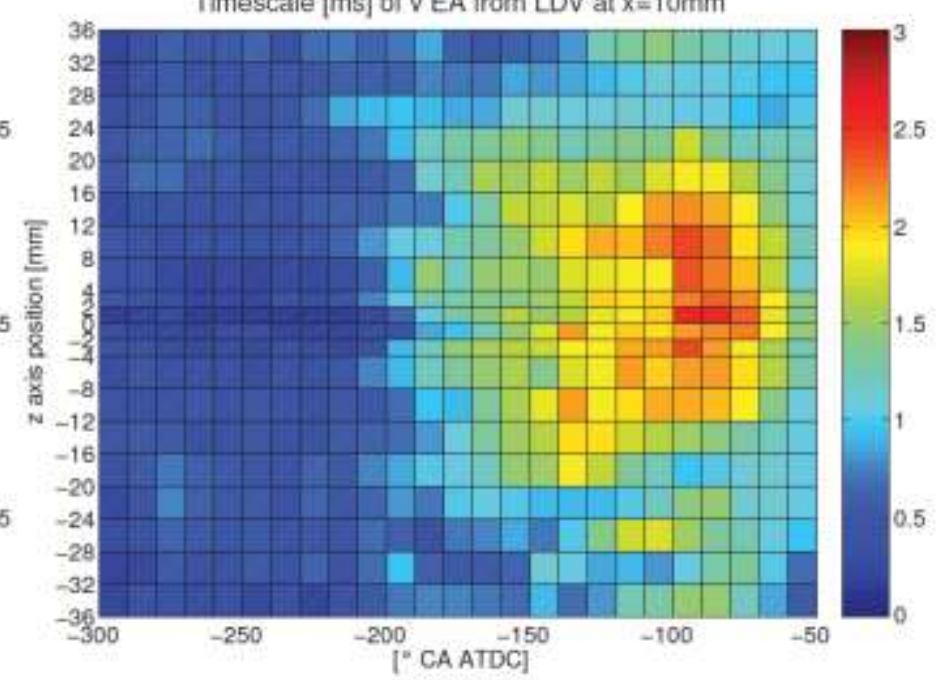

Timescale [ms] of $W$ EA from LDV at $x=10 \mathrm{~mm}$

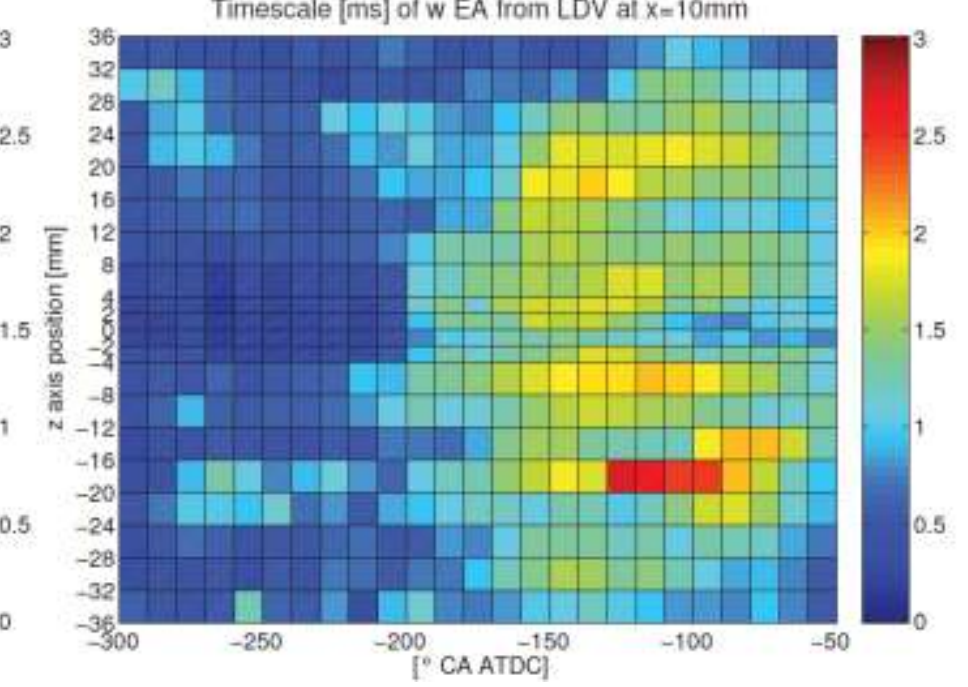

Figure 24. Integral time scales along $y$ - and $z$-axis at $x=10 \mathrm{~mm}, \mathrm{LDV}$. 
$\mathrm{x}=-3 \mathrm{~mm}, \mathrm{z}=0$, along $\mathrm{y}$-axis
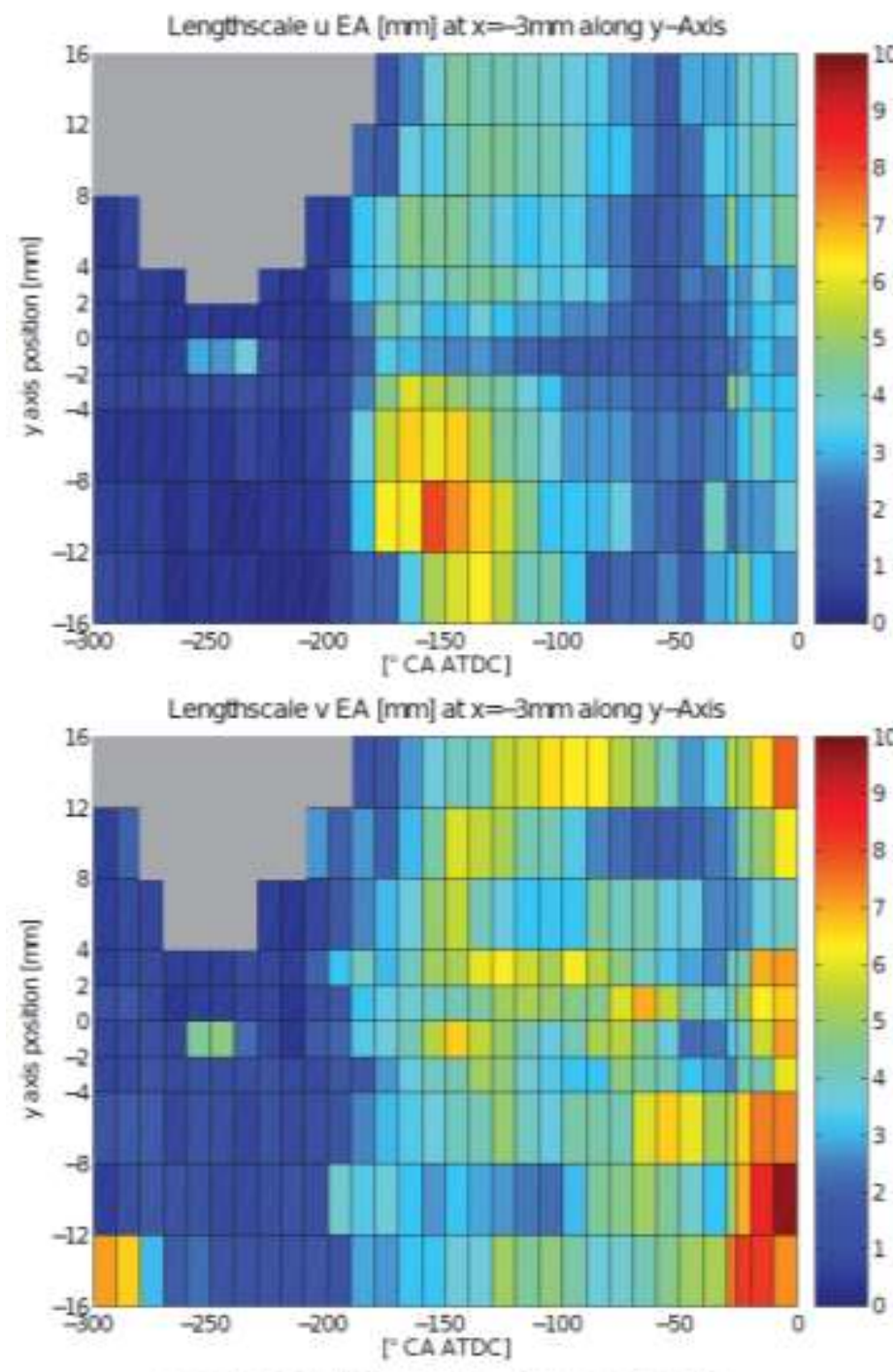

Lengthscale $w$ EA $[\mathrm{mm}]$ at $\mathrm{x}=-3 \mathrm{~mm}$ along $\mathrm{y}$-Axis

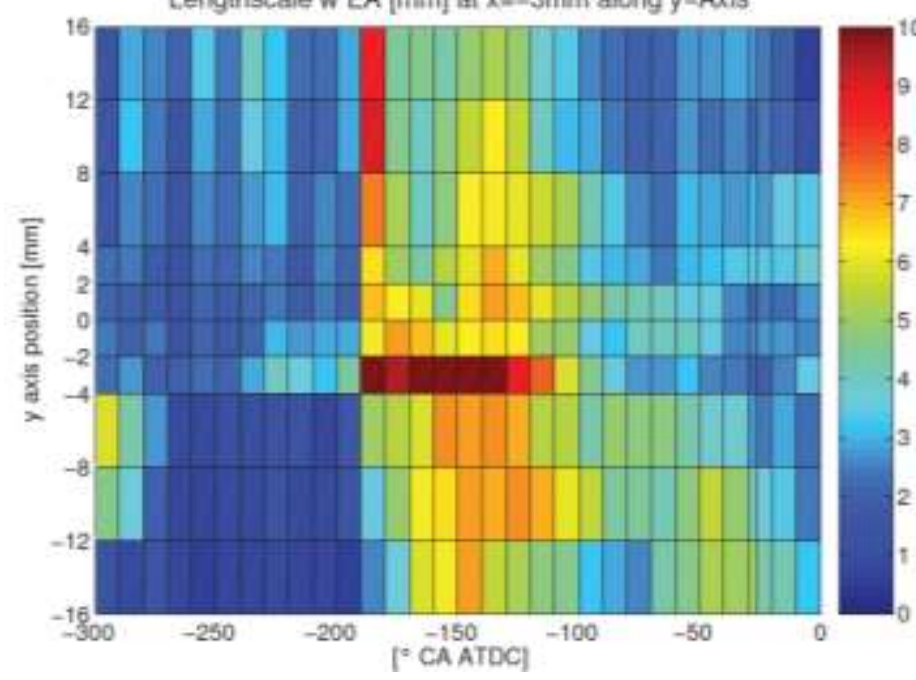

$\mathrm{x}=-3 \mathrm{~mm}, \mathrm{y}=0$, along $\mathrm{z}$-axis
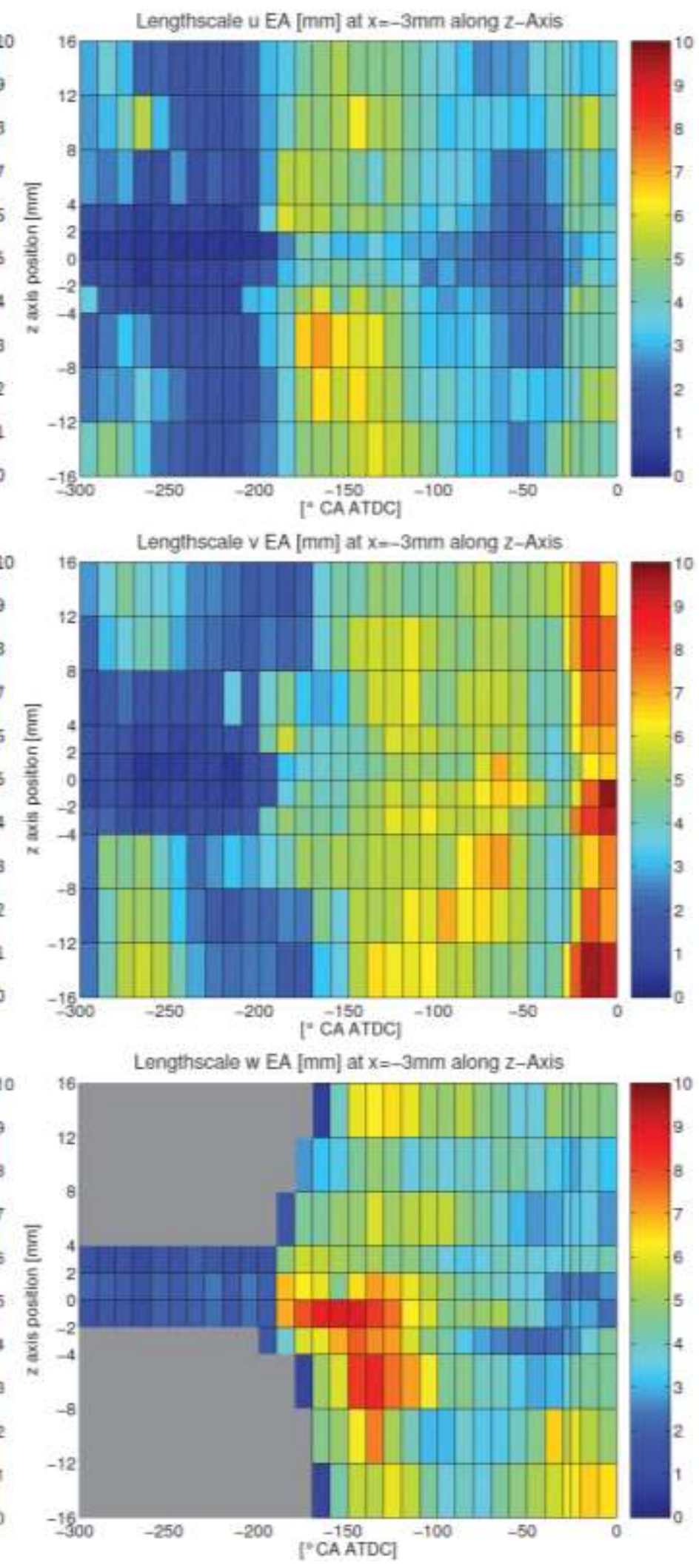

Figure 25. Integral length scales along $y$ - and $z$-axis at $x=-3 \mathrm{~mm}$, from integral time scale and ensemble averaged fluctuation, LDV. 

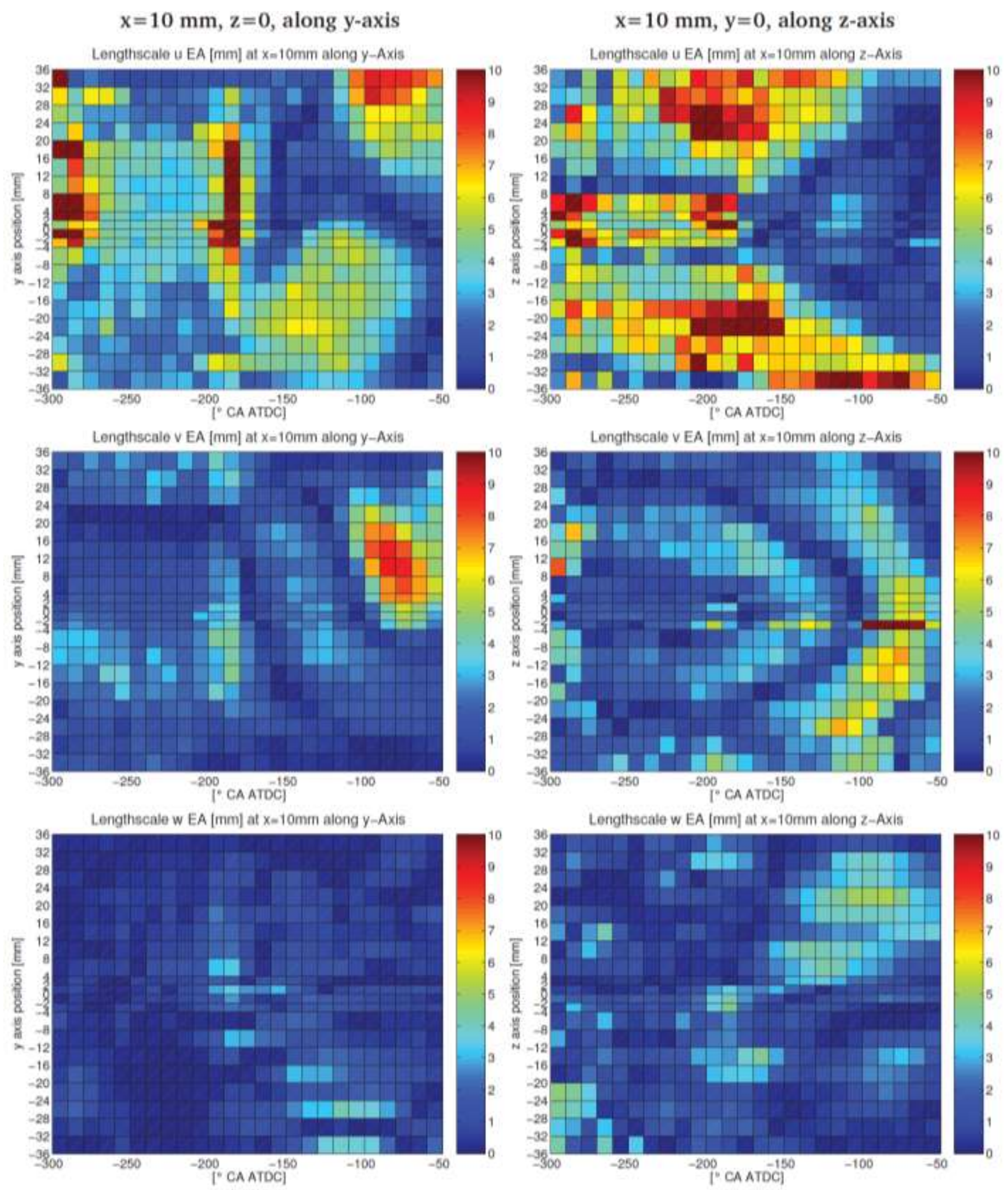

Figure 26. Integral length scales along $y$ - and $z$-axis at $x=10 \mathrm{~mm}$, from integral time scale and ensemble averaged mean velocity, $L D V$. 
$\mathrm{x}=10 \mathrm{~mm}, \mathrm{z}=0$, along $\mathrm{y}$-axis
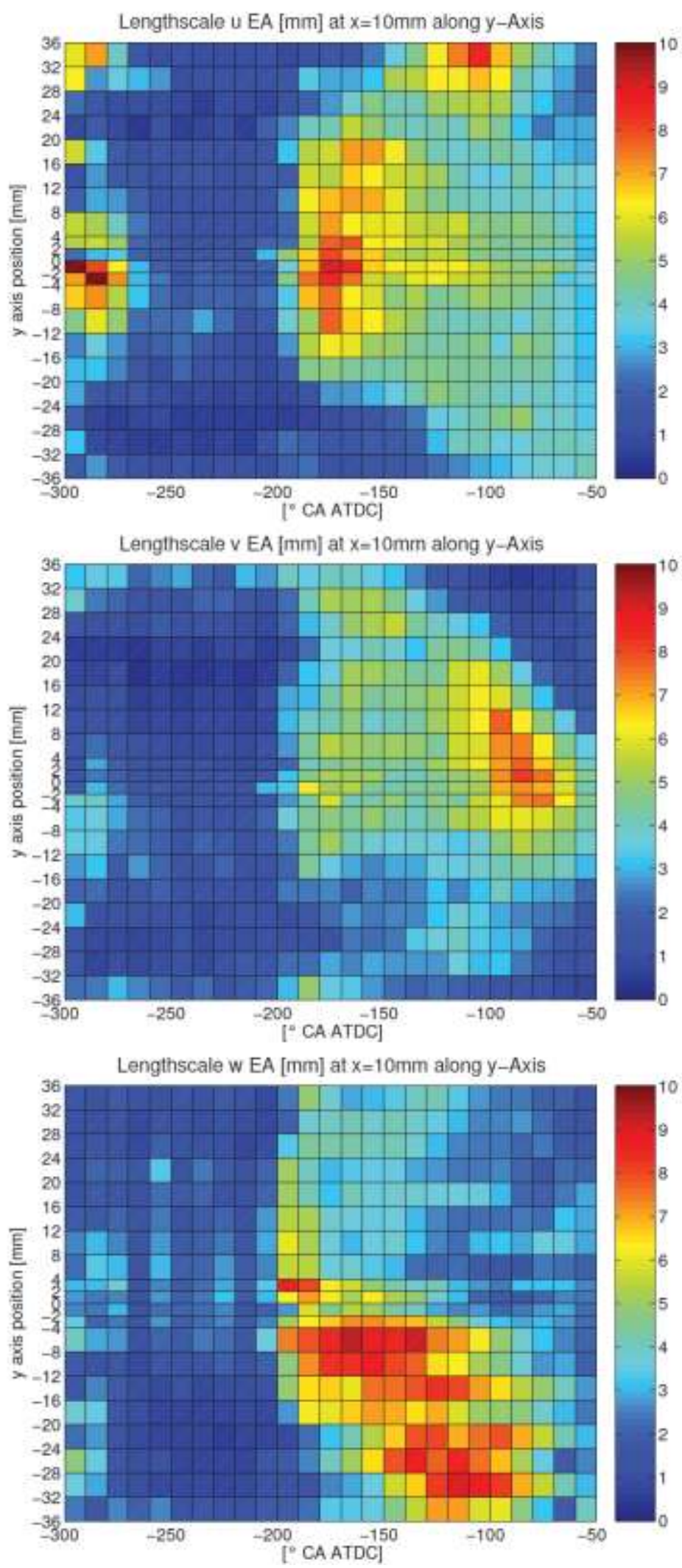

$\mathrm{x}=10 \mathrm{~mm}, \mathrm{y}=0$, along $\mathrm{z}$-axis
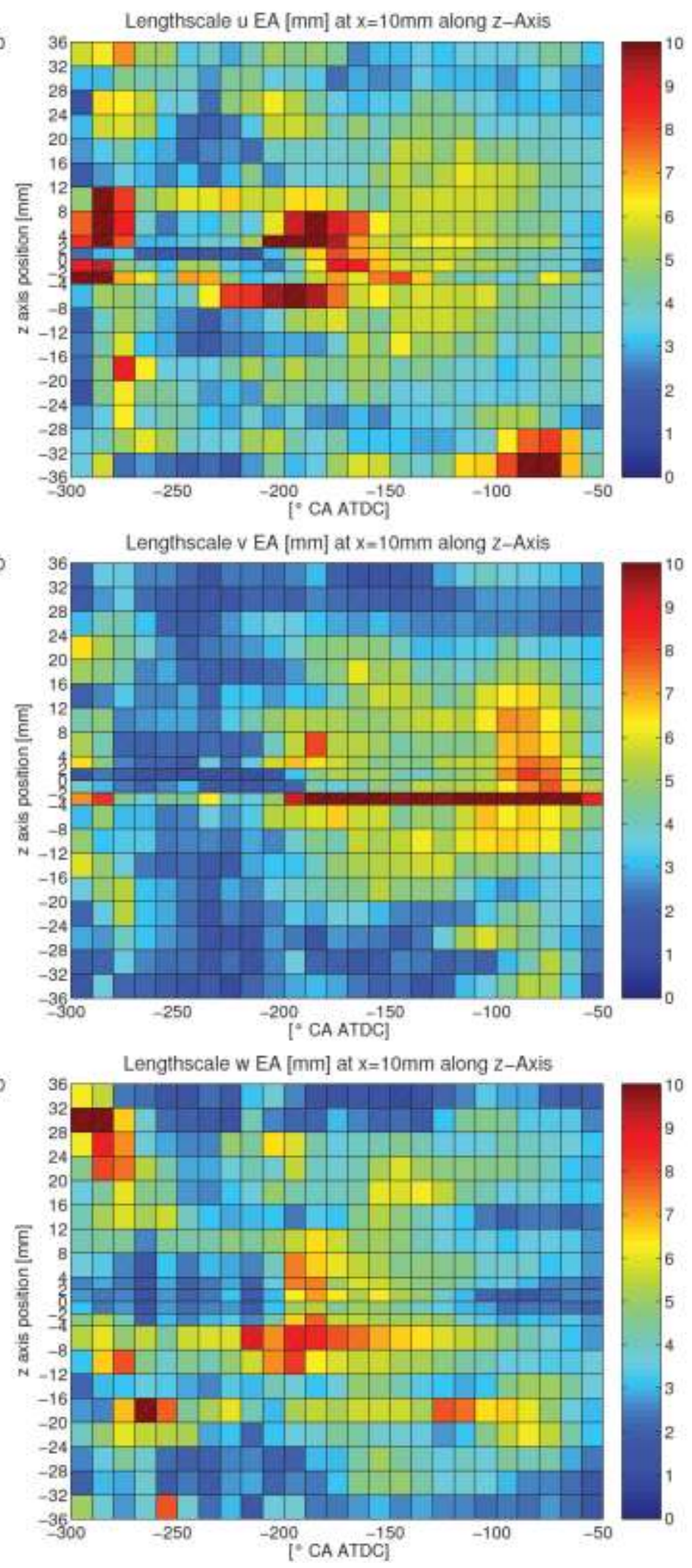

Figure 27. Integral length scales along $y$-and $z$-axis at $x=10 \mathrm{~mm}$, from integral time scale and ensemble averaged fluctuation, $\mathrm{LDV}$. 

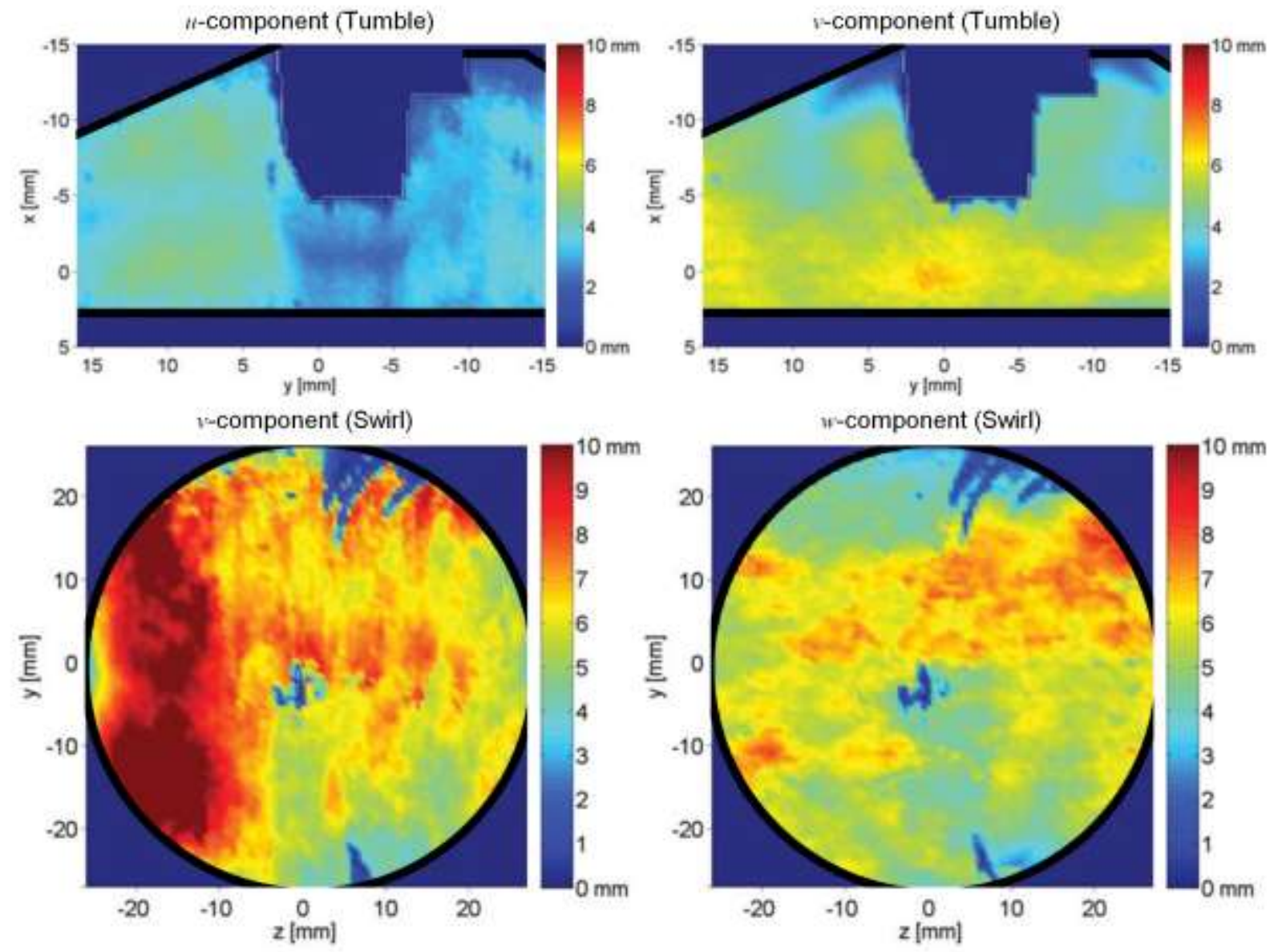

Figure 28. Integral length scale maps as obtained by PIV at $26{ }^{\circ} \mathrm{CA}$ BTDC. 